\title{
Evaluating The ENVIRONMENTAL IMPaCts of CONVENTIONAL AND Organic Apple Production in Nova Scotia, Canada, Through Life Cycle Assessment
}

\author{
by
}

Sarah Keyes

Submitted in partial fulfillment of the requirements for the degree of Master of Environmental Studies

at

Dalhousie University

Halifax, Nova Scotia June 2013

(C) Copyright by Sarah Keyes, 2013 


\section{DALHOUSIE UNIVERSITY}

\section{SCHOOL FOR RESOURCE AND ENVIRONMENTAL STUDIES}

The undersigned hereby certify that they have read and recommend to the Faculty of Graduate Studies for acceptance a thesis entitled "Evaluating the Environmental Impacts of Conventional and Organic Apple Production in Nova Scotia, Canada, Through Life Cycle Assessment" by Sarah Keyes in partial fulfillment of the requirements for the degree of Master of Environmental Studies.

Dated: June $26^{\text {th }}, 2013$

Supervisor:

Readers: 


\title{
DALHOUSIE UNIVERSITY
}

DATE: June $26^{\text {th }}, 2013$

\section{AUTHOR: Sarah Keyes}

TITLE: Evaluating the Environmental Impacts of Conventional and Organic Apple Production in Nova Scotia, Canada, Through Life Cycle Assessment

DEPARTMENT OR SCHOOL: School for Resource and Environmental Studies

DEGREE: MES CONVOCATION: October YEAR: 2013

Permission is herewith granted to Dalhousie University to circulate and to have copied for non-commercial purposes, at its discretion, the above title upon the request of individuals or institutions. I understand that my thesis will be electronically available to the public.

The author reserves other publication rights, and neither the thesis nor extensive extracts from it may be printed or otherwise reproduced without the author's written permission.

The author attests that permission has been obtained for the use of any copyrighted material appearing in the thesis (other than the brief excerpts requiring only proper acknowledgement in scholarly writing), and that all such use is clearly acknowledged.

\author{
Signature of Author
}




\section{TABLE OF Contents}

LIST OF TABLES........................................................................................................... vii

LIST OF FIGURES ............................................................................................................. viii

ABSTRACT ............................................................................................................................................ ix

LIST OF ABBREVIATIONS USED................................................................................................. $x$

ACKNOWLEDGEMENTS........................................................................................................................ xi

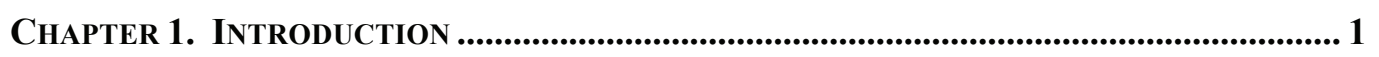

1.1 Apples in a global, national, and Nova Scotian context .......................................... 2

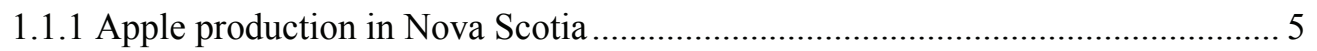

1.1.2 Integrated and organic orchard management systems....................................... 7

1.2 Assessing the sustainability of agricultural systems.............................................. 13

1.2.1 Evaluating environmental impacts of agriculture ............................................ 15

1.3 LCA Methodology ................................................................................................................ 16

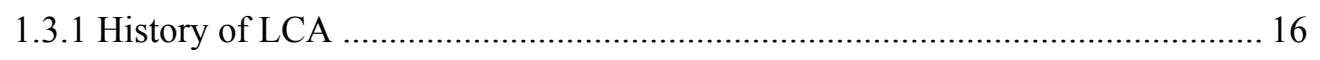

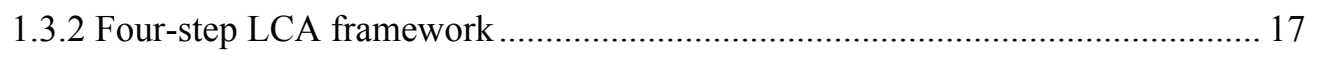

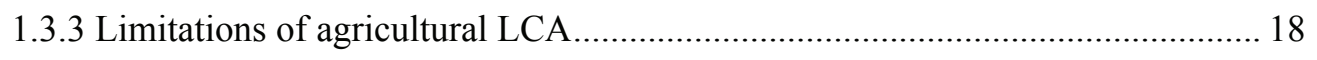

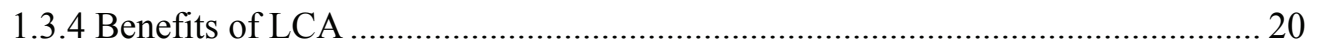

1.4 LCA and food systems.......................................................................................................... 21

1.4.1 Conventional, integrated and organic agricultural LCA ….............................. 23

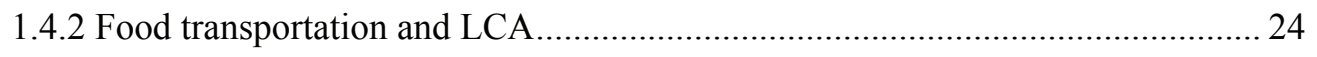

1.5 Apple research in focus .................................................................................................. 24

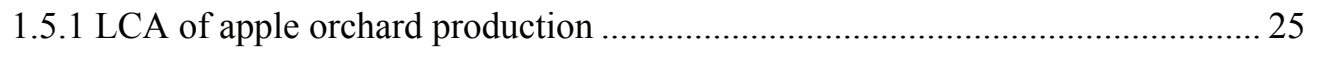

1.5.2 LCA of apple cultivation and post-harvest processes ...................................... 27

1.6 Thesis rationale and objectives........................................................................................ 30

1.7 Organization of thesis.............................................................................................................. 31 
CHAPTER 2: EVALUATING THE ENVIRONMENTAL IMPACTS OF CONVENTIONAL AND ORGANIC APPLE PRODUCTION IN NOVA SCOTIA, CANADA, THROUGH LIFE CYCLE

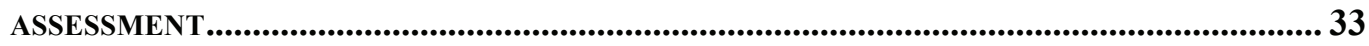

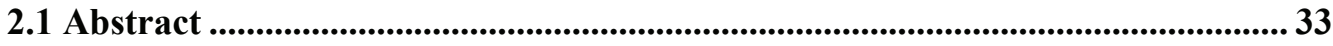

2.2 Introduction ............................................................................................................................. 33

2.3 The Nova Scotia apple industry ..................................................................................... 35

2.4 Materials and methods ........................................................................................................... 35

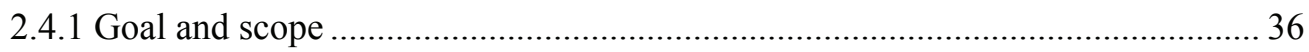

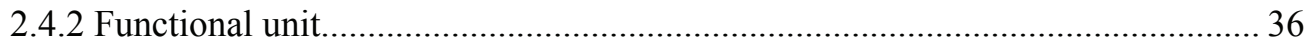

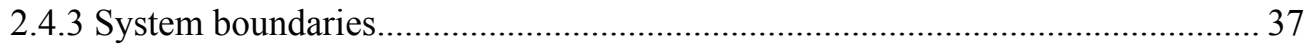

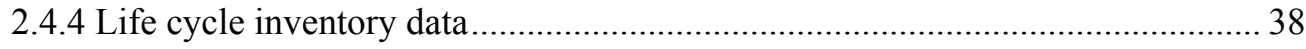

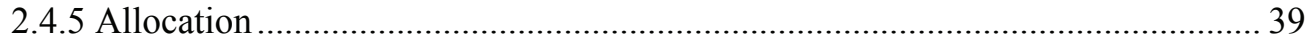

2.4.6 Life cycle impact assessment …................................................................... 40

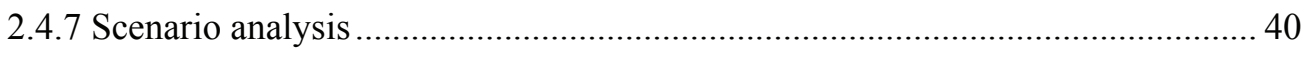

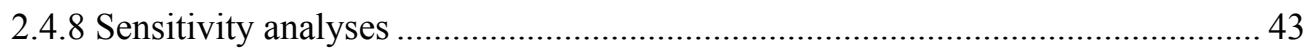

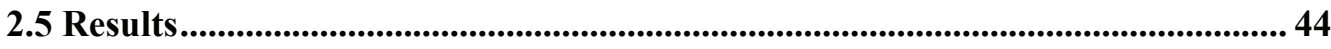

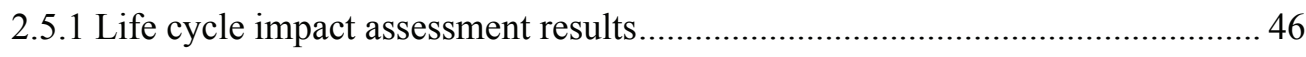

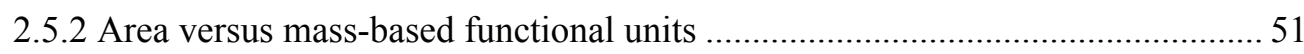

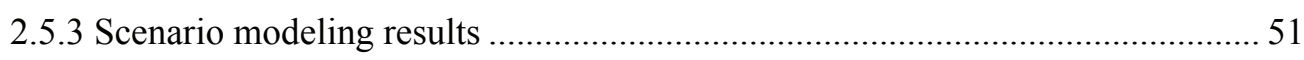

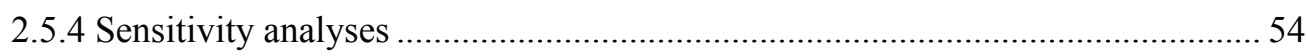

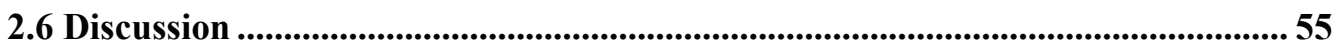

2.6.1 Nova Scotia apple production in a global context............................................. 55

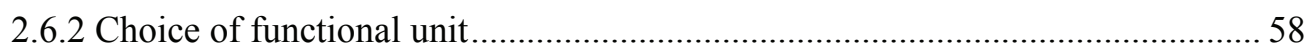

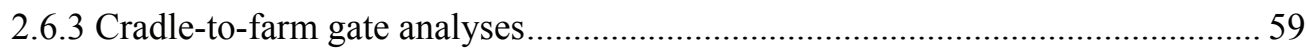

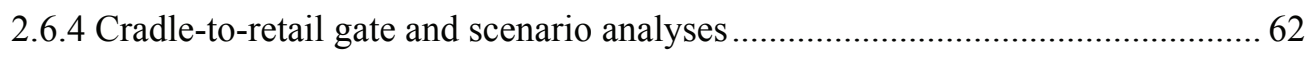

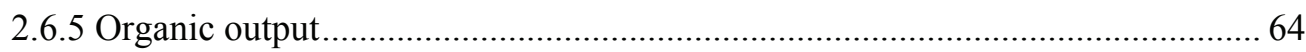

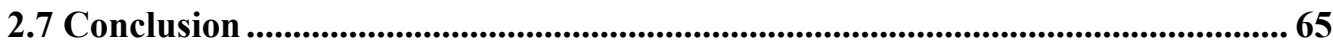

CHAPTER 3. DISCUSSION AND CONCLUSION........................................................................68

3.1 Food for thought on organic and local production systems ...................................6 69

3.2 Research challenges and project limitations ................................................................ 74

3.3 Current and on-going LCA research ................................................................................. 78 
3.4 Future research opportunities............................................................................ 79

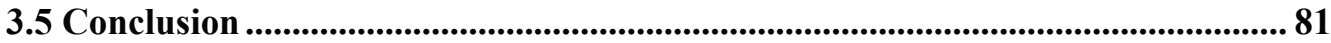

APPENDIX A: PESTICIDES ON APPLE ORCHARDS ..................................................................... 83

APPENDIX B: APPLE INVENTORY SURVEY ............................................................................ 85

APPENDIX C: EMISSION CALCULATIONS ................................................................................93

APPENDIX D: DATA USED IN LCA MODELING SOFTWARE.................................................. 99

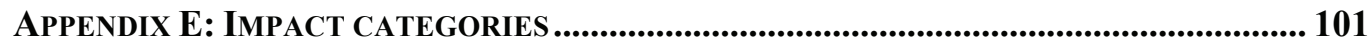

APPENDIX F: AREA-BASED LIFE CYCLE RESULTS .......................................................103

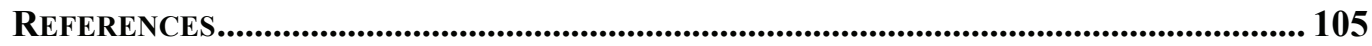




\section{LiST OF TABLES}

TABLE 1. Transportation scenarios

TABLE 2. Recent (2011) and hypothetical primary energy inputs to Nova Scotia electricity generation

TABLE 3. Combined orchard production characteristics upon which analyses were undertaken

TABLE 4. Life cycle inventory results for 2010 conventional Nova Scotia orchard production of 1 tonne of apples.

TABLE 5. Life cycle inventory results for 2010 organic Nova Scotia orchard production of 1 tonne of apples

TABLE 6. Life cycle impact assessment results of 2010 conventional Nova Scotian apple production to farm-gate and Halifax retail-gate per tonne of apples....

TABLE 7. Life cycle impact assessment results of 2010 organic Nova Scotian apple production to farm-gate and Halifax retail-gate per tonne of apples.

TABLE 8. Transportation and improvement scenario analyses results

52

TABLE 9. Sensitivity analyses results: hypothetical changes in inputs modeled and resulting changes to impact categories relative to baseline findings.

TABLE A1. US EPA acute human toxicity classification of active ingredients (AI) of substances applied to conventional and organic apple orchards in Nova Scotia in 2010

TABLE C1. Illustrates $\mathrm{N}_{2} \mathrm{O}, \mathrm{NH}_{3}, \mathrm{NO}, \mathrm{NO}_{3}, \mathrm{P}_{2} \mathrm{O}_{5}$, and $\mathrm{CO}_{2}$ emission calculations from fertilizers and lime applied on conventional orchards....

TABLE C2. Illustrates $\mathrm{N}_{2} \mathrm{O}, \mathrm{NH}_{3}, \mathrm{NO}, \mathrm{NO}_{3}, \mathrm{P}_{2} \mathrm{O}_{5}$, and $\mathrm{CO}_{2}$ emission calculations from manure and lime applied on organic orchards...

TABLE E1. Impact categories used in analysis, with associated characterization models and factors, units of calculation, and LCIA methods package....

TABLE F1. Life cycle impact assessment results of 2010 conventional Nova Scotian apple production to farm-gate per hectare of orchard area.

TABLE F2. Life cycle impact assessment results of 2010 organic Nova Scotian apple production to farm-gate per hectare of orchard area. 


\section{LiST OF FigureS}

FIgURE 1. Location of Nova Scotia, Canada.................................. 3

FIGURE 2. Life cycle stages of Nova Scotia apple production..................... 38 


\begin{abstract}
Agricultural production and post-harvest supply systems are major causes of resource and energy consumption throughout the world, with associated emissions contributing to global scale environmental burdens. Focusing on apple systems in Nova Scotia, Canada, this project used life cycle assessment to evaluate the environmental performance of conventional and organic orchards, as well as post-production systems of storage and transportation. Results indicate that on-orchard hotspots include fuel use, fertilizers, and inputs to pest and disease management on both conventional and organic orchards. Extending system boundaries to cradle-to-retail locations revealed that electricity required for storage caused substantial burdens, highlighting the problem of coal-based electricity generation in Nova Scotia. Findings also illustrate that the relative impact of transportation changes according to distance travelled and mode of delivery. Consuming locally produced apples when in season was found to be environmentally preferable than those requiring year round storage, while transport by freight ship is more favourable than long distance transport truck delivery.
\end{abstract}




\section{List of Abbreviations USED}

\begin{tabular}{|c|c|}
\hline AP & Acidification potential \\
\hline CED & Cumulative energy demand \\
\hline $\mathrm{CO}_{2}$ & Carbon dioxide \\
\hline FEP & Freshwater eutrophication potential \\
\hline ETP & Aquatic ecotoxicity potential \\
\hline E.U. & European Union \\
\hline FAO & Food and Agriculture Organization (of the United Nations) \\
\hline FU & Functional unit \\
\hline GHG & Greenhouse gas \\
\hline GWP & Global warming potential \\
\hline FDP & Fossil depletion potential \\
\hline ha & Hectare(s) \\
\hline НСТР & Human cancer toxicity potential \\
\hline HNCTP & Human non-cancer toxicity potential \\
\hline IPCC & Intergovernmental Panel on Climate Change \\
\hline IPM & Integrated pest management \\
\hline ISO & International Organization for Standardization \\
\hline $\mathrm{K}$ & Potassium \\
\hline kcal & Kilocalorie (s) \\
\hline $\mathrm{kg}$ & Kilogram(s) \\
\hline $\mathrm{km}$ & Kilometre(s) \\
\hline LCA & Life cycle assessment \\
\hline LCIA & Life cycle impact assessment \\
\hline MDP & Metal depletion potential \\
\hline MEP & Marine eutrophication potential \\
\hline MJ & Megajoule(s) \\
\hline $\mathrm{N}$ & Nitrogen \\
\hline $\mathrm{N}_{2} \mathrm{O}$ & Nitrous Oxide \\
\hline $\mathrm{NH}_{3}$ & Ammonia \\
\hline NO & Nitric Oxide \\
\hline $\mathrm{NO}_{3}$ & Nitrate \\
\hline N.S. & Nova Scotia \\
\hline NSDA & Nova Scotia Department of Agriculture \\
\hline $\mathrm{P}$ & Phosphorus \\
\hline POFP & Photochemical oxidant formation potential \\
\hline $\mathrm{P}_{2} \mathrm{O}_{5}$ & Phosphorus pentoxide \\
\hline QU & Quebec \\
\hline SETAC & Society for Environmental Toxicology and Chemistry \\
\hline tkm & Tonne-kilometre(s) \\
\hline $\mathrm{TX}$ & Texas \\
\hline UNEP & United Nations Environment Program \\
\hline USDA & United States Department of Agriculture \\
\hline U.S. & United States \\
\hline U.K. & United Kingdom \\
\hline
\end{tabular}




\section{ACKNOWLEDGEMENTS}

There are many people to whom I owe acknowledgement and gratitude towards for aiding me throughout this degree. Although my full appreciation cannot be expressed in one page, the following addresses some key people that have made this journey successful.

My utmost gratitude goes to my supervisor, Dr. Peter Tyedmers for his support and guidance throughout this whole process. Had Peter not contacted me to work with him in the MES stream I would not have had the opportunity to explore agriculture through a life cycle lens. Thank you for challenging me to both think and work in ways that were new to me, and for your insight and encouragement the entire way through. I would also like to thank Dr. Karen Beazley for her support over the past year and thoughtful comments on my manuscript. Thank you as well to Dr. Goretty Dias for serving as my external examiner and for the insights that you provided. My gratitude also goes to Nathan Ayer, whose LCA expertise aided significantly in the modeling process.

I would also like to thank the research participants from the Nova Scotia apple industry who provided their time and information to make this project possible. A special thanks to Charles Embree, whose wisdom of apple production and contacts with producers was of substantial value.

My appreciation also goes to the SRES community who has been there in so many ways throughout this experience - for intellectual stimulation, support, advice, and laughter. In particular, thanks to Ella for being my 'team finish' partner over the past few months - late night writing sessions would not have been as productive or fun without you. Thanks to Jen, one of my first friends at SRES, who demonstrated that determination would end in success. Thanks to Chloe, who played a major role in convincing me to come to Halifax at the outset, and who has been a great friend/wife the whole way through.

Additionally, I would like to acknowledge my parents and family, as well as my family of friends for all their love, encouragement, and escapes they provided me with throughout this journey. I would not have been able to do it without such a solid community of support behind me.

Finally, thanks to Paul for your love, support, distractions, and so much more. 


\section{CHAPTER 1. INTRODUCTION}

Industrial society has witnessed the scale of production and technologies used in agriculture intensify significantly, resulting in widespread conversion of land and increased use of fossil fuel based inputs (Horne \& Grant, 2009). While such measures have led to a notable rise in food productivity, systems are now reliant on a finite reserve of non-renewable energy (Pimentel \& Wilson, 2005; Pelletier et al., 2008), the use of which has resulted in the depletion of resources and natural capital that may be undermining future productive capacities (Herdt \& Steiner, 1995). Indeed, recognition that global food systems are contributing to environmental degradation and future vulnerabilities is widespread (Pimentel et al., 1973; Tilman, 1999; Horrigan et al., 2002; Bruinsma, 2003; Brown, 2009; Horne \& Grant, 2009; Giovannucci et al., 2012; Ehlrich \& Ehlrich, 2013). On top of continuing to produce food from constrained and in many cases degraded ecosystems, additional challenges emerge as a result of the need to increase food production to meet demands of an ever-growing population, rising consumption patterns, and growing biofuel markets (Pretty, 2008; FAO, 2009). In fact, the United Nation's (UN) Food and Agriculture Organization (FAO) estimates that a 70 percent increase in production will be required to raise average per person food consumption to $3130 \mathrm{kcal} /$ day to feed the projected population of 9.1 billion in 2050 (Bruinsma, 2009). Not only must more food be produced, it must also be grown more sustainably, recognizing that both the energy and resources that underpin food supply systems, and the waste assimilation capacity of the biosphere are finite (Pelletier et al., 2011; Giovannucci et al., 2012).

Growing awareness of problems associated with conventional agriculture has given rise to the development of alternative production practices throughout much of the world. Addressing the global-scale concerns of agriculture, however, requires information on the environmental implications of both conventional and alternative food systems (Horne \& Grant, 2009; Roy et al., 2009). By understanding how energy consumption and resource inputs of food production and supply chains contribute to ecological burdens, improvements can be developed that are more environmentally benign. 
Focusing specifically on apple systems in Nova Scotia, Canada, this thesis explores how typical conventional and organic production, storage and transportation activities contribute to a set of global resource depletion and emission-based environmental impacts using life cycle assessment (LCA) methodology (ISO, 2006a,b). The goals of this project were to characterize the broad scale environmental impacts of dominant commercial apple production, as well as emerging organic apple systems in the province. Post-harvest systems of storage and transportation were also quantified and assessed, and scenario models were constructed to understand how potential changes to key input variables affected life cycle impacts. This measurement and evaluation has allowed for the environmental performance of Nova Scotian apple systems to emerge. The results of this analysis will provide an environmental 'profile' of one the province's major agricultural industries and provide a basis upon which future management decisions to improve the sustainability of the sector may be made by industry and government. Results will also be of value to those parts of the retail and consumer sectors who are increasingly concerned with the sustainability implications of products (BontiAnkomah \& Yiridoe, 2006) and the rapidly growing international academic community that is focused on better understanding and improving food system sustainability.

\subsection{Apples in a global, national, and Nova Scotian context}

Apple production in Canada dates back to the 1600s; first brought to the country by European settlers, apple production was responsible in part for developing the national economy at the time (Agriculture and Agri-Food Canada, 2012). In fact, the U.S. and Canada were the two largest apple-producing countries in the early $20^{\text {th }}$ century (Luby, 2003). By the turn of the $21^{\text {st }}$ century, however, China had taken the lead. Today, China dominates global apple production, with over 50 percent of total production; European Union countries are second in terms of tonnes of apples produced, followed by the U.S. (United States Department of Agriculture (USDA), 2012). Globally, Canada currently ranks $15^{\text {th }}$ in world apple production, accounting for 0.7 percent of production worldwide (USDA, 2011; Orange Pippin, 2013). Although production has been decreasing over the past decade, apples still represent a substantial industry in Canada, valued at \$148.5 million dollars at farm gate in 2010 (Agriculture and Agri-Food 
Canada, 2012). Within the country, Ontario produces the largest volume of apples, with $38 \%$ of production, followed by Quebec (27\%), British Columbia (24\%), Nova Scotia (10\%) and New Brunswick (1\%) (Agriculture and Agri-Food Canada, 2012).

\section{Figure 1. Location of Nova Scotia, Canada}

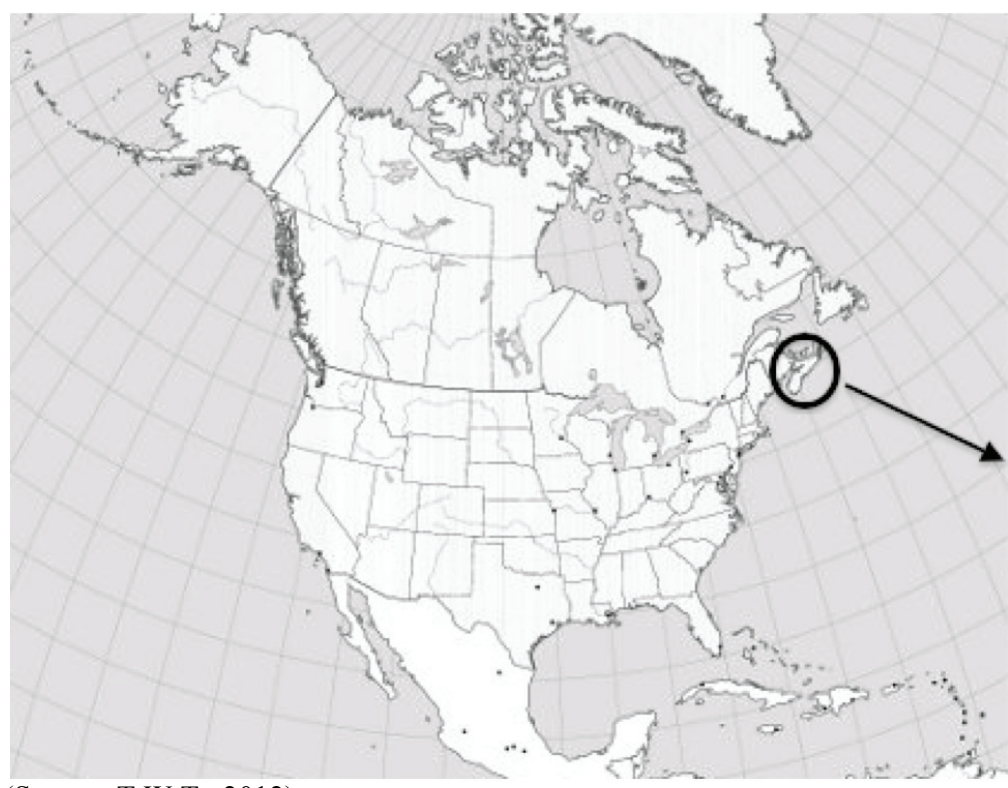

Nova Scotia, Canada (Source: T.W.T., 2012)

Turning to Nova Scotia, an average of 2.5 million bushels of apples are produced annually in the province (AgraPoint, 2009) and the sector has a substantial economic impact. For example, in 2010, the 33,700 tonnes of apples produced, had a farm-gate value of \$12.2 million dollars and a total economic spin-off value of \$61 million (Statistics Canada, 2012). The majority of N.S. orchards are located in the Annapolis Valley, with approximately 150 farmers producing apples on 1850 hectares of land (Statistics Canada, 2012). Of the approximate 40 cultivars grown, the most prominent varieties sold in retail outlets include Honeycrisp, McIntosh, Cortland, Gala, Jonagold, Golden and Red Delicious, and Gravenstein; Ida red, Spartan and Spy are also traditional cultivars produced for processing. Fresh fruit varieties (e.g., Honeycrisp) have taken center stage in recent years, leading to a reduction in total cultivars grown as some of those for processing have been abandoned. In fact, this trend has been occurring for over a century, with many of the $\sim 1000$ varieties discontinued over the years due to changing 
consumer preference and poor storage capabilities of cultivars (Agriculture and AgriFood Canada, 2012).

Once produced, Nova Scotia apples are sent to diverse markets including a wide range of local, regional and national retail outlets, value-added processing plants (e.g., for use in pies, juice, ciders), and export. While local markets and processing is of great importance, the export market for the province's apples is also substantial, as 50 percent of apples grown are sent to locations throughout the world, including the U.S. (80\%) the United Kingdom (8\%), and Mexico (6\%) (Agriculture and Agri-Food Canada, 2012). If recent patterns continue, expansion of export markets is likely, as exports in 2010 increased by 64 percent from the previous year (Agriculture and Agri-Food Canada, 2012). This is important, for according to Ngo and Dorff (2009), Canada spends three times as much importing fresh apples as it receives in fresh apple exports. Indeed, although Nova Scotia orchardists produce nearly twice the amount of apples consumed in the province, 50 percent of apples that are consumed are imported (Scott \& MacLeod, 2010). Representation of Nova Scotia apples on local retail shelves vary depending on the time of year, with the highest percentage appearing between September and May, and the lowest between May and September (AgraPoint, 2009).

Given its scale and importance, there is a well-established service industry, specialized infrastructure and research systems that support the apple industry in Nova Scotia. Infrastructure includes five major packing and storage facilities, two pie-making plants (accounting for $65 \%$ of the packaged pies sold to major groceries stores in Canada), and one juice plant (Nova Scotia Department of Agriculture (NSDA), 2013). Foundational, scientific and production-based tree fruit research takes place through various projects at Kentville's Atlantic Food and Horticulture Research Centre, the fruit tree research program at the Nova Scotia Agricultural College, and the Nova Scotia Tree Fruit Research Foundation (NSDA, 2013). Producers also benefit from networking capacities that exist in the province. For example, The Nova Scotia Fruit Growers Association holds meetings and produces newsletters each month to keep producers informed about industry matters. Engaging with the pubic is also a priority, where producers not only celebrate the traditions and importance of the apple industry with the annual Annapolis Valley Apple Blossom Festival (currently in its $80^{\text {th }}$ year), but also 
conduct orchard tours each year, the purpose of which are to inform and share knowledge on orchard operations and the industry in general.

Both strengths and challenges exist for apple producers in Nova Scotia. To their benefit, producers have a competitive advantage in the production of the cultivar Honeycrisp ${ }^{1}$; have a strong network of collaboration among industry professionals; are diversified in their production abilities and cultivars produced; have leading research facilities; and are well equipped in terms of high-tech packing and processing facilities (NSDA, 2013). Meanwhile, fruit growers in the province are under significant financial pressure from low commodity prices that result from a general global over-supply and intense foreign competition, retail consolidation, high production costs, and a growing reliance on offshore labour for much of the harvest (Atlantic Canada Opportunities Agency, 2011). Further, increased weather-related events (e.g., late frosts) and prospective increased levels of environmental regulations might place additional constraints on apple producers in the future (Scott \& MacLeod, 2010).

\subsubsection{Apple production in Nova Scotia}

Apples are grown in Atlantic Canada through practices that are both customary to typical apple production elsewhere, as well as through methods that complement regional characteristics and climates. Indeed, the Annapolis Valley of Nova Scotia offers climatic advantages to producers in terms of the short, cool, and moist growing climate. High annual precipitation rates - averaging $1211 \mathrm{~mm}$ annually in Kentville - benefit growers by making irrigation systems largely unnecessary, thereby reducing input costs and leading to improved apple quality (NSDA, 2013). The exclusion of irrigation on most orchards also means that concerns over water scarcity are reduced. Moreover, orchards in the region are less prone to frost damage and adverse weather events, meaning that less infrastructure is required for their operations, further adding to their climatic benefits (NSDA, 2013).

Turning to the specifics of apple production, producers must take many variables into account prior to planting an orchard, similar to orchardists elsewhere. Site selection

\footnotetext{
${ }^{1}$ Ideal growing conditions exist in Nova Scotia for the production of Honeycrisp, which has become one of the most important and sought after cultivars in terms of fresh apple exports.
} 
is key, for example, where the microclimate of the area, soil, and topography must all be considered. For instance, a gently slopping hillside with good drainage is preferred as to provide the greatest protection against late spring frost, while a south slopping site is ideal for increased sunlight (NSDA, 2009). Meanwhile, as in most arable crop production, soil analysis is encouraged to ensure $\mathrm{pH}$ levels are favourable for fruit growing, with an optimal level of 6.5 for apple growth (Craig, 2010). Soil tests are conducted on average once every five years, and lime is applied as necessary. In addition, sites may require tile drain installation, tilling, fumigation, and application of fertilizer and/or manure as soil tests indicate (NSDA, 2009).

Following careful selection of the orchard site, producers must prepare for the six stages of fruit tree growth, all of which have varying years of duration and require different resource and energy inputs. Stages include 1) Nursery (2-3yrs); 2) Establishing and planting (1-3yrs); 3) Young tree and low yield (3-5yrs); 4) Mature tree and high yield (10-30yrs); 5) Old trees and low yield (0-5yrs); and 6) Destruction stage (1yr) (Mila i Canals \& Polo, 2003). Upon completion of the nursery stage in which seedlings are grown and rootstocks selected, the initial year of planting brings with it additional input requirements, including farm supplies, infrastructure, and labour. For infrastructure in Nova Scotia, trellis systems are the major material input; constructed of steel or wood they vary in design according to the rootstock and cultivar being grown. Some orchardists also use fencing for protection against animals and irrigation systems for tree growth. Apple producers use a range of equipment on orchards, including tractors, mowers, hand saws and loppers, pole saws, ladders and hydra-ladders, hydraulic-lift platforms, air pruners, sprayers, and at times, irrigation pumps. Diesel fuel is used to run most motorized equipment on the farm, which is consumed primarily by tractor use, while gasoline is used primarily for transporting apples to storage upon harvest, which takes place via truck or tractor and trailer.

Additionally, fertilizers (e.g., synthetic or manure) and soil amendments (e.g., boron, calcium chloride, magnesium, zinc, compost, and mulching) are required for apple growth, primarily throughout the third and fourth stages of tree maturity. Pest and disease treatments, including a variety of fungicides, insecticides, herbicides and growth regulators are also used, ranging in mass and rate of application according to the orchard 
management regime, degree of outbreaks, and climatic requirements. In terms of climate, in Nova Scotia, for example, moist growing conditions lead to the fungal disease apple scab (Venuria inaequalis), which causes significant challenges for producers throughout Atlantic Canada as it leads to reduced yields and spotted, unmarketable fruit (Craig, 2010). In fact, apple scab is of central concern to apple producers around the world, responsible for the majority of fungicide and pest control costs on orchards (MacHardy, 2000). In Nova Scotia, orchardists must apply upwards of ten fungicide treatments to ensure crops are not affected. This disease drives pest management activities in the province, as $\sim 75$ percent of pesticides used on orchards in the region are applied to combat apple scab and secondary plant pathogens; left untreated orchards are in danger of total crop loss (Craig, 2010). This is typical of perennial tree crop systems, where application of pesticides on apple orchards is amongst the highest per hectare compared to other arable crops (Mouron et al., 2012).

Finally, labour is a substantial input for orchardists, as it can be one of the most costly operational requirements (Craig, 2010). As with other fruit crops, labour on apple orchards is seasonal, with most employees hired at harvest for picking. Orchardists typically hire local and out of province workers for harvest season, as well as fruit pickers from Jamaica, Mexico, the U.S., and Europe.

\subsubsection{Integrated and organic orchard management systems}

Apple producers typically follow one of three prominent management regimes in their orchards: integrated pest management, integrated fruit production, or organic production. Evolving from conventional practices ${ }^{2}$, these regimes came to fruition upon recognition that the intensive spraying practices of industrial agricultural may have harmful consequences, with worries of environmental degradation, toxicity exposure (see Appendix A), and growth of pest and disease resistances (Beers et al., 2003). Growing consumer demands for better quality fruit with less environmental consequences has also driven apple producers to use both integrated and organic farming techniques on orchards (Peck et al., 2005). Moreover, there is financial impetus for growers to reduce pesticide use, further provoking them to find new and more sustainable ways to manage pest

\footnotetext{
${ }^{2}$ Conventional practices refers to management regimes that have no set target for pesticide reduction, where inputs are applied according to time/season specific schedules without considering external factors.
} 
populations. In each management system, a variation of monitoring, prevention, and suppression techniques are used to combat and control pest and disease problems (Slattery et al., 2011). Although such pest control tactics can mean more demands on producers in terms of education and training, labour, and equipment costs, many growers have nonetheless adopted programs, albeit on different scales.

To begin, integrated pest management (IPM) represents the first transition away from conventional practices: rather than applying pesticides according to the time of year or a specific schedule as in conventional production, they are applied instead when monitoring tests indicate as necessary, adopting a more targeted approach to pest and disease management. Indeed, IPM promotes minimal, well-timed and planned application of chemicals in conjunction with non-chemical techniques (Government of Nova Scotia, 2012). Guidelines include, for instance, employing preventative tactics and control methods (e.g., sanitation, fertilization); accurately identifying pests and beneficial control agents; monitoring and evaluating for pathogens, insects and mites; ensuring that treatments are based on pre-established thresholds (e.g., by use of pheromone lure-bated traps); using appropriate pest management strategies (e.g., use of beneficial control agents, extensive pruning regimes); and evaluating IPM programs through yield monitoring and record keeping (Canadian Horticulture Council, 2009; Government of Nova Scotia, 2012). By following such IPM guidelines, growers can establish targetspecific pest and disease management regimes, helping to encourage beneficial relationships and a balance of ecosystems (Phillips, 2005).

Different levels of IPM programs are practiced depending on the management decisions of the producer. On apple orchards in particular, IPM implementation is diverse. While most apple producers follow some level of IPM strategy, efficiency-based models that are centered on use of chemical pesticides (e.g., spraying, insect trapping) are more widely employed than more advanced IPM programs, which are biologically or culturally based (e.g., integrating multiple behavioral, biological, and chemical tactics to control pests) (MacHardy, 2000). For instance, while IPM has been practiced in Nova Scotia for over 60 years, the majority of growers (95\%) adhere to level one guidelines, using thresholds and monitoring to rationally fight pests (Canadian Horticulture Council, 2009). Of the producers practicing IPM, $\sim 25$ to 40 percent also follow level two (e.g., 
bio-intensive and bio-rational, relying primarily on the integration of low risk, nonchemical IPM tools) and level three strategies (e.g., integrated crop management or integrated fruit production, combining IPM with entire apple cropping system) (Canadian Horticulture Council, 2009). Policy guidelines for management regimes are absent in Canada, where individual producer preferences guide practices. Meanwhile in Europe, IPM implementation is scheduled to be mandatory as part of the E.U.'s 2014 agricultural policy (Mouron et al., 2012).

While IPM efforts are an improvement over conventional spraying tactics, leading to a reduction in the quantity of chemicals applied, associated problems with synthetic pesticides persist. Indeed, since many growers continue to rely on chemical measures in place of more developed IPM programs, pesticides are reduced but not eliminated; potential for pesticide resistance, harms to beneficial organisms, labour and equipment costs thus persist for apple growers (MacHardy, 2000).

Development of integrated fruit production (IFP) programs has taken place in the context of these ongoing issues, expanding further than IPM principles to incorporate all areas of production. Taking a systems-based approach, IFP aims to achieve long-term socio-economic and environmental sustainability (Nemecek et al., 2011). For instance, IFP systems seek to balance orchard inputs and outputs, maintain and improve biodiversity and ecological quality, while at the same time ensuring the economic viability of the orchard and the production of optimal yields of high quality fruit (Canadian Horticulture Council, 2003). In IFP, emphasis is placed on preventative measures rather than direct control measures for plant protection (Boller et al., 1998 as cited in Avilla \& Riedl, 2003). As such, a commonly held definition of IFP is "the economical production of high quality fruit, giving priority to ecologically safer methods, minimizing the undesirable side effects and use of agrichemicals, to enhance the safeguards to the environment and human health" (Cross, 2002, p.1).

Systems of integrated agricultural production such as IFP have emerged as the result of collaborative efforts over the past 25 years, with significant direction from the West Palearctic Regional Section of the International Organization for Biological and Integrated Control of Noxious Animals and Plants (Avilla \& Riedl, 2003). With implementation beginning predominantly in Europe, IFP programs have since spread to 
other fruit growing countries including South Africa, Argentina, Uruguay, Brazil, Chile, and New Zealand (Avilla \& Riedl, 2003), while practiced to a lesser extent in the U.S. and Canada. Provoking this transition has been both consumer demand and marketing by European grocery chains, where preferential treatment is given to IFP-grown fruit (Granatstein, 2013). In New Zealand, for example, industry-wide IFP programs began in 2000, driven largely by growing U.K. market export demands (Granatstein, 2013).

Today, over 90 percent of producers in New Zealand adhere to IFP standards (Mila i Canals et al., 2006), as all apple exports require IFP labeling (Avilla \& Riedl, 2003). IFP also dominates orchard management regimes in Switzerland, practiced on $\sim 87$ percent of orchards (Nemecek et al., 2011). The scale of IFP production varies in most other countries, meanwhile, dependent on producer preferences, financial considerations, and conversion restraints. In fact, McKenna (1998) found the main reasons for producers converting to IFP were economical. As a result, IFP practices may be molded by financial considerations instead of ecological objectives, thereby falling short of the full intent of sustainability in terms of decision rationale. Nevertheless, environmental achievements can be realized despite the primary pursuit of economic gain.

Although IFP takes a more holistic approach to orchard management, using less and safer pest and disease control methods, the use of synthetic pesticides persists. Organic production, in contrast, requires that chemical pesticides be eliminated completely, using alternatives to naturally control pests (including copper, sulphur, and lime sulphur on apple orchards). Relying on natural cycles and ecological processes in place of external inputs to encourage stability within production systems, the goals of organic agriculture include producing high quality and healthy foods; building soil fertility; maintaining natural processes and cycles; conserving biodiversity; and eschewing the use of genetically modified organisms and pesticides (Weibel \& Haseli, 2003). While organic agriculture entails the pursuit of a range of alternative production practices $^{3}$, those specific to apple production include orchard-stabilizing elements such as planting disease resistant cultivars, lower planting densities, establishing areas of biodiversity, and ensuring soil fertility (Weibel et al., 2007). However, such indirect

\footnotetext{
${ }^{3}$ Organic agriculture incorporates alternative production methods such as building soils with compost additions and green manures, crop rotation, and diversification (Reganold, 2004), aiming to encourage overall ecological integrity.
} 
measures are not necessarily undertaken by all organic orchard operators; indeed, similar to many integrated regimes, direct methods of pest control are more common, as organic orchard design typically follow that of conventional models (Weibel et al., 2007). In the U.S., for example, a variety of organic operations exist, ranging from closed-cycle systems that focus on limiting external inputs, to more customary systems that adhere to solely organic certification guidelines (Slattery et al., 2011).

Organic production has taken hold in many industrialized countries, driven largely by consumer demand for products with superior nutritional value, quality, safety, and environmental impact (Bonti-Ankomah and Yiridoe, 2006). Described as the fastest growing industry in the food sector, the organic market was valued at $\$ 63$ billion in 2011, with demand centered in North America and Europe, representing 97 percent of revenues globally (Sahota, 2009; Willer et al., 2013). Expansion of the organic industry is predicted to continue, with rates of growth estimated at 20 to 25 percent annually over the next decade (Kortbech-Olesen, 2004). In Canada, organic retail sales were \$2 billion in 2008, representing approximately 2.5 percent of total food purchases (Roukhkian, 2011). Of this, fruits and vegetables account for 35 percent of organic sales, followed by dairy (18\%) and processed foods (17\%) (Roukhkian, 2011), while organic apples are one of the top three fresh fruit purchased by organic food consumers (Slattery et al., 2011).

Although organic food production is growing, it continues to represent only a fraction of total food grown globally, with an estimated $\sim 0.86$ percent of total agricultural land in organic production (Willer et al., 2013). The U.S. is home to the largest area of organic apple production, with approximately 7,284 ha in production as of 2008 (Slattery et al., 2011). Production of certified organic apple acreage doubled in the U.S. between 1997 and 2008, now accounting for approximately six percent of total apple production, with the majority of organic orchards concentrated in Washington State (Slattery et al., 2011). Organic apple growth has flourished in this area due, in part, to ideal growing conditions, as the arid climate in the region keeps fungal problems such as apple scab at bay (Peck et al., 2005). This comparative advantage, however, does not hinder organic apple production in other areas of the world. In New Zealand, for example, $\sim 9$ percent of apples are produced on organic orchards, with $>2,900$ ha in production (Mila i Canals et al., 2006; Delate et al., 2008). Several European countries 
also have substantial land under organic apple management (see Delate et al., 2008), while production is also occurring in Argentina, Chile, Canada, China and Australia, albeit on a smaller scale (Kirby \& Granatstein, 2009). In Nova Scotia, organic apple production remains relatively modest at present; development is needed, however, to meet increasing market demands (Agriculture and Agri-Food Canada, 2007). Indeed, growing demand for organic apples in France, Germany the U.K. offers potential market opportunities, as these countries currently account for 90 percent of apple exports from the U.S. (Peck et al., 2005).

Despite price premiums paid for organic apples, several factors keep growers from transitioning to organic production. Not only is converting to organic production expensive, the labour intensive nature of organic operations can result in increased costs for growers (Weibel, 2002; Mon \& Holland, 2006; Delate et al., 2008). Furthermore, yields are typically 15 to 30 percent lower on organic orchards (Weibel, 2002), further impacting the financial viability of orchards. These market constraints are important, for farm income has been found to be one of the central reasons for transitioning to organic production, with health, safety and environmental protection coming secondary (Slattery et al., 2011), as some farmers concentrate on capturing the economic benefits of the expanding organic markets despite these potential financial drawbacks. On top of this, adequate pest and disease control measures and appropriate thinning technologies have not been sufficiently developed and therefore infringe on the economic viability of organic orchards (do Amarante et al., 2008), causing further problems in terms of transitioning to organic production.

However, whether a production system is organic does not necessarily imply that it is either sustainable or environmentally benign (do Amarante et al., 2008). Although many research models and indicators have been developed to assess the sustainability of agriculture, debates persist over how to comprehensively evaluate its impacts. This is important, for understanding how different agricultural production regimes impact the environment is essential in moving us towards more sustainable practices (Roy et al., 2009; Nemecek et al., 2011). As such, the following section examines issues around research on 'sustainable agriculture', as well as the underlying difficulties with agricultural-based research. 


\subsection{Assessing the sustainability of agricultural systems}

A growing body of research on food systems has emerged in response to concerns over the impacts of agriculture (Roy et al., 2009). Central to many of these investigations is the concept of sustainable agriculture, promoted as a way to improve the food system and ensure that production is in tune with ecological processes. Indeed, research and projects on sustainable agriculture are wide-ranging, considered theoretically (e.g., Rodriguez, 2008; Altieri, 2009; Gomiero et al., 2011), through case studies (e.g., Pretty et al., 2006; Badgley et al., 2007), and through organizational initiatives (e.g., FAO; World Sustainable Agriculture Association).

Nevertheless, despite its popularity, the concept of sustainable agriculture, similar to the concept of 'sustainable development', is problematic when it comes to actualization, for it can take various forms and follow a range of paradigms (e.g., biodynamic, low-input, permaculture, regenerative systems, agroecology, and conservation agriculture). The central focus within these different conceptualizations lies in the ability of agro-ecosystems to remain productive in the long-term; methods to do so, however, are diverse. Indeed, variations in the definition, theoretical underpinnings, and methods of application have led to obstacles in actualizing sustainable agricultural practices universally, for it is dependent on the aims of different organizations and the scale at which sustainability is being pursued (Binder et al., 2010). Moreover, sustainability in agriculture is assessed in the academic realm by a wide range of criteria, through different sets of indicators, as well as on varying scales. The divergent objectives and methodologies have left a wide-ranging scope of practices, literature, and methods for implementation.

To understand why research of food systems differs, it is important to note the inherent complexity in agricultural systems. At the outset, developing evaluation and implementation strategies is difficult when considering the site and case-specific nature of agriculture, as production depends on climatic settings, and socio-political and technical conditions (von Wirén-Lehr, 2001). Methods of assessment, therefore, are much more restricted than in industrial systems (Cowell \& Clift, 1997). Furthermore, to analyze whether a system is in fact sustainable in its entirety, one must consider the multifunctional nature of agriculture (Binder et al., 2010). Studies should therefore not 
only consider the commodity of food that is being produced, but also the impact the agricultural system has on the ecosystems, communities, and consumers that it affects, thereby incorporating the complex set of relationships that exist between environmental conditions and human activities (von Wirén-Lehr, 2001). Indeed, impacts of food production on food security, biodiversity, conservation of natural resources, and landscape maintenance should all be considered when investigating agriculture (Binder et al., 2010). This analysis requires a multidimensional approach, integrating economic, social, cultural, and environmental perspectives.

Analyzing the sustainability of agriculture through these holistic and dynamic parameters necessarily causes methodological problems for researchers (von Wirén-Lehr, 2001; Gomiero et al., 2011). Indeed, establishing criteria to evaluate different variables for sustainability can be difficult. For example, parallel analysis of science based, quantitative data (e.g., results from LCA), which represent environmental aspects of sustainability, and normative, qualitative data (e.g., values based farmers' perspectives or consumer preferences) that are meant to represent social dimensions, is challenging for practitioners (von Wirén-Lehr, 2001). Although this type of dual analysis is certainly possible, it is rarely undertaken, as restrictions on time, funding, resources, aims of research, and knowledge of methodologies limit their widespread application.

Meanwhile, studies that focus on particular dimensions (e.g., economic, environmental, social) of food continue, as researchers hope analyses can be used to inform certain aspects of the overall picture. Indeed, Gomiero and colleagues (2011) note that since it is largely impossible to reach an optimal solution to the problem of sustainability, researchers should address 'for whom and in which sense' the sustainability evaluation is being carried out. Although a complete assessment of the food system is not being undertaken, evaluations as such continue to be useful by providing knowledge on different aspects of agricultural production. Indeed, results of these studies can be used in conjunction with other analyses, providing information to inform decision-making processes. In light of this, the following section will review several biophysical assessment techniques that are used to assess agriculture, with particular focus on Life Cycle Assessment (LCA). 


\subsubsection{Evaluating environmental impacts of agriculture}

The environmental dimension is important when considering food production, for understanding whether current agro-ecosystems have the ability to remain productive in the long-term is essential in achieving agricultural sustainability (van Werf \& Petit, 2002). To be environmentally or ecologically sustainable, an agriculture system must theoretically be able to supply sufficient inputs for production, as well as be a sink for waste without compromising its ability to renew itself or be renewed (van der Werf \& Petit, 2002). Investigating different agricultural management regimes, as well as their energetic and material demands, and evaluating them in terms of their environmental impacts is therefore of substantial value, for this may allow for the development of strategies that enhance productivity and are in tune with ecological considerations, which are both crucial in the transition to more sustainable agricultural practices.

Various tools and indicators have been developed to assess and benchmark environmental impacts of different products and production systems. These biophysical accounting techniques have been adopted as a way to re-integrate the value of ecological goods and services into the economy and develop a better understanding of the linkages between humans and the natural world (Wackernagel et al., 2002). Depending on the aims and objectives of different analyses, the tools of measurement vary considerably. For example, procedural techniques such as Environmental Impact Assessment (EIA) and Strategic Environmental Assessment (SEA) are used to assess environmental impacts of projects or proposals on a case-by-case basis, while Environment Management Systems (EMS) is a set of comprehensive management procedures that specify ways in which companies and organizations can organize their efforts towards sustainability (Baumann \& Tillman, 2004).

Several analytical techniques have been put forth which quantify energy and material flows as proxies for environmental burdens. Examples include Material Flow Accounting (MFA) and Material Intensity Per Unit Service (MIPS), both of which measure material inputs to systems (Finnveden \& Moberg, 2005). Energy analysis (e.g., exergy or emergy anlaysis) is used to evaluate the accumulation of energy associated with different types of inputs in a system (Finnveden \& Moberg, 2005). The flow of biologically productive land needed to supply resources and absorb wastes can be 
measured through the Ecological Footprint (EF), the results of which are used to illustrate human demand on the Earth's ecosystems (Wackernagel \& Rees, 1995). Further, Human Appropriation of Net Primary Productivity (HANPP) measures a system's appropriation of biologically available energy used by organisms. These latter two tools have shown that on a global scale, humans are placing demands on the ecosphere at rates that greatly exceed its biological productivity and waste assimilation capacity (Gomiero et al., 2011). While calling for change, however, they are not able to give specific recommendations for alternative courses of action. Finally, various researchers have used LCA to understand the environmental impacts of agriculture, as is examined at length in the next section.

\subsection{LCA Methodology}

LCA is a biophysical accounting tool used to evaluate the environmental effects of a product, process, or activity throughout its entire life cycle (i.e. from 'cradle to grave') (ISO, 2006a). This is accomplished by identifying and measuring the flows of material and energy inputs associated with selected life cycle stages, including extraction of raw materials through to processing, packaging, storage, transportation, distribution, use, and final disposal, quantifying them in terms of their contributions to a range of global scale environmental impact categories (Rebizter et al., 2004). Examples of energy and resource-based impact categories considered in LCA include potential for global warming, ozone depletion, photochemical oxidant formation, acidification, eutrophication, human and ecosystem toxicity, natural resource depletion, energy use, land use, and water use (Guinee et al., 2001).

\subsubsection{History of LCA}

Modeled on energy flow analyses, the concept of LCA emerged in the early 1970s in the context of the limits to growth debate and oil crisis, both of which incited interest in energy use and waste flows of industrial systems (Baumann \& Tillman, 2004). First undertaken by Coca Cola, LCA soon became a tool used widely in the packaging and waste management industries to understand the environmental impacts of the production and disposal of different packaging methods. Over the next twenty years, 
LCA underwent various changes and advancements in methodologies under the direction of the International Organization for Standardization (ISO) and the Society for Environmental Toxicology and Chemistry (SETAC), with input from national and international organizations and scholars. In 1997, the International Standards Organization (ISO) published its first standards of LCA methodology, which has been followed by several updates (ISO 14040/44, 2006). These standards have been critical in ensuring assessments are conducted according to a rigourous methodological framework, and as such have been vital in the international acceptance of LCA in both the scientific and policy-making realm. Indeed, LCA is now the foremost methodology used to implement energy analyses of food systems from a life cycle viewpoint (Pelletier et al., 2011), as well as to measure environmental impacts of products and production systems, for it is able to identify hotspots (i.e. areas in a production chain's life cycle contributing to the greatest environmental burdens) and make appropriate recommendations that can lead to a reduction of ecological burdens.

\subsubsection{Four-step LCA framework}

ISO-compliant LCA framework contains four stages. In the first stage, practitioners define the goal and scope definition, where the purpose, application, audience, and expected outcomes of the study are expressed (ISO, 2006). The functional unit (FU) is defined in this stage, which provides a basis of measurement upon which environmental impacts are quantified. This stage also defines the scope of the study through the definition of system boundaries, as well as the types of environmental impacts that will be considered. The second stage is life cycle inventory (LCI) analysis, where data are collected, inventoried, and modeled, calculating the resource and energy use for each unit process of the life cycle stages. The third stage is life cycle impact assessment (LCIA), wherein inventory results are quantified in relation to relative energy and resource-based environmental impact categories, allowing for the evaluation of the product's life cycle. Finally, the fourth stage is interpretation, where environmental issues are identified and recommendations and conclusions about the LCA are developed. Here, results are checked and evaluated through sensitivity analyses, and 
completeness and correctness tests (Roy et al., 2009), ensuring findings have undergone rigourous analyses and allowing for accurate representation of results.

\subsubsection{Limitations of agricultural LCA}

Akin to alternative environmental assessment tools, LCA is prone to methodological challenges (e.g., uncertainty and variability in underlying data, methodological inconsistency, limitations in methodological development, etc). To begin, LCA data can be prone to variability and uncertainty due to the dynamic nature and inherent complexity of agricultural systems (Horne \& Grant, 2009). In terms of variability, natural processes may not be accurately represented in LCA due to the inability of models to characterize temporal and spatial considerations (Reap et al., 2008). For example, temporal scope may be affected due to static and linear models of LCA, as they do not commonly take into account differences in yearly emissions inventories in agriculture (Björklund, 2002). As well, spatial variations within a farming system such as on-farm practices, location of farm, climate and soil conditions, and crops being grown are also not typically accounted for when data are aggregated and presented as point estimates, potentially leading to unrepresentative conclusions (Horne \& Grant, 2009). Data uncertainty, meanwhile, can arise from lack of knowledge of behaviour of systems, errors in measurements, outdated data, or because data are extrapolated from limited datasets (Owens, 1997; Björklund, 2002). Although methods to overcome uncertainty and variability in LCA have been suggested (e.g., data quality goals, uncertainty and sensitivity analysis, peer-reviewed databases) (Björklund, 2002; Reap et al., 2008), problems nevertheless persist.

Furthermore, LCA findings can vary significantly depending on choices made by practitioners (Guinee et al., 2001). Indeed, the multitude of decisions and assumptions (e.g., choice of the unit basis of analysis, system delimitation, impact categories, allocation, and data sources) needed for analyses means that studies are prone to subjectivity (Guinee et al., 2001). For example, when a unit process produces more than one product, questions on how flows and burdens should be partitioned among the multiple outputs arise, and decisions on how to allocate must be made without doublecounting impacts. In milk production, for example, LCA practitioners must determine 
how to most appropriately allocate inputs and impacts to the co-product of beef that is produced since it is not possible to precisely determine what feed use, land use, emissions, etc. are related to each of the products specifically. While ISO gives direction on allocation (ISO, 2006b) guidelines still allow for a spectrum of allocation options; depending on what allocation method is chosen, results can vary significantly (Schau \& Fet, 2008). Similarly, rules for choice of functional unit, essentially the unit or basis of analysis, and system boundaries are limited, and choices are largely reliant on external factors and practitioner preferences, leading to a wide variation amongst LCA results. One major drawback to such analytical or methodological inconsistencies is that results are not readily comparable, which limits the accessibility of the tool to non-practitioners and can lead to misrepresentation of results.

Limitations in methodological development can also be a challenge for LCA practitioners. For example, impacts of particular relevance to agriculture, such as land use and ecotoxicity are often missing from analysis due to high levels of uncertainty in impact assessment modeling, and because of lack of inventory data (De Schryver et al., 2010). Indeed, it has not been conclusively determined how to assess the impacts to biotic depletion and chemical toxicity due to lack of model development on fate pathways of toxic emissions in the environment (Mungkung \& Gheewala, 2007). Likewise, models for soil quality, alterations and impacts to biodiversity, landscape transformation, as well as habitat quality have not been sufficiently developed due to lack of adequate impact indicators and insufficient data on parameters (Anton et al., 2007; Mungkung \& Gheewala, 2007), which limits the scope of evaluations that are possible for agricultural systems. Moreover, LCA impact categories focus on global-scale environmental issues instead of effects on the local environment (Guinée et al., 2001), which can be problematic in terms of food production.

These challenges and shortcomings indicate that while LCA provides a rigourous framework for evaluating a number of important environmental performance parameters of products and production systems, it should not be the only tool used in decisionmaking processes. Notably absent from LCAs are social and economic impacts of the production system being studied (Guinée et al., 2001). Although historically viewed as ill equipped to include these aspects into evaluation, work is being conducted to include 
social aspects in LCAs (e.g., United Nations Environment Program (UNEP)-SETAC Life Cycle Initiative), though methodological shortcomings remain (Tillman, 2010). ${ }^{4}$ For now, results of LCAs are therefore best used in conjunction with other biophysical tools, and social and economic analyses (e.g., valuation techniques, qualitative analyses and interpretation), because achieving sustainability requires a holistic approach, informed by well-grounded, collaborative, and transdiciplinary research.

\subsubsection{Benefits of LCA}

Despite the challenges presented above, LCA remains a valuable tool for measuring the environmental performance of agricultural products or production systems. In terms of policy making, governmental bodies can use evidence from LCA results to guide decisions. For instance, energy and emission-related results of LCA have been used for eco-labeling (e.g., Eco Label in the E.U. or Green-to-Gold label in the U.S.) and legislation (e.g., E.U. Emission Trading Scheme and Carbon Tax) (Wognum et al., 2011). LCA results can also be used for marketing through Environmental Product Declarations to inform consumers about the environmental performance of products or production systems (Wognum et al., 2011). LCA results could be expressed in a nonstandardized format, or simply by promoting the fact that an LCA has been conducted, which may influence companies with green purchasing mandates (Tillman, 2010). Furthermore, results of LCAs can potentially be used to compare products, systems, and management practices, so long as the same assumptions and methodological choices are made (Wognum et al., 2011), and variation amongst agricultural systems accounted for.

Opportunities also exist for industry to use results of LCA research, as the evaluation of an industry's environmental performance can lead to market advantages. For example, industry can make improvements in production processes so that environmental standards can be met, adjust and prepare for future environmental regulations, as well as seek greater profits or market share through green marketing

\footnotetext{
${ }^{4}$ The UNEP-SETAC Life Cycle Initiative, launched in 2002, has been important for the advancement of life cycle research (Guinee et al., 2011). Some objectives of the initiative include enhancing global consensus on LCA methodology and expanding worldwide capacity to improve and apply life cycle approaches. Specific projects examples include the integration of socio-economic aspects into LCA, capacity building for conducting LCA, and development of land and water use impact categories (UNEPSETAC Life Cycle Initiative, 2010).
} 
(Hayashi et al., 2007). Results are also frequently used to identify and address hotspots in production systems - essentially those sub-systems that contribute disproportionately to overall impacts - ensuring that changes that are made in production processes are not unintentionally shifting burdens to other parts of the production chain (Baumann \& Tillman, 2004). In doing so, they can identify waste and inefficiency that can reduce environmental impacts and enhance profitability once corrected. Agricultural industries will also benefit from having a clearer picture of greenhouse gas emissions, which is extremely important with growing concerns of climate change (Weber \& Matthews, 2008). Moreover, LCA results can be used as a benchmark for future environmental assessments.

Due to the fact that LCA results are not easily accessible to consumers, they are least apt to use LCA outcomes directly. Nevertheless, changes made in industry and retailers can be more beneficial than individual consumer choices, as improvements in the production chains can lead to greater benefits (Edwards et al., 2009). Meanwhile, agricultural LCA can also add to a growing body of research on LCA and food systems, where findings, methodological issues and conclusions will aid researchers and academics that employ LCA methodology.

\subsection{LCA and food systems}

Over the past few decades, awareness has grown that both downstream and upstream activities affect the life cycle environmental performance of agricultural systems. This supply chain oriented understanding is due in part to food-related LCA research, which has flourished since the early 1990s. Beginning predominately with European based studies, agricultural LCA has grown in North American (e.g., Pelletier \& Tyedmers, 2007; Pelletier et al., 2008; Point et al., 2012), Australian (e.g., Biswas et al., 2008) and New Zealand (e.g., Mila i Canals et al., 2006, 2007a) contexts in recent years.

Numerous LCAs have been performed to examine the life cycle impacts of specific food products, including dairy (Cederberg \& Mattsson, 2000; Haas et al., 2001); beef (Cederberg \& Stadig, 2003; Pelletier et al., 2010); poultry (Pelletier, 2008); pork (Carlsson-Kanyama, 1998; Basset-Mens \& van der Werf, 2005); bread (Andersson \& Ohlsson, 1999); tomato ketchup (Andersson, 2000); sugar beets (Brentrup et al., 2001); 
apples (Mouron et al., 2006a,b; Mila i Canals et al., 2006); grains (Brentrup et al., 2004; Pelletier et al., 2008); potatoes (Mattsson \& Wallen, 2003); rice (Roy et al., 2005); and fisheries (Hospido \& Tyedmers, 2005; Parker \& Tyedmers, 2012). In addition to evaluating specific food products, further objectives of LCA research include comparing products from different regions and the relative importance of transport distances (e.g., Sim et al., 2007; Mila i Canals et al., 2007a); comparing different and potentially competing products (e.g., Carlsson-Kanyama, 1998; Williams et al., 2006); evaluating conventional and alternative management practices (e.g., Haas et al., 2001; BassetMens \& van der Werf, 2005; Nemecek et al., 2011); and comparing different scales of production (e.g., Andersson \& Ohlsson, 1999; Schlich \& Fleissner, 2005).

LCA findings have also shown that the degree of environmental impact varies in relation to the food group or production system under investigation. For instance, the production of livestock has been found to be more impactful than the production of fruit and vegetables (Carlsson-Kanyama et al., 1998). Inefficiencies in feed conversions and higher resource demand associated with producing fat and protein molecules in livestock systems is a major cause of the increased energy demands (Pelletier et al., 2011). As a result, it may be more relevant to focus on a cradle-to-farm gate scope of analysis for products with higher overall environmental impacts, while extending system boundaries further than farm gate is recommended for crops with lower environmental profiles such as vegetables, fruits and grains (Edwards et al., 2009). Meanwhile, the extent to which a product is processed, packaged, stored, transported, and prepared causes environmental impacts to increase as well (Carlsson-Kanyama et al., 2003). Site-dependency is also important when conducting agricultural LCAs, because both within and between countries variations in soil type, climate, and management practices cause impacts to vary (Mila i Canals et al., 2006; Pelletier et al., 2011). Finally, the scale of production, processing, and distribution can also influence the overall impact of food LCAs; evidence as to whether small or large size enterprises are more efficient is conflicting, however (Schlich \& Fleissner, 2005; Pelletier et al., 2010; Pelletier et al., 2011).

Previous LCAs have been conducted on organic and integrated production regimes, supply chain sub-system of transportation, and on apple production and distribution, specifically. An in-depth examination is presented in the following sections. 


\subsubsection{Conventional, integrated and organic agricultural LCA}

Increasingly, LCA has been employed to evaluate alternative production practices, where conventional and organic practices have been compared (e.g., Cederberg and Mattsson, 2000; Haas et al., 2001; Mattsson \& Wallen, 2003; Basset-Mens \& van der Werf, 2005; Pelletier \& Tyedmers, 2007; Pelletier et al., 2008; De Backer et al., 2009; Nemecek et al., 2011). Such assessments have commonly found reduced toxicity potentials in organic production compared to conventional, attributed to the exclusion of synthetic pesticides and fertilizers (De Backer et al., 2009). Correspondingly, organic production practices have also been found to be superior when biodiversity conservation and land management functions are being considered (Cederberg \& Mattsson, 2000; Haas et al., 2001; Nemecek et al., 2011). Apart from these findings, however, results are mixed depending on which crops and impact categories are being investigated. For example, scenario models produced by Pelletier and colleagues (2008) found that organic production can reduce the ozone depletion potential and the total energy demand for wheat and canola crops; differences between greenhouse gas emissions were minor, however. Importantly, Williams and colleagues (2006) demonstrated that analyses are crop dependant: energy use in organic wheat production was found to be 27 percent less than in non-organic, yet for potatoes the difference was negligible. In contrast, organically grown greenhouse tomatoes produced 30 percent more emissions per tonne than conventional production, chiefly due to reduced yields (Williams et al., 2006). Likewise, when conventional and organic milk production was compared, lower yields in organic systems led to higher land requirements, while larger feed concentrate inputs in conventional systems led to increased energy demands (Cederberg \& Mattsson, 2000). Further, results from Nemecek and colleagues (2011) show that the organic farming systems studied were either superior or equal to integrated production, noting that environmental gains in organic production came as a result of resource conservation through reliance on on-farm material use as opposed to auxiliary inputs in integrated practices. Generalizations of the environmental superiority of particular management regimes, therefore, should be taken with caution, as the impacts of production systems are dependent on the supply chain inputs of specific productions systems, and the environmental impact categories under investigation (Venkat et al., 2012). 


\subsubsection{Food transportation and LCA}

LCA has been used to understand the impacts of transportation in global food systems. While long distance transport has been found to be a hotspot in some agricultural LCAs (e.g., Stadig, 1997; Blanke \& Burdick, 2005; Sim et al., 2007), others have found it to be less significant when additional input variables are taken into account (Smith et al., 2005; Schlich \& Fleissner, 2005; Mila I Canals et al., 2007a). For example, importing tomatoes from Spain has been found to be environmentally preferable to producing them in heated U.K. greenhouses (Smith et al., 2005). Further, the impact of transportation has been found to be relative to size and efficiency of operations in the cases of lamb and fruit juices (Schlich \& Fleissner, 2005). Additionally, the inclusion of site-specific data such as country specific production inputs, as well as storage length, and time of consumption has been highlighted as crucial in the life cycle of apples (Mila i Canals et al., 2007a). As such, transportation must be examined in relation to other supply chain inputs before conclusions are drawn on whether eating locally produced or imported products is environmentally superior (Mila i Canals, 2007a; Edwards-Jones et al., 2008; Pelletier et al., 2011).

\subsection{Apple research in focus}

Research on apples is wide-ranging, with several disciplines investigating distinctive aspects of production systems. Some of the particular characteristics evaluated in previous studies include tree growth, yield, fruit quality, and fruit taste under conventional, integrated, and organic management systems (Weibel et al., 2000; Bertschinger et al., 2004; Peck et al., 2006; do Amarante et al., 2008; Roussos \& Gasparatos, 2009). Previous research has also investigated methods of disease and pest control (Ellis et al., 1998; Friedrich et al. 2003); biodiversity and pest management in orchard systems (Simon et al., 2010); consumer purchasing preferences of conventional, integrated and organic apples (Loureiro et al., 2001); IFP implementation decisions of New Zealand apple producers (McKenna, 1998); sustainability assessments of apple crop protection strategies, focusing on implementation of IPM practices (Mouron et al., 2012); carbon footprinting of the New Zealand apple supply chain (McLaren et al., 2010); carbon sequestration in Chinese apple orchards (Wu et al., 2012); economic input-output 
assessment of organic and conventional production in Washington State (Mon \& Holland, 2006); postharvest quality and sensory attributes of conventional and organic apple production (DeEll \& Prange, 1992); and international export markets for organic apples (Peck et al., 2005). Furthermore, best practices guidelines for producers have been compiled (e.g., Phillips, 2005; Canadian Horticulture Council, 2009; Craig, 2010), as well as economic analysis of the industry (e.g., Slattery et al., 2011), and new fruit growing initiatives (Agrapoint, 2009).

For the purpose of this research, studies using both formalized LCA methodologies and those using non-standardized life cycle approaches are reviewed below, so as to enable a thorough understanding of the environmental impacts of apple production systems in various regions throughout the world. Although methodological choices (e.g., system boundaries, assumptions in modeling, reporting) vary, these findings are important in the context of results that have emerged in Nova Scotia, explored at length in Chapter 2.

\subsubsection{LCA of apple orchard production}

Mila i Canals and colleagues (2006) used LCA to analyze the cradle-to-farm gate impacts of integrated apple production in two fruit growing regions of New Zealand. They found that energy related inputs were responsible for the majority of potential burdens, with fuels, fertilizers, and pesticides driving the bulk of impact categories under investigation. Indeed, on-orchard energy consumption due to mechanization was the primary cause of burdens across all impact categories, while provision of nitrogen $(\mathrm{N})$ fertilizers also contributed substantially to energy consumption, climate change, and acidification, and pesticide provision and use substantially impacted energy consumption and toxicity potentials. By comparing the impacts of orchards on a case-by-case basis, results were also successful in highlighting the importance of site-dependency, as variability between management techniques and locations of studies affected the environmental impact of each orchard. For example, despite production occurring in the same region, a 30 to 50 percent variation in energy consumption for similar field operations was found. Further, climate change impacts varied widely between orchards 
(from $\sim 40$ to $\sim 100 \mathrm{~kg} \mathrm{CO} 2$ eq. emissions per tonne of grade 1 and 2 apples produced) as the result of different fertilizer application rates.

Variability in orchard management practices and the effects on environmental impact categories was the focus of the study conducted by Mouron and colleagues (2006b). Here, a cradle-to-farm gate LCA was used as one component of analysis to compare the impacts of twelve orchards in Switzerland over a four-year time frame. Using an area-based unit of analysis (per ha), the authors emphasized the impact categories of energy use, aquatic ecotoxicity and aquatic eutrophication. By lowering use of energy carriers and machinery, pesticides, and fertilizers (respectively), improvement possibilities were identified. Interestingly, results also showed that the degree of impacts depended upon the management practices of producers. For example, applications of insecticides varied widely between orchards, resulting in a range of impact intensity, with resulting aquatic ecotoxicity potential ranging from a minimum of 2.0 to a maximum of $9.3 \mathrm{~kg} \mathrm{Zn}$ eq. per ha between orchards. Indeed, despite the fact that producers were largely homogenous in terms of geographic location, technical capacity, and level of education, environmental impacts nevertheless change according to the level of inputs used, indicating that there is a large potential for improvements in orchard management techniques.

Hayer and colleagues (2008) conducted a LCA of integrated and organic apple and wheat production in Europe, using a cradle-to-farm gate scope of analysis. Employing both mass and area based functional units, findings indicate that organic apple systems had lower overall impacts per hectare than integrated systems, yet due to lower yields in organic production, impacts are higher when analyzed on a per kilogram basis. Organic systems, however, were found to have higher eutrophication and acidification potentials per hectare in all countries studied save Italy. When comparisons of wheat and apple production systems were made, results showed that eutrophication and acidification potentials were lower in apple production than in wheat, due largely to the low input of fertilizer used in orchards.

Results produced in a cradle-to-farm gate analysis conducted by Mila i Canals and Polo (2003) provided insight into organic apple production in a New Zealand context. Findings show that energy consumption on organic farms was substantially 
higher than on integrated orchards surveyed, contributing by more than 50 percent to most impact categories under investigation.

Finally, apple cultivation was also analyzed by Reganold and colleagues (2001), who reported on the environmental and economic sustainability of conventional, integrated, and organic apple orchards in Washington State, U.S. Rather than using formalized LCA methodology, this frequently cited study employed a suite of sustainability indicators for comparison, finding that organic and integrated production were superior to conventional practices in terms of soil quality, consumer preferences, profitability, and environmental impacts. Organic production was also found to be more energy efficient than conventional and IPM systems; however, energetic impacts increased by only 7 and 5 percent respectively from the organic baseline. Comparable results were also found for yield between the three production systems, while organic production was found to be more costly in terms of production and labour expenses. From these results, the authors claim that organic apple production is more sustainable than integrated and conventional systems. Elliot and colleagues (2002) rebut this conclusion, however, arguing that the environmental and horticultural data did not, in fact, show any substantial difference between organic and integrated systems of production, and that certain methodological decisions are invalid. Instead, Elliot et al. (2002) suggest that integrated production may be the better choice for sustainable apple systems.

\subsubsection{LCA of apple cultivation and post-harvest processes}

Several geographically focused LCAs have been conducted to understand the environmental impacts of domestic and imported apples, adding to the on-going dialogue on 'food miles' and the impacts of consuming locally produced food. Stadig (1997) evaluated the environmental impact of apples grown in Sweden, France, and New Zealand, using a cradle-to-retail scope of analysis, including storage and transportation in system delimitation. Transportation was found to be responsible for the majority of burdens to impact categories, driven primarily by energy inputs. Despite efficiencies in New Zealand production, apples produced in France and shipped to Sweden by truck were still found to be less impactful than those imported from New Zealand. In fact, 
apples produced in France and New Zealand respectively require 1.7 and $5.5-7.5$ times the energy of those produced, stored and consumed in Sweden. In contrast, the subsystem of cold storage did not result in substantial impacts; apples grown and consumed in Sweden were therefore found to be the most environmentally favourable in that marketplace.

Using a LCA style methodology, Jones (2002) took a means/end approach to study the transportation stage of apples in the United Kingdom (U.K), assessing the impacts of apples with different sourcing origins (e.g., homegrown, locally, nationally or imported). This was accomplished by quantifying the fuel consumption and associated $\mathrm{CO}_{2}$ emissions through all stages of the transport supply chain. In this study, the packing sub-system is excluded completely from analysis, while apple cultivation is represented solely by energy consumption (using data from Stadig, 1997). Given this narrow system delimitation, it is not surprising that results suggest that apples sourced from further distances have greater environmental impacts, and that the majority of burdens are related to transportation. Not only are the inputs for cultivation unrepresentative of the production system under investigation in this study, they were only applied to apples that were grown nationally or imported, implying that homegrown and locally sourced products do not have any energetic input requirements. Indeed, the relative impacts of transportation in comparison to other supply chain sub-systems were not clearly defined (Sim et al., 2007), which limits the robustness of conclusions.

In another non-standardized life cycle study, Blanke and Burdick (2005) took an input-output approach to compare the primary energy requirements for apples grown in Germany to those grown in New Zealand. Fruit in Germany was stored in controlled atmosphere storage rooms for five months before transport to local retailers, while apples in New Zealand were shipped directly to Germany $(\sim 23,000 \mathrm{~km})$ by reefer ship without storage, and then transported to retail outlets. Results found that apples produced in Germany require 27 percent less energy than those shipped from New Zealand. However, methodological choices (e.g., outdated datasets, lack of cultivation inputs from country of origin, and not accounting for storage losses) may have led to a limited analysis of the production system (see further discussion in Chapter 2). 
Using a non-formalized LCA framework, the primary energy and $\mathrm{CO}_{2}$ emissions of apples produced in the U.K. and New Zealand were also assessed by Saunders and Barber (2008). This cradle-to-retail gate analysis showed that for apple cultivation specifically, the primary contributor to impact categories came as the result of direct energy consumption in the form of fuel and electricity used on orchards. However, when post-production sub-systems of the apple supply chain were considered, the impacts caused by transportation and storage were more significant. Indeed, the majority of burdens from apples produced in New Zealand were related to the long-distance shipping requirement, while in the U.K. substantial impacts arose from storage. As such, findings suggest that apples grown in New Zealand and shipped to the U.K. were environmentally superior to those grown in the U.K. and stored for six months, in contrast to results produced by Jones (2002).

Sim and colleagues (2007) also used LCA to study the relative impacts of transportation in relation to supply chain sub-systems of apple production and storage. The aim was to understand whether it is environmentally preferable to grow and consume apples in the U.K., or import them from Italy, Chile or Brazil, and how impacts vary with seasons. Here, a 10 month storage scenario was modeled to cover year round supply in the U.K., while transport scenarios were modeled for the countries of import. It was found that electricity consumption was again responsible for contributions to aquatic ecotoxicity potential, driven by inputs of storage, packing, pesticide production and transport. In contrast, pesticide use was found to be the primary cause of aquatic ecotoxicity in Chile and the U.K. Further, transport was the dominant cause of burdens to global warming and acidification potentials in Chile and Brazil, while in Italy GWP was driven chiefly by pesticide use on orchards. These results highlight the importance of country-specific analyses, as well as the efficiency of different transport modes. Ultimately, findings suggest that storing apples in the U.K. results in lower impacts for half the categories under investigation.

Further evaluating the impacts of domestic versus imported apples, Mila i Canals and colleagues (2007a) used LCA to quantify the primary energy use of apples produced in Europe and the Southern hemisphere. Building from previous apple-related LCAs, this study includes input variables that are lacking in previous work (e.g., Blanke \& Burdick, 
2005; Sim et al., 2007). Indeed, the model includes energy use for cultivation on a country-specific basis; consideration of storage length, time of consumption, and wastage; and exclusion of consumer shopping phases. Findings indicate that apples stored for longer periods had larger impact intensities, as storage losses contribute to primary energy consumption. As energy use varies depending on the season, the relative impact of storage and transport also changes in conjunction with these input requirements. Results, therefore, suggest that it may be more environmentally preferable to consume a combination of both domestic and imported apples depending on these factors, unlike results suggested by Sim et al. (2007) and Blanke \& Burdick (2005).

\subsection{Thesis rationale and objectives}

The evaluation of Nova Scotia's apple industry is important, for addressing the global scale environmental problems associated with modern agriculture requires knowledge about the environmental impacts of different production methods and locales. Indeed, scientifically defensible information is needed in order to determine the most environmentally sound options for the production, distribution, and consumption of food, for this is a prerequisite for moving to a more sustainable food system (Haas et al., 2001; Schlich \& Fleissner, 2005; Roy et al., 2009). While several LCA studies have focused on apple production elsewhere, to date no research has been conducted on apples grown or sold in Canada. It is necessary to address this gap in research, given the scale and value of this domestic industry (Section 1.2). Apple producers may benefit from this study, as the quantification of the industry's environmental performance can enable improvements in their production processes, helping to increase their competitiveness in the face of growing international competition. Furthermore, this environmental evaluation can provide opportunities for producers to lower costs associated with energy and material inputs, reduce greenhouse gas emissions, and help industry move toward the goals mandated in Nova Scotia's Environmental Goals and Sustainable Prosperity Act (2007). Additionally, this research will contribute to the application of LCA as a tool of analysis, for its findings, methodological issues, and conclusions may also aid researchers and academics that use LCA to study environmental impacts of agricultural supply chains. 
The specific research objectives of this thesis include:

1) Quantifying the life cycle environmental performance of typical commercial apple production systems in Nova Scotia;

2) Quantifying the life cycle environmental performance of emerging organic production systems in Nova Scotia;

3) Quantifying the environmental performance of post-harvest apple supply chains, including storage and transportation;

4) Conducting sensitivity analyses and scenario modeling to understand how input parameter variation and potential changes in production systems, respectively, affect global scale impact categories;

5) Identifying improvement opportunities of apple supply chains in Nova Scotia; and,

6) Contributing to knowledge of agricultural sustainability.

\subsection{Organization of thesis}

Two chapters and six appendices form the remainder of this thesis. Chapter 2 was written as a stand-alone article that will be submitted for publication to an academic journal. In Chapter 2, methods and results are presented for the Nova Scotia apple industry and associated supply chains, along with a discussion of improvement possibilities for identified hotspots, as well as a context specific discussion of how provincial results compare to apple LCA research in the past. Chapter 3 concludes the thesis by giving a summary of the research project; presenting project limitations and challenges encountered throughout; more thoroughly contextualizing the significance of results in regards to global scale ecological and sustainability issues; and providing recommendations for future research opportunities. In Appendix A, the toxicological effects of pesticides used on conventional and organic apple orchards are examined. The orchard production survey completed by Nova Scotia growers for 2010 is found in Appendix B. Appendix C contains emission calculations for fertilizer application (e.g., synthetic and manure) and liming materials on conventional and organic orchards and their resulting impacts to air and water. Appendix D holds the LCA databases from which both background and foreground systems processes were taken for modeling in the 
SimaPro v. 7.3.3 software program (Earthshift, 2012). Appendix E contains information related to the impact categories, and their associated models and characterization factors used to evaluate the Nova Scotia apple industry. Finally, Appendix F presents results of conventional and organic apple production calculated using an area based functional unit (per hectare). 


\section{CHAPTER 2: EVALUATING THE ENVIRONMENTAL IMPACTS OF CONVENTIONAL AND ORGANIC APPLE PRODUCTION IN NOVA SCOTIA, CANADA, THROUGH LIFE CYCLE ASSESSMENT}

\subsection{Abstract}

Life cycle assessment (LCA) was used to characterize the environmental performance of conventional and organic apple systems in Nova Scotia, Canada. The goal was to quantify and evaluate resources and energy required for production, storage, and transportation, determining how each supply chain sub-system contributes to relevant global scale environmental burdens. Scenario models were also constructed to explore how changes to key supply chain inputs affect overall life cycle results. Results indicate that on-orchards the combustion of diesel fuel, production and associated field-level emissions of fertilizers (i.e. synthetic and manure), and inputs to pest and disease management were major contributors to environmental impacts on both conventional and organic orchards. Extending system boundaries to cradle-to-retail locations, results reveal that electricity needed for storage caused substantial burdens, highlighting the problems of coal-based electricity generation in Nova Scotia. Findings also indicate that the relative impact of transportation varies according to distance travelled and mode of delivery. Consuming locally produced apples when in season was found to be environmentally preferable to those requiring year round storage, while transport by freight ship is more favourable than long distance transport truck delivery.

\subsection{Introduction}

Global food systems are contingent on resource and energy inputs, as they are required for the production and provision of food. This consumption is associated with environmental alterations, where changes to habitat and biodiversity loss (Butler et al., 2007), emissions to air, water, and soil (Foster et al., 2006), and depletion of materials and non-renewable energy have occurred (Matson et al., 1997; Carlsson-Kanyama et al., 2003). Such changes are leading to a decline in natural capital, the effects of which could threaten the productive capacity of agricultural systems in the future (Herdt $\&$ Steiner, 1995). In response, some farmers have begun to employ management techniques that attempt to protect the environment and improve biological and natural processes. Apple 
producers in Nova Scotia, Canada are engaging in these practices, where upwards of 95 percent of growers employ some measure of integrated pest management (IPM), and organic production is beginning to emerge (Canadian Horticultural Council, 2009).

Understanding how and to what extent conventional improvements such as IPM and organic production practices contribute to relative environmental burdens is a prerequisite in moving towards more sustainable food systems (van der Werf \& Petit, 2002; Roy et al., 2009). Although there is a growing body of literature with this focus (e.g., Cederberg \& Mattsson, 2000; Haas et al., 2001; Pimentel et al., 2005; Pretty et al., 2006; Badgley et al., 2007; Pelletier et al., 2008; De Backer et al., 2009; Mouron et al., 2012; Venkat et al., 2012), further research is required to ensure a rigorous evaluation has occurred. Studies that contribute to the development of greater resource and energy efficiencies are essential in minimizing environmental impacts of agriculture.

One tool to carry out this type of analysis is life cycle assessment (LCA). This ISO-standardized biophysical accounting tool evaluates the environmental performance of a product or production system from 'cradle to grave' by assessing material and energy inputs and quantifying them in terms of a suite of global scale environmental impact categories (e.g., global warming potential) (Guinee et al., 2001). This throughput assessment allows for a full account of the production system, resulting in the identification of hotspots in the production chain that cause the most environmental burdens, inefficiencies and waste. Once recognized, improvements can be made that can lead to a reduction of environmental impacts and decreases in costs of production (Guinee et al., 2001). Moreover, results can be used to ensure that alternatives employed do not unintentionally shift impacts to different parts of the supply chain; instead, appropriate solutions can be implemented to further optimize food systems.

Due to these strengths, application of LCA to agricultural systems has proliferated over the past decade (e.g., Cederberg \& Mattsson, 2000; Haas et al., 2001; Brentup et al., 2004; Pelletier et al., 2008; Thomassen et al., 2008; Hokazono et al., 2009; Nemecek et al., 2011; Point et al., 2012), and apple production specifically has been studied using a life-cycle lens (e.g., Stadig, 1997; Blanke \& Burdick, 2005; Mouron et al., 2006a,b; Mila i Canals et al., 2006 \& 2007a; Sim et al., 2007; Saunders \& Barber, 2008). To date, however, no research has been conducted to evaluate the environmental 
performance of apple production in an Atlantic Canadian context. Impetus for this research project thus emerged, with aims of both improving the environmental performance of apple production systems, and to create competitive advantages for producers of the region. More broadly, results, methodological issues, and conclusions of this research may contribute to the application of LCA as a tool of analysis for the LCA community, as well as wider scholarship on food systems.

\subsection{The Nova Scotia apple industry}

Apple production is a significant industry in Canada, valued at $\$ 148.5$ million dollars in 2010 (Agriculture and Agri-Food Canada, 2012). Nova Scotia, a province that has been producing apples since the 1600s, represents approximately 10 percent of the Canadian apple industry, with an average of 2.5 million bushels of apples produced per year (AgraPoint, 2009). The economic impact of this industry is substantial, for in 2010, 33,700 tonnes of apples were produced, valued at $\$ 12.2$ million dollars at farm-gate, which has an economic spin-off of $\$ 61$ million (Statistics Canada, 2012). Within Nova Scotia, production is located primarily in the Annapolis Valley, where over 150 farms produce apples on approximately 1850 hectares of land (Statistics Canada, 2012). Apples produced in Nova Scotia are destined for diverse markets, including local retail, processing into value-added products (e.g., juice, pies, and ciders), and export. Over fifty cultivars are grown in Nova Scotia, with the most prominent varieties including Honeycrisp, McIntosh, Cortland, Gala, Jonagold, Golden and Red Delicious, and Gravenstein.

\subsection{Materials and methods}

LCA was employed to quantify the material and energy inputs of apple production in Nova Scotia, measuring its contribution to several global scale resource depletion and environmental concerns. LCA is well suited to inform how orchard activities and beyond are affecting both resource and emission-based impact categories, as results can pinpoint sub-systems in the life cycle where the greatest improvements in environmental performance can be achieved. The four-step analytical LCA framework 
provided by ISO-standardized guidelines (ISO, 2006a,b) was followed in the present study, allowing for a robust environmental analysis to be conducted.

\subsubsection{Goal and scope}

The central objectives of this project were to characterize the life cycle environmental performance of typical commercial apple production, and of emerging organic apple production in Nova Scotia. Direct comparisons of the two modes of production have not been made because substantial differences in scale and age exist between them. Organic apple production is only beginning to emerge in the province, as only eight producers are currently in operation, in contrast to the approximate 150 conventional growers. Further, while the average total years of operation for conventional orchards surveyed is 34 , for organic production the mean is 12 years. It follows that the scale of production, and as we will see, average yields, between conventional and organic systems in the province is quite different. Therefore, not only is the production of organic apples nascent, the length of operations and level and output of the two industries are not parallel. For these reasons, direct comparisons were not made; rather, the two production systems were characterized independently in order to understand how they each impact the environment on their own accord.

\subsubsection{Functional unit}

Due to the multifunctional nature of agriculture, the functional unit in LCA can take various forms, the choice of which can significantly affect outcomes (Basset-Mens \& van der Werf, 2005; De Backer et al., 2009). Here, two functional units were chosen: the production of food (i.e., per tonne), and the function of land quality (i.e., per hectare). Both mass and area-based units of analysis are appropriate when considering conventional and organic production, because minimizing impacts per product unit allows for optimal maximization of productivity, and lowering impacts per area unit allows for land quality to be achieved. These functional measures provide information relevant to determining preferable levels of production intensity (Charles et al., 2006; Nemecek et al., 2011). 


\subsubsection{System boundaries}

An initial cradle-to-farm-gate scope of analysis was chosen in order to understand burdens that arise on orchards, as on-farm production has been responsible for a majority of impacts in previous food-related LCAs (Weber \& Matthews, 2008; Schau \& Fet, 2008). However, since most apple production systems are less input intensive than are other arable crops and livestock systems, a more holistic picture of the apple life cycle was sought, and the system boundary thus extended from cradle to retail gate. Consequently, results are presented for both cradle-to-farm-gate and cradle-to-retail-gate system boundaries for conventional and organic production. Noteworthy, while a cradleto-retail-gate system scope was modeled for organic production, data on storage inputs obtained for this study reflect conventional apple storage. This scenario model was developed to understand how organic production would fair if post-production systems of storage in organic mirrored those of conventional production. In terms of time boundaries, a snapshot of the 2010 growing season was considered for this study.

On-farm boundaries included all major production processes, including inputs to land preparation (e.g., fumigants, limestone, hay, compost, manure, fertilizers) infrastructure (e.g., trellis system, fencing, on-farm storage boxes), farm equipment (e.g., tractors and other farm implements), fuel use (e.g., diesel, gasoline, and propane burned on farm), soil amendments and fertilizers (e.g., fertilizers, boron, calcium chloride, zinc, etc.), and chemical and non-chemical crop inputs (e.g., fungicides, growth regulators, herbicides and insecticides). Post orchard production sub-processes included storage inputs (e.g., concrete for storage buildings and rooms, plastic and cardboard for packing inputs, equipment used, and electricity for storage in controlled atmosphere and cold storage rooms), and transport to various retail locations throughout Canada and abroad via transport truck, rail and freight ship (Figure 1). 
Figure 2. Life cycle stages of Nova Scotia apple production

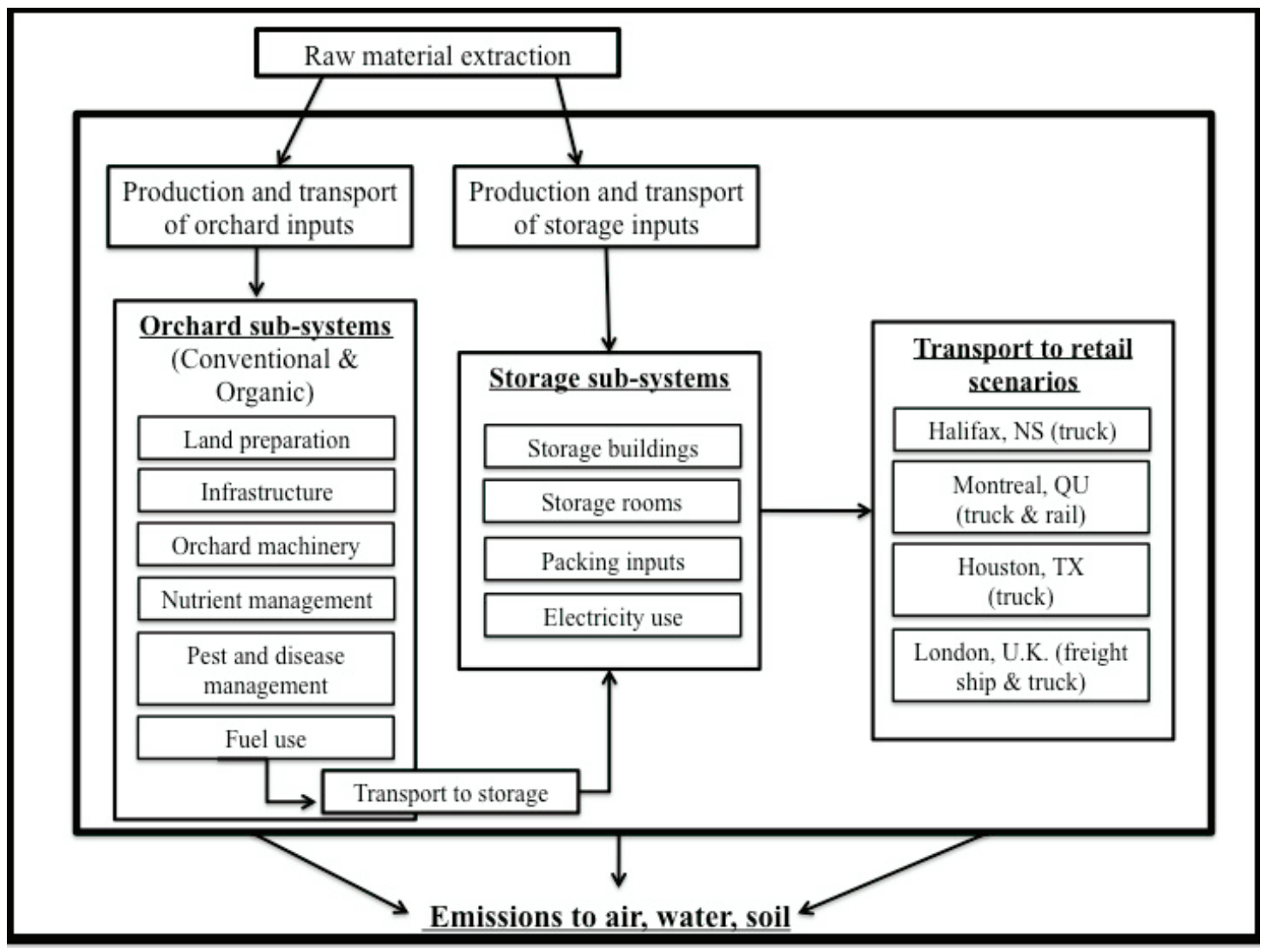

\subsubsection{Life cycle inventory data}

Orchard and storage facility input data were obtained for the 2010 season via questionnaires (Appendix B) and follow-up personal communications with industry informants. Lacking a complete orchard directory for Nova Scotia, Internet searches provided an initial sample of $\sim 25$ conventional and 8 organic apple growers. Five additional contacts were made through participation in Kentville's apple orchard tour in 2011, and with the aid of an industry informant, Charles Embree. This consultation also ensured the sample was geographically representative of the Annapolis Valley, and that producers operating on a range of orchard sizes (i.e. $<1$ to $>50$ ha) were contacted. ${ }^{5}$ Once

\footnotetext{
${ }^{5}$ Apple producers were contacted first via email, with subsequent follow up by phone, which ultimately yielded the most effective response rate. Survey completion took place over a six-month period from October 2011 to March 2012.
} 
collected, foreground inventory data were compiled in Excel. Given the range of orchard sizes, inputs were averaged using 2010 production tonnage as the weighting factor to produce a representative model of Nova Scotia apple production. Similarly, storage input data were compiled and averaged using storage volumes for the 2010 season. Storage data were analyzed using an integrated average for 2010, where inputs were divided by the total sum of apples stored throughout to get the 'average' kg per tonne. Calculations did not include losses, as data indicated that less than $1 \%$ of apples are ultimately discarded during storage.

Field level greenhouse gas emissions from fertilizer and manure applications were estimated following methods employed by Point and colleagues (2012) and Pelletier (2006), both of which based calculations on Brentrup et al. (2000), the Intergovernmental Panel on Climate Change (IPCC, 2006), and Dalgaard et al. (2006) (Appendix C). Although consensus on emission potentials from fertilizers and manures has not been reached, and external variables such as soil, climate, rate of application and nutrient uptake can affect their accurate calculation (Eichner, 1990; Pelletier, 2006), comparative emission potentials were nevertheless calculated for nitrogen, phosphorus, and carbon dioxide using best available information in the literature, serving to represent emission potentials for this study.

Background system processes (e.g., agro-chemical and fertilizer production, provision of steel, wood, and plastic for infrastructure and orchard machinery) and upstream processes (e.g., provision of concrete, plastic and cardboard packing materials, and transportation) were compiled primarily from the EcoInvent 2.2 database (Pre Consultants, 2010), with additional peer-reviewed LCA databases (e.g., US LCI 1.6, ELCD 2.0) used when necessary (Appendix D). Electricity production mixes were developed to reflect the temporal and location-specific realities of the electricity grid analyzed.

\subsubsection{Allocation}

Grade specific (i.e., direct consumption; processing) allocation of apples was not conducted in this analysis, as has been in past apple LCA research (e.g., Mila i Canals et al., 2006; Sim et al., 2007). Although co-production of grade specific apples occurs, both 
those intended for direct consumption and those for processing are sent to storage facilities before reaching their final destinations, thereby using inputs involved in the storage process. Separate partitioning of apple grades was also unnecessary due to the fact that an integrated average of apples stored throughout the year was used to determine the amount of materials used per tonne of apples, following the project's objectives to understand the environmental impacts of typical commercial apple production in Nova Scotia, rather than those with superior or inferior economic value. Moreover, grade specific data were unavailable for this project.

\subsubsection{Life cycle impact assessment}

Model construction was facilitated by the use of a LCA software program, SimaPro, version 7.3.3 (Earthshift, 2010), allowing for inventory data to be quantified in relation to relative impact categories, employing characterization factors from established impact assessment characterization models (Appendix E). The impact assessment methods package 'Recipe H' (Pre Consultants, 2010) was used to quantify global warming potential (GWP), photochemical oxidant formation potential (POFP), terrestrial acidification potential (AP), freshwater and marine eutrophication potential (FEP \& MEP), metal depletion potential (MDP), and fossil depletion potential (FDP). Human cancer and non-cancer toxicity potential (HCTP, HNCTP), and aquatic eco-toxicity potential (ETP) were quantified using the UseTox methodology, recently developed through the UNEP-SETAC Life Cycle Initiative (Pre Consultants, 2010), and cumulative energy demand (CED) was calculated independently as a single issue impact.

\subsubsection{Scenario analysis}

Several scenarios were modeled to explore the effects of future and hypothetical changes to the apple supply chain in order to understand how they impact life cycle burdens. Scenario models were designed by considering possible changes to the baseline model that may have an effect on environmental performance, with models constructed around supply chain sub-systems that had demonstrated weight to the relative contribution of the life cycle. As a result, several scenario models for transportation and electricity generation improvement possibilities were constructed. 


\subsubsection{Transportation scenarios}

Transportation scenarios were conducted to show potential impacts of both distance and mode of transport in order to understand what role these factors play in the life cycle of apples. Growing interest in the concept of 'food miles' and the impact of export-oriented food systems, coupled with debates over local production (e.g., LaTrobe \& Acott, 2000; Schlich \& Fleissner, 2005; Smith et al., 2005; Edward-Jones et al., 2008; Weber \& Matthews, 2008; Coley et al., 2009; Duram \& Oberholtzer, 2010; Mundler \& Rumpus, 2012) prompted this investigation. Further, post-production stages such as storage and transport have been the focus of apple LCAs in the past (e.g., Blanke \& Burdick, 2005; Sim et al., 2007; Mila i Canals et al., 2007a). Understanding how apples from Nova Scotia would fare in these discussions and what impact transportation makes to overall life cycle burdens was therefore the goal of these scenarios.

Five transportation scenarios were identified using insight from Agriculture and Agri-Food Canada (2012) and questionnaire responses from orchard and storage operations (Table 1). All were modeled from cradle-to-farm-gate, with transport originating in Kentville, the approximate center of Nova Scotia apple production. Return trips were excluded from scenarios.

Table 1. Transportation scenarios

\begin{tabular}{|l|l|r|}
\hline Location & Mode of transport & km from Kentville, NS \\
\hline A) Halifax, Nova Scotia & Transport truck (28t)* & 103 \\
\hline B1) Montreal, Quebec & Transport truck (28t) & 1275 \\
\hline B2) Montreal, Quebec & Freight rail & 1275 \\
\hline C) Houston, Texas & Transport truck (28t) & 4167 \\
\hline D) London, England & $\begin{array}{l}\text { Freight ship, transport truck } \\
(28 \mathrm{t})\end{array}$ & 4638 (ship) + 250 (truck) \\
\hline
\end{tabular}

*Note: Inputs for refrigeration (Tassou et al., 2008) were included for all transport trucks used in models.

\subsubsection{Improvement possibility scenarios}

To explore potential environmental benefits that could arise from modifications to key supply chain inputs, two sets of improvement possibility scenarios were modeled and analyzed pertaining primarily to electricity as described in the following sections. 
Scenarios E1 \& E2 explore future and hypothetical electricity production in Nova Scotia, and scenario $\mathrm{F}$ examines the impacts of increased transportation and subsequent storage using a renewable energy source. Models were constructed using data from conventional orchard production and analyzed using impact categories identified in section 2.4.6.

\subsection{Electricity mix scenarios (E1 \& E2)}

Given that Nova Scotia's energy generation is principally dependent on imported coal, accounting for $57 \%$ of the primary energy inputs in 2011 (Nova Scotia Department of Energy, 2009), it was important to understand the role this plays in the life cycle of apples, and how changes in energy inputs could lead to environmental improvements. To this end, the following scenarios were devised and compared to the baseline model of cradle-to-Halifax-retail (transportation scenario A), using the 2011 energy mix.

Scenario E1: Working from the projection that 40 percent of electricity in the province will be generated by renewable sources by 2020 (Nova Scotia Department of Energy, 2010), a model was constructed to represent this target (Table 2). Coal continues to dominate in this scenario, providing $34 \%$ of electricity generated, while wind and hydropower increase to 19 and $21 \%$ respectively.

Scenario E2: Building on scenario E1, this scenario replaces coal with natural gas (Table 2), accounting for $54 \%$ of the electricity generated, while wind and hydropower each represent 19 and $21 \%$ respectively, following the 2020 mandate.

Table 2. Recent (2011) and hypothetical primary energy inputs to Nova Scotia electricity generation

\begin{tabular}{|l|c|c|c|}
\hline Energy source & $\begin{array}{l}\text { 2011 Actual } \\
\mathbf{( \% )}\end{array}$ & $\begin{array}{l}\text { High renewable } \\
\text { (scenario E1) } \\
(\%)\end{array}$ & $\begin{array}{l}\text { High natural gas } \\
\text { (scenario E2) } \\
(\%)\end{array}$ \\
\hline Coal & 57 & 34 & 0 \\
\hline Natural Gas & 20 & 20 & 54 \\
\hline Hydro \& Tidal & 10 & 21 & 21 \\
\hline Wind & 7 & 19 & 19 \\
\hline Other (imported oil \& power) & 6 & 6 & 6 \\
\hline
\end{tabular}

\subsection{Montreal scenario: Electricity for storage and transportation (F)}

The role of Nova Scotia's electricity generation mix was again the genesis of this hypothetical improvement scenario. Here the goal was to understand how life cycle 
impacts would vary if apple storage were to be undertaken in a province almost entirely reliant on renewable sources of electricity. This scenario is identical to scenario $\mathrm{C}$ in which conventionally produced Nova Scotia apples are shipped to Houston, TX, with the exception that upon harvesting, apples are trucked to Montreal, QU for storage. All inputs to storage and packing are identical to the Nova Scotia reality except electricity inputs, which were changed to mirror the reality in Quebec, where $97 \%$ of electricity is generated by hydropower. The aim was to understand how life cycle impacts would be affected with additional transport (i.e. to Montreal after harvest) and a change to the storage electricity source, comparing the relative role of electricity and transportation to results from scenario $\mathrm{C}$, as well as the impact to overall life cycle burdens in each case.

\subsubsection{Sensitivity analyses}

Sensitivity analyses were conducted to assess the effect of variability and uncertainty in data and assumptions on modeled outputs in the pursuit of testing the robustness of conclusions. Supply chain variables (e.g., inputs to land preparation and crop management; fuel and fertilizer use) were assessed according to overall life cycle

impact, degree of data variation, and assumptions made during the modeling process. As a result, sensitivity tests were developed according to the uncertainty and variability levels found in these parameters, as well as the relative weight of the input to life cycle impacts. Based on the results, it was determined that six tests should be conducted. They include: $1 \& 2$ ) a 10 percent increase/decrease in fuel use on conventional and organic orchards, respectively; $3 \& 4$ ) a 10 percent increase/decrease in the quantity of chemical and non-chemical pest and disease management inputs on conventional and organic orchards, respectively; and $5 \& 6$ ) a 10 percent increase/decrease in the amount of fertilizers and manure used on conventional and organic orchards, respectively. A 10 percent rate of change was chosen due to the probability that input variations would be within this range, and also so sensitivity test results could be compared to higher input percentage changes (i.e. 20, 30, 40, 50, etc.) without difficulty. 


\subsection{Results}

Table 3 displays characteristics of orchard data obtained from ten conventional and three organic growers that completed surveys for the 2010 season, representing a 33 and 37.5 percent response rate, respectively. These data underpinned the weighted averages used in the calculation of sub-system contributions to impact categories. In total, data received represents $\sim 15$ percent of the total conventional apple growing area in Nova Scotia. Statistics on total organic orchard production in Nova Scotia are unavailable; however, data were obtained from three of the eight known producers in the province. Tables 4 and 5 display detailed life cycle inventory results for conventional and organic orchard data collected, respectively, with results displayed per tonne of apples produced.

Table 3. Combined orchard production characteristics upon which analyses were undertaken

\begin{tabular}{|l|l|r|r|}
\hline Orchard Data & Unit & $\begin{array}{l}\text { Conventional } \\
\text { orchards (n=10) }\end{array}$ & $\begin{array}{l}\text { Organic } \\
\text { orchards (n=3) }\end{array}$ \\
\hline Combined orchard size & ha & 282.86 & 19.02 \\
Combined annual production & tonnes & 6691.68 & 225.82 \\
Yield & tonnes/ha & 23.66 & 11.88 \\
\hline
\end{tabular}


Table 4. Life cycle inventory results for 2010 conventional Nova Scotia orchard production of 1 tonne of apples (crop yield: 23.66)

\begin{tabular}{|c|c|c|c|c|c|}
\hline Material and Energy Inputs & Unit & $\begin{array}{l}\text { Per } \\
\text { tonne }\end{array}$ & Material and Energy Inputs & Unit & $\begin{array}{l}\text { Per } \\
\text { tonne }\end{array}$ \\
\hline \multicolumn{3}{|l|}{ Land Preparation ${ }^{1,2}$} & \multicolumn{3}{|l|}{ Pest and Disease Management ${ }^{1,5}$} \\
\hline Calcite limestone & $\mathrm{kg}$ & 2.99 & Captan (fungicide) & $\mathrm{kg}$ & 0.71 \\
\hline Dolomite & $\mathrm{kg}$ & 4.15 & Mancozeb (fungicide) & $\mathrm{kg}$ & 0.03 \\
\hline Compost & $\mathrm{kg}$ & 8.10 & Dithiocarbamate-compounds (fungicide) & $\mathrm{kg}$ & 0.19 \\
\hline Hay & $\mathrm{kg}$ & 3.99 & Fungicides, at regional storehouse & $\mathrm{kg}$ & 0.19 \\
\hline $\mathrm{N}$-fertilizer (synthetic) & $\mathrm{kg}$ & 0.044 & Glyphosate (herbicide) & $\mathrm{kg}$ & 0.37 \\
\hline P-fertilizer (synthetic) & $\mathrm{kg}$ & 0.039 & Bipyridylium-compounds (herbicide) & $\mathrm{kg}$ & 0.03 \\
\hline K-fertilizer (synthetic) & $\mathrm{kg}$ & 0.039 & 2,4-D (herbicide) & $\mathrm{kg}$ & 0.09 \\
\hline Fumigant 1,3-dichloropropene & $\mathrm{kg}$ & 0.31 & Mineral Oil (herbicide) & $\mathrm{kg}$ & 1.00 \\
\hline \multirow[t]{2}{*}{ Glyphosate } & $\mathrm{kg}$ & 0.002 & Herbicides, at regional storehouse & $\mathrm{kg}$ & 0.06 \\
\hline & & & Insecticides, at regional storehouse & $\mathrm{kg}$ & 0.01 \\
\hline \multicolumn{3}{|l|}{ Nutrient Management $^{1,4}$} & Pyretriod-compounds (insecticide) & $\mathrm{kg}$ & 0.0006 \\
\hline N-fertilizer (synthetic) & $\mathrm{kg}$ & 0.81 & Growth regulators & $\mathrm{kg}$ & 0.14 \\
\hline P-fertilizer (synthetic) & $\mathrm{kg}$ & 0.95 & Ammonium sulphate (growth regulator) & $\mathrm{kg}$ & 0.006 \\
\hline K-fertilizer (synthetic) & $\mathrm{kg}$ & 1.02 & & & \\
\hline Urea, as $\mathrm{N}$ & $\mathrm{kg}$ & 0.30 & \multicolumn{3}{|l|}{ Trellis System \& Infrastructure } \\
\hline Zinc & $\mathrm{kg}$ & 0.005 & Steel wire & $\mathrm{kg}$ & 0.09 \\
\hline Zinc sulphide & $\mathrm{kg}$ & 0.02 & Steel posts & $\mathrm{kg}$ & 0.40 \\
\hline Magnesium sulphate & $\mathrm{kg}$ & 0.11 & Wooden posts & $\mathrm{kg}$ & 3.60 \\
\hline Calcium chloride & $\mathrm{kg}$ & 0.64 & Wood preservative & $\mathrm{kg}$ & 0.11 \\
\hline Boron & $\mathrm{kg}$ & 0.02 & Polyvinylchloride (fencing) & $\mathrm{kg}$ & 0.001 \\
\hline Calcite limestone & $\mathrm{kg}$ & 1.20 & Wooden storage boxes & $\mathrm{kg}$ & 2.38 \\
\hline \multirow[t]{2}{*}{ Mulching } & \multirow[t]{2}{*}{$\mathrm{kg}$} & \multirow[t]{2}{*}{0.30} & & & \\
\hline & & & Fuel Use $^{1}$ & & \\
\hline \multicolumn{3}{|c|}{ Emissions from Fertilizers \& Liming Materials $^{3}$} & Diesel & $\mathrm{L}$ & 6.88 \\
\hline $\mathrm{CO}_{2}$ (from lime in land prep.) & $\mathrm{kg}$ & 3.29 & Gasoline & $\mathrm{L}$ & 1.69 \\
\hline $\mathrm{CO}_{2}$ (from lime in nutrient mgmt.) & $\mathrm{kg}$ & 0.53 & Liquified petroleum gas & $\mathrm{L}$ & 0.27 \\
\hline $\mathrm{CO}_{2}$ (from urea in nutrient mgmt.) & $\mathrm{kg}$ & 0.22 & & & \\
\hline $\mathrm{N}_{2} \mathrm{O}$ to air & $\mathrm{kg}$ & 0.02 & \multicolumn{3}{|l|}{ Orchard Machinery } \\
\hline NO to air & $\mathrm{kg}$ & 0.02 & Tractor & $\mathrm{kg}$ & 0.53 \\
\hline $\mathrm{NH}_{3}$ to air & $\mathrm{kg}$ & 0.38 & Farm implements & $\mathrm{kg}$ & 0.26 \\
\hline $\mathrm{NO}_{3}$ to water & $\mathrm{kg}$ & 0.56 & & & \\
\hline \multirow[t]{2}{*}{$\mathrm{P}_{2} \mathrm{O}_{5}$ to water } & $\mathrm{kg}$ & 0.03 & Transport to Storage & & \\
\hline & & & Single unit truck, gasoline powered & $\mathrm{tkm}$ & 23.8 \\
\hline
\end{tabular}

Table 4 notes:

1. Inputs were calculated as a weighted average of inputs reported by 10 responding conventional producers, where the total tonnage of apples produced in 2010 was used as the weighting factor.

2. 'Land preparation' inputs encompass all inputs used for orchard establishment, and on a frequent periodic basis (e.g., every 5 years) but less than annually. Inputs were calculated using a 20-year time frame to account for the lifespan of orchards.

3. Field level emissions for nitrogen, phosphorus, and carbon dioxide were calculated using methods employed by Point and colleagues (2012) and Pelletier (2006). See Appendix $\mathrm{C}$ for further details.

4. 'Nutrient management' includes all reported inputs applied on an annual basis.

5. Emissions from active ingredients in pesticides to air $(10 \%)$, water (1\%), and soil $(85 \%)$ were calculated according to values in Audsley (2003). 
Table 5. Life cycle inventory results for 2010 organic Nova Scotia orchard production of 1 tonne of apples (crop yield: 11.88)

\begin{tabular}{|c|c|c|c|c|c|}
\hline Material and Energy Inputs & Unit & $\begin{array}{l}\text { Per } \\
\text { tonne }\end{array}$ & Material and Energy Inputs & Unit & $\begin{array}{l}\text { Per } \\
\text { tonne }\end{array}$ \\
\hline Land Preparation ${ }^{1,2}$ & & & \multicolumn{3}{|c|}{ Emissions from Manure \& Liming materials ${ }^{3}$} \\
\hline Dolomite & $\mathrm{kg}$ & 1.49 & $\mathrm{CO}_{2}$ (from lime in land prep.) & $\mathrm{kg}$ & 0.71 \\
\hline Compost & $\mathrm{kg}$ & 11.34 & $\mathrm{~N}_{2} \mathrm{O}$ to air & $\mathrm{kg}$ & 0.04 \\
\hline \multirow[t]{2}{*}{ Hay } & $\mathrm{kg}$ & 25.10 & NO to air & $\mathrm{kg}$ & 0.03 \\
\hline & & & $\mathrm{NH}_{3}$ to air & $\mathrm{kg}$ & 0.86 \\
\hline \multicolumn{3}{|l|}{ Nutrient Management ${ }^{1,4}$} & $\mathrm{NO}_{3}$ to water & $\mathrm{kg}$ & 0.97 \\
\hline \multirow{7}{*}{$\begin{array}{l}\text { N-fertilizer (from manure) } \\
\text { P-fertilizer (from manure) } \\
\text { K-fertilizer (from manure) } \\
\text { Calcium chloride } \\
\text { Boron } \\
\text { Hay intensive organic, at farm }\end{array}$} & $\mathrm{kg}$ & 1.60 & $\mathrm{P}_{2} \mathrm{O}_{5}$ to water & $\mathrm{kg}$ & 0.03 \\
\hline & $\mathrm{kg}$ & 1.05 & & & \\
\hline & $\mathrm{kg}$ & 1.20 & \multicolumn{3}{|l|}{ Trellis System \& Infrastructure ${ }^{1}$} \\
\hline & $\mathrm{kg}$ & 0.37 & Steel posts & $\mathrm{kg}$ & 0.16 \\
\hline & $\mathrm{kg}$ & 0.03 & \multirow[t]{2}{*}{ Wooden storage boxes } & \multirow[t]{3}{*}{$\mathrm{kg}$} & \multirow[t]{3}{*}{4.1} \\
\hline & $\mathrm{kg}$ & 4.43 & & & \\
\hline & & & Fuel Use ${ }^{1}$ & & \\
\hline \multicolumn{3}{|l|}{ Pest and Disease Management ${ }^{1,4}$} & \multirow[t]{2}{*}{ Diesel } & \multirow[t]{2}{*}{$\mathrm{L}$} & \multirow[t]{2}{*}{8.64} \\
\hline \multirow{6}{*}{$\begin{array}{l}\text { Copper, primary at refinery } \\
\text { Sulphur, from crude oil } \\
\text { Lime sulphur }\end{array}$} & & 0.16 & & & \\
\hline & $\mathrm{kg}$ & 10.0 & \multicolumn{3}{|l|}{ Farm Equipment $^{1}$} \\
\hline & $\mathrm{kg}$ & 1.13 & Tractor & $\mathrm{kg}$ & 1.76 \\
\hline & & & Farm Implements & $\mathrm{kg}$ & 0.88 \\
\hline & & & \multicolumn{3}{|l|}{ Transport to Storage } \\
\hline & & & Tractor, trailer & $\mathrm{tkm}$ & 5.88 \\
\hline
\end{tabular}

Table 5 notes:

1. Inputs were calculated as a weighted average of inputs reported by 3 responding organic producers, where the total tonnage of apples produced in 2010 was used as the weighting factor.

2. Land preparation' inputs encompass all inputs used for orchard establishment, and on a frequent periodic basis (e.g., every 5 years) but less than annually. Inputs were calculated using a 20-year time frame to account for the lifespan of orchards.

3. Field level emissions for nitrogen, phosphorus, and carbon dioxide were calculated using methods employed by Point and colleagues (2012) and Pelletier (2006). See Appendix $\mathrm{C}$ for further details.

4. Values include all reported inputs applied on an annual basis.

\subsubsection{Life cycle impact assessment results}

Tables 6 and 7 present a detailed account of life cycle contributions from both cradle-to-farm-gate and cradle-to-Halifax-retail-gate (transportation scenario A) for conventional and organic systems, showing how both on-orchard activities and postorchard inputs contribute to impact categories considered. These results reflect a massbased functional unit, showing impacts per tonne of apples produced; relative contributions using an area-based point of reference mirrored these proportions, with minor percentage changes (Appendix F). 


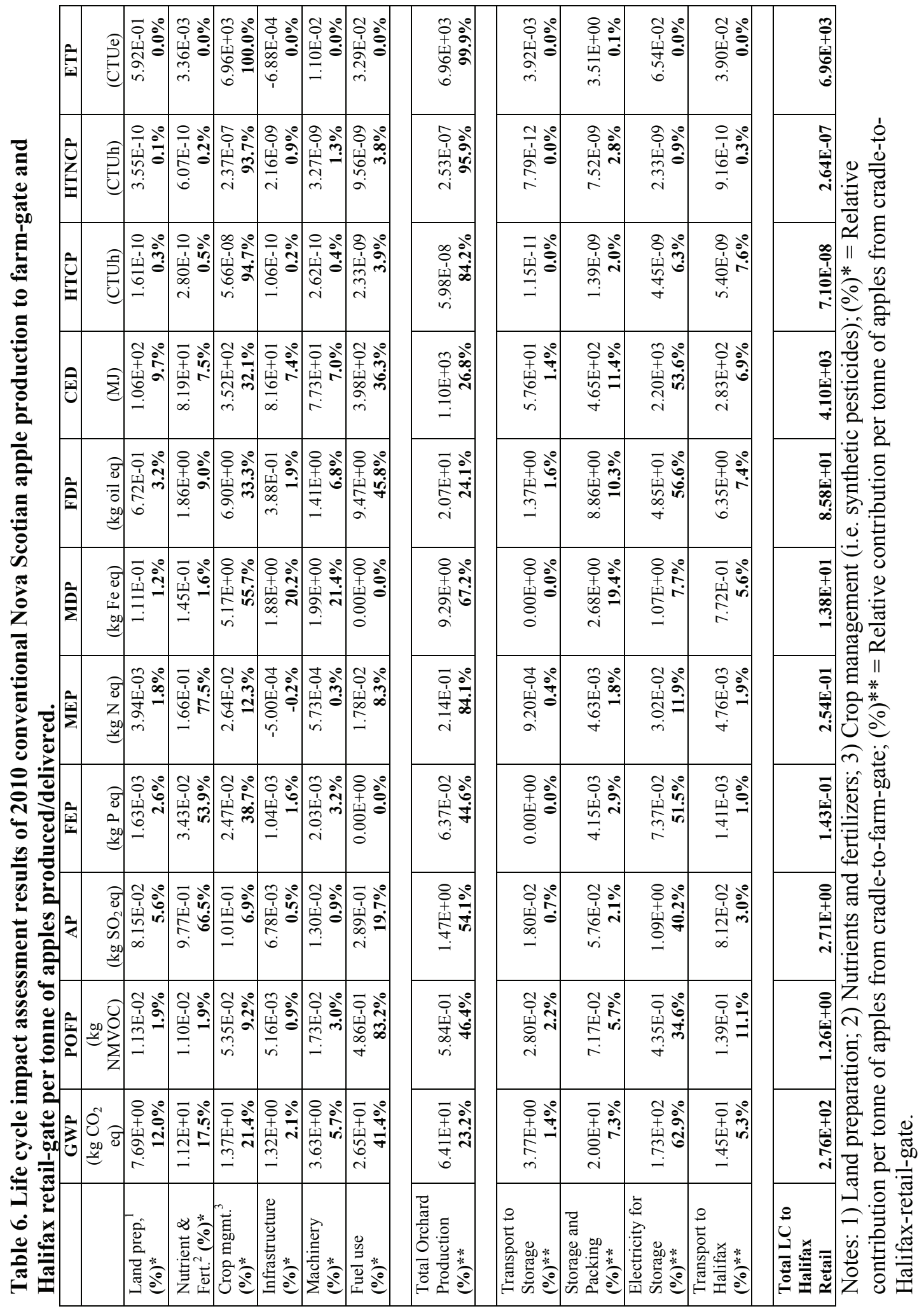




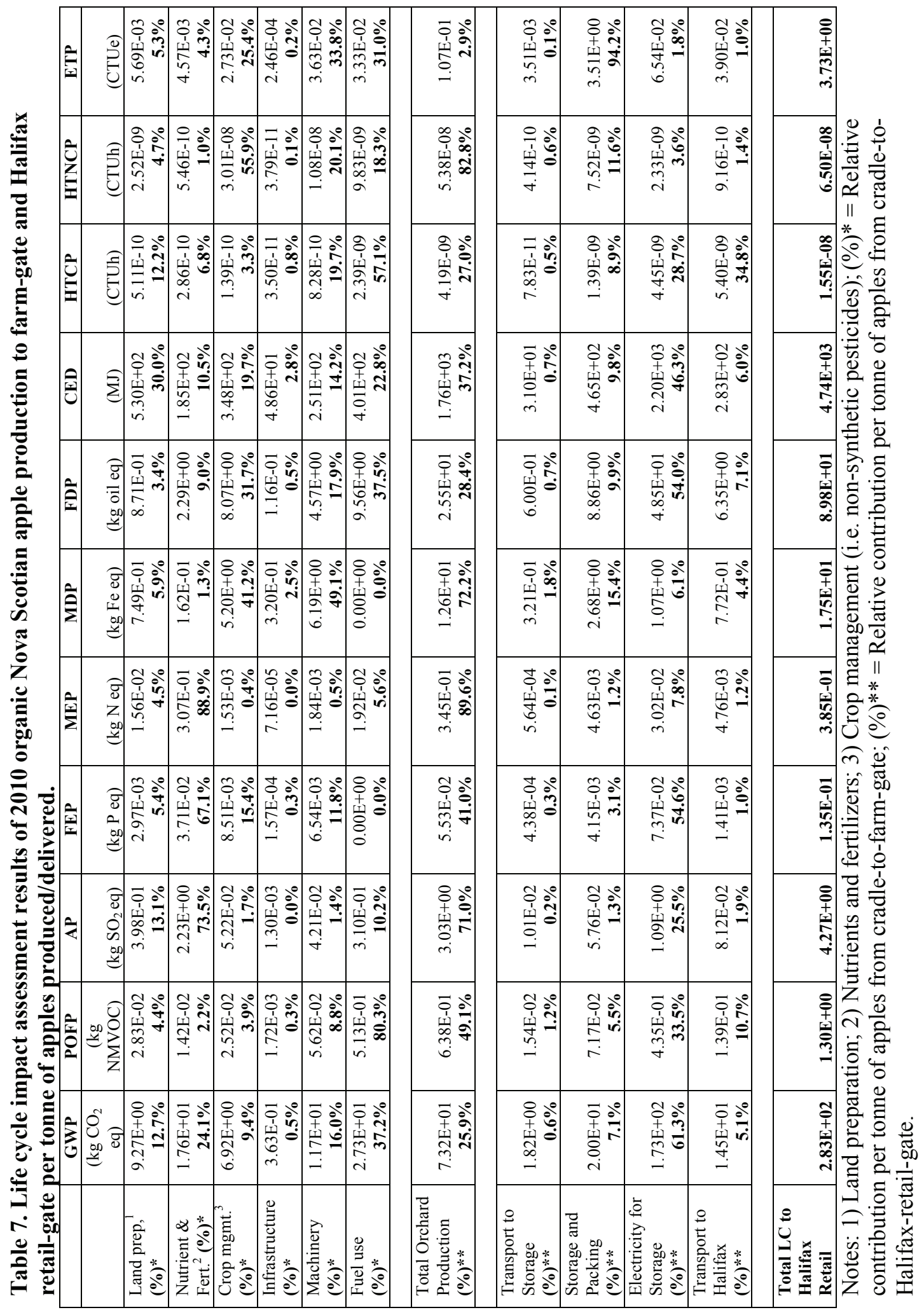




\subsubsection{Conventional production results}

In the conventional cradle-to-farm-gate model, impacts were driven largely by fuel use, fertilizers, and chemical inputs to production, while farm ancillaries had a relatively low contribution overall. Fuel use contributed most significantly to global warming potential (GWP - 41\%), photochemical oxidant formation potential (POFP $83 \%$ ), fossil depletion potential (FDP - 46\%), and cumulative energy demand (CED $36 \%$ ), and led to significant impacts to acidification potential (AP - 20\%), caused primarily by the combustion of diesel fuel. Nitrogenous emissions resulting from the application of fertilizers on orchards led to the majority of burdens for AP (67\%) and marine eutrophication (MEP - 78\%). Specifically, $\mathrm{NH}_{3}$ emissions to air contribute most substantially to AP, while MEP is driven by $\mathrm{NO}_{3}$ leaching to water, as well as volatilization of $\mathrm{NO}$ and $\mathrm{NH}_{3}$ to air. Further, the provision of P-fertilizers, along with resulting $\mathrm{P}_{2} \mathrm{O}_{5}$ emissions to water cause substantial impacts to freshwater eutrophication potential (FEP - 54\%), while production of $\mathrm{N}$-fertilizers and associated $\mathrm{N}_{2} \mathrm{O}$ emissions also contributed to GWP (18\%). Chemical inputs to orchard production dominated metal and toxicological impact categories. Indeed, metal depletion potential (MDP - 56\%), human toxicity cancer potential (HTCP - 95\%), human toxicity non-cancer potential (HTNCP - 94\%), and aquatic ecotoxicity potential (ETP - 100\%) were underpinned by electricity and materials required for the production and provision of fungicides and growth regulators, as well as emissions to air, water, and soil from their application. Chemical inputs were also responsible to burdens to GWP (21\%), FEP (39\%) FDP (33\%), and CED (32\%), driven by energetic inputs of herbicides, fungicides and growth regulators. Other significant on-orchard processes include inputs to machinery and infrastructure, which caused $21 \%$ and $20 \%$ of impacts to MDP, respectively, driven primarily by the manufacturing of steel.

When a cradle-to-Halifax retail gate is modeled for conventional production, the most significant impacts resulted from electricity for storage and on-orchard production activities. Electricity for storage drove the impacts for GWP (63\%), FEP (52\%), FDP (57\%), and CED (54\%), with the combustion of coal as the underpinning cause.

Meanwhile, orchard production inputs accounted for the main burdens to POFP (46\%), 
AP (54\%), MEP (84\%), MDP (67\%), and the toxicity potentials of HTCP (84\%), HTNCP (96\%), and ETP (100\%), driven by fuel, fertilizers, and chemical inputs.

\subsubsection{Organic production results}

Relative contributions to life cycle impacts originated from a diverse range of sub-systems when cradle-to-farm-gate analysis was conducted for organic production. The burning of diesel fuel was a major source of burdens, dominating GWP (37\%), POFP (80\%), FDP (38\%), HTCP (57\%), and causing substantial impacts to CED (23\%), and ETP (31\%). Manure fertilizers were noteworthy in terms of life cycle impacts, where nitrogenous emissions resulting from the application of manure on orchards drove AP (74\%) (i.e. $\mathrm{NH}_{3}$ to air) and $\mathrm{MEP}(89 \%)$ (i.e. $\mathrm{NO}_{3}$ to water; $\mathrm{NO}$ and $\mathrm{NH}_{3}$ to air). Further, manure based phosphorus emissions contributed significantly to FEP (67\%) due to $\mathrm{P}_{2} \mathrm{O}_{5}$ emissions to water, and caused substantial burdens to GWP (24\%) by the release of $\mathrm{N}_{2} 0$ to air. Non-chemical crop management was the main source of burdens for HTNCP (56\%), and a secondary driver of MDP (41\%), while contributing substantially to FEP (15\%), FDP (32\%), CED (20\%), and ETP (25\%). These burdens came predominately from the production and use of copper and sulfur used for disease and pest treatments on organic orchards. Inputs to land preparation drove CED (30\%), driven chiefly by the electricity required for the production of hay. Finally, farm machinery was the main source of MDP (49\%), and caused notable burdens for HTCP (20\%), HTNCP (20\%), and ETP (34\%), due centrally to the electricity and toxins associated with the manufacturing of steel.

Similar to findings for conventional production, most burdens originate from electricity and on-orchard production when a cradle-to-Halifax-retail system boundary is considered for organic. The following patterns emerged: coal driven electricity generation for storage was responsible for the majority of impacts to GWP (61\%), FEP (54\%), FDP (54\%), and CED (46\%). On orchard production practices were the primary cause of POFP (49\%), AP (71\%), MEP (89\%), MDP (72\%), and HTNCP (83\%).

Interestingly, materials associated with storage and packing led to the largest contributions for ETP (94\%), driven mainly by potato starch needed for the manufacture 
of corrugated cardboard boxes. Meanwhile, shipment of apples via transport truck from Kentville to Halifax was primarily responsible for burdens to HTCP (34.9\%).

\subsubsection{Area versus mass-based functional units}

Although this study is not making a direct comparison between conventional and organic orchards, it is nevertheless important to note differences in results that arise from the use of alternate functional units and the results that would have been produced if a comparison had been possible. For example, when results are conveyed using an areabased functional unit, per hectare of orchard production (Appendix F), potential emissions change considerably for both conventional and organic production. Reflecting less inputs per hectare on organic orchards, life cycle impacts are substantially lower than results from the conventional orchards surveyed: GWP (43\%) POFP (45\%), FEP (56\%), MEP (21\%), MDP (27\%), FDP (38\%), CED (19\%), HTCP (98\%), HTNCP (91\%), and ETP (100\%). Per hectare results are favourable for conventional production for AP, as impacts increase by $4 \%$ when compared to conventional results. In contrast, when a mass-based functional unit is being employed, conventional production fares better than organic in several impact categories, including GWP (14\%), POFP (9\%), AP (>100\%), MEP (61\%), MDP (36\%), FDP (23\%), and CED (61\%), while organic production is superior to conventional for FEP (13\%), HTCP (93\%), HTNCP (79\%), and ETP (100\%).

\subsubsection{Scenario modeling results}

Results of transportation and improvement possibility scenarios are displayed in Table 8. Findings illustrate the importance of transportation in relation to both mode of transport and final end-point destinations, as the relative role of transportation changes in relation to these factors, thereby altering the overall environmental profile of each scenario. Substitutions to electricity grid input variables also point to the consequence of using specific energy sources in supply chain sub-systems, as findings indicate that life cycle impacts change in association with electricity models constructed. 


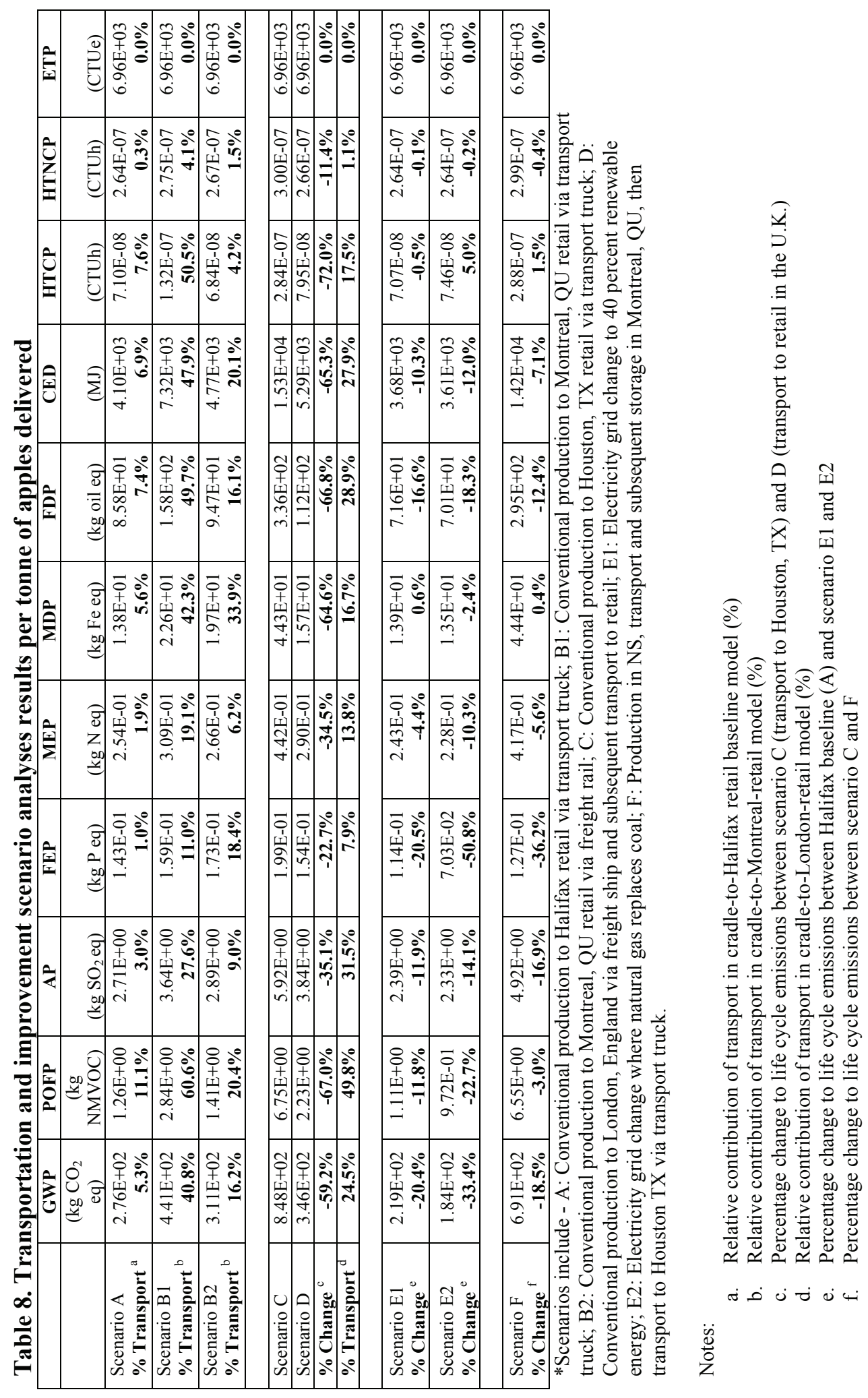




\subsubsection{Transportation scenario results}

Transportation scenarios were constructed to understand how mode and distance of transport affect life cycle burdens of apples. Not surprisingly, the further distance apples are shipped within North America via transport truck, the greater the environmental burdens become. Indeed, transport related impacts increased 40 percent or more in impacts to GWP, POFP, MDP, FDP, CED, and HTCP when the baseline Halifax scenario (A) was compared to transport to Montreal (B1) (Table 8). Meanwhile, when the method of transport was changed to freight rail, findings show that the relative contribution of transport decreased substantially compared to the impact associated with transport truck use (scenarios B1 to B2). Similarly, comparing impacts of apples transported to Houston and London (scenarios C and D, respectively), two retail destinations of similar distances (Table 1), shipment by freight ship to London resulted in drastically lower emissions (11 and 70 percent across almost all categories studied) than shipment to Houston via transport truck (Table 8).

\subsubsection{Improvement possibility scenario results}

Modeled improvement possibility scenarios showed that moving away from coalbased electricity generation would reduce the environmental impacts of apples stored in Nova Scotia. Indeed, substituting coal with renewable energy sources (i.e. wind, hydro and tidal), and less impactful fossil fuel-based energy sources (i.e. natural gas) resulted in improved environmental profiles when compared to the impact of electricity from the current Nova Scotia baseline (Table 8).

\subsubsection{Electricity mix scenarios}

Substantial reductions to life cycle impacts of apple production occurred when alternative electricity generation options were considered. Under scenario E1, in which renewable energy played a greater role as mandated by current government policy, impacts to GWP, POFP, AP, FEP, FDP, and CED were between 10 and 21 percent below the baseline scenario A (Table 8). Further, when natural gas substituted entirely for coal 
(scenario E2), life cycle impacts were reduced between 14 and 51 percent across the same impact categories.

\subsubsection{Montreal scenario: Electricity for storage and transportation}

The problematic nature of coal-based electricity generation further emerges when scenario F (N.S. production, transport to and storage in Montreal, QU, and final shipment to Houston, TX) is compared to scenario C (production and storage in Nova Scotia, and subsequent shipment to Houston, TX). Indeed, a preferable environmental profile was found for scenario $\mathrm{F}$ across the same six energy sensitive impact categories, with reductions from the baseline model (C) ranging from 3 to 36 percent (Table 8).

\subsubsection{Sensitivity analyses}

Table 9 illustrates results of the six sensitivity tests performed, including changes to inputs of fuel, chemical and non-chemical crop management, and fertilizer use on both conventional and organic orchards.

Table 9. Sensitivity analyses results: hypothetical changes in inputs modeled and resulting changes to impact categories relative to baseline findings

\begin{tabular}{|c|c|c|c|c|c|c|c|c|c|c|c|}
\hline Sensitivity & \multicolumn{11}{|c|}{ Sensitivity test results - Changes to life cycle impacts (\%) } \\
\hline & GWP & POFP & AP & FEP & MEP & MDP & FDP & CED & HTCP & HTCNP & ETP \\
\hline 1 & $+/-4.1$ & $+/-8.3$ & $+/-2.0$ & 0.0 & $+/-0.8$ & 0.0 & $+/-4.6$ & $+/-3.6$ & $+/-0.4$ & $+/-0.4$ & 0.0 \\
\hline 2 & $+/-3.6$ & $+/-7.9$ & $+/-1,0$ & 0.0 & $+/-0.5$ & 0.0 & $+/-3.6$ & $+/-2.1$ & $+/-5.5$ & $+/-1.7$ & $+/-2.8$ \\
\hline 3 & $+/-2.0$ & $+/-0.9$ & $+/-0.6$ & $+/-3.3$ & $+/-1.1$ & $+/-5.1$ & $+/-3.2$ & $+/-3.1$ & $+/-7.4$ & $+/-9.1$ & $+/-9.1$ \\
\hline 4 & $+/-0.8$ & $+/-0.3$ & $+/-0.1$ & $+/-0.8$ & 0.0 & $+/-2.1$ & $+/-3.0$ & $+/-1.6$ & $+/-0.1$ & $+/-3.2$ & $+/-2.1$ \\
\hline 5 & $+/-1.6$ & $+/-0.1$ & $+/-6.3$ & $+/-6.4$ & $+/-7.4$ & 0.0 & $+/-0.6$ & $+/-0.5$ & 0.0 & 0.0 & 0.0 \\
\hline 6 & $+/-0.6$ & $+/-0.1$ & $+/-6.9$ & $+/-6.4$ & $+/-8.9$ & $+/-0.4$ & $+/-0.7$ & $+/-0.4$ & $+/-0.3$ & $+/-0.2$ & 0.0 \\
\hline
\end{tabular}

Note: Results appear in the same direction as the change in parameter. Sensitivity analysis $1-10 \%$ increase/decrease in fuel use to conventional N.S. cradle-to-farm gate analysis; Sensitivity analysis 2 $10 \%$ increase/decrease in fuel use to organic N.S. cradle-to-farm gate analysis; Sensitivity analysis $3-$ $10 \%$ increase/decrease in chemical crop management to conventional N.S. cradle-to-farm gate analysis; Sensitivity analysis $4-10 \%$ increase/decrease in crop management to organic N.S. cradle-to-farm gate analysis; Sensitivity analysis $5-10 \%$ increase/decrease in fertilizer inputs to conventional N.S. cradle-tofarm gate analysis; Sensitivity analysis $6-10 \%$ increase/decrease in manure inputs to organic N.S. cradleto-farm gate analysis. 
Sensitivity tests conducted do not significantly change burdens to most impact categories under investigation when compared to the cradle-to-farm-gate baseline models (Table 9). For example, the $10 \%$ decrease/increase in fuel use $(1 \& 2)$ in both conventional and organic systems led to a change of $<5 \%$ across all impact categories except of POFP, which changed by $\sim 8 \%$ on both conventional and organic orchards. Meanwhile, 10\% changes to chemical crop management inputs (3) on conventional orchards resulted in increases/decreases of 5\% or less across all fields except the toxicity related categories, which increase between 7.4 and 9.1\%, an unsurprising outcome given their relative role in toxicological impacts (Table 6). On organic orchards, crop management sensitivity tests (4) resulted in changes of $3.2 \%$ or less across all fields. Finally, the $10 \%$ increase/decrease of synthetic fertilizer and corresponding nitrogen and phosphorus emissions (5) in conventional production led to negligible changes across all impact categories except acidification and euthrophication, where it varied between 6.3 to $7.4 \%$. Similarly, tests on manure fertilizers on organic orchards led to changes between 6.4 and $8.9 \%$ across the same three impact categories.

\subsection{Discussion}

Taking methodological differences into consideration, results from Nova Scotia apple production can be compared with previous apple research in terms of cradle-tofarm and cradle-to-retail-gate analyses. Following this review, strategies to reduce impacts of production, storage and distribution of Nova Scotia apples are developed according to hotspots identified through impact assessment results.

\subsubsection{Nova Scotia apple production in a global context}

Previous research has investigated environmental impacts of apple production using both LCA and non-formalized life cycle methodologies, with studies carried out in New Zealand (Mila i Canals et al., 2006), European countries (Jones, 2002; Mouron et al., 2006a,b; Hayer et al., 2008), and Washington State (Reganold et al., 2001). Analyses have also been made comparing apples produced, distributed, and consumed in a mixture of Northern and Southern hemisphere countries (Stadig, 1997; Blanke \& Burdick, 2005; 
Sim et al., 2007; Mila i Canals, 2007a; Saunders \& Barber, 2008). Despite differences in methodological decisions (e.g., system boundaries) and ways of reporting results in previous work, qualitative comparisons can be drawn in the context of Nova Scotia apple production. In terms of on-orchard impacts, for example, energy and fuel consumption has been identified as a hotspot in past cradle-to-farm gate apple LCAs (Mila i Canals et al., 2006; Mouron et al., 2006b), as well as in non-standardized cradle-to-retail gate life cycle studies (Saunders \& Barber, 2008), corresponding with findings in Nova Scotia. Previous studies have also reported that pesticide use cause burdens to energy and toxicity related impact categories (Mila i Canals et al., 2006; Mouron et al., 2006b), further supporting results in the province. Additionally, past studies have shown that the provision of $\mathrm{N}$ and $\mathrm{P}$-fertilizers and their associated emissions to air and water drove eutrophication potentials (Mouron et al., 2006b) and played a noteworthy role in GWP (Mila i Canals et al., 2006), corresponding with present results. Interestingly, emissions from $\mathrm{N}$-fertilizers played a more substantial role to acidification in Nova Scotia than has been the case previously (Mila i Canals et al., 2006), where fertilizers came secondary to energy related acidifying emissions.

Furthermore, studies using relevant system boundaries and methods of reporting can be looked to with caution for quantitative comparisons between apple production systems. Focusing specifically on energy use for cultivation, for example, cumulative energy demand for conventional orchards in Nova Scotia is $\sim 1100 \mathrm{MJ} /$ tonne (Table 6). This value falls in the range reported for apples produced in Europe and the Southern Hemisphere, ranging from $\sim 400$ to $\sim 2000 \mathrm{MJ} /$ tonne (Mila i Canals, 2007a), while primary energy use between $\sim 400$ and $\sim 700 \mathrm{MJ} /$ tonne has been reported in New Zealand (Stadig, 1997; Mila i Canals, 2006), with lower impacts in the country attributed to cultivation efficiencies and climatic advantages (Mila i Canals, 2007a). In terms of GWP emission potentials, furthermore, results of cradle-to-farm-gate analyses in Nova Scotia (Table $6 \& 7$ ) are similar to those generated in New Zealand, where ranges from $\sim 40$ to $\sim 100 \mathrm{~kg}$ of $\mathrm{CO}_{2}$ eq/tonne have been reported (Mila i Canals et al., 2006). Although energy use was the primary driver of impacts to GWP in both New Zealand and Nova Scotia, fertilizer use was the secondary cause of burdens to the former, while both fertilizers and pesticides contributed to additional impacts to the latter (Table 6). 
Moving beyond apple cultivation to include post-harvest activities such as storage and transportation, additional life cycle studies have been conducted to understand the environmental impacts of producing and consuming domestic versus imported apples (Stadig, 1997; Jones, 2002; Blanke \& Burdick, 2005; Sim et al., 2007; Mila i Canals, 2007a; Saunders \& Barber, 2008). Contributing to debates over 'food miles' and local food production, many of these geographically focused studies have found that procurement of locally produced apples is environmentally superior to imports, with transportation cited as the primary cause of impacts (Stadig, 1997; Jones, 2002; Blanke \& Burdick, 2005; Sim et al., 2007). Indeed, Stadig (1997) found that consuming apples produced and cold stored in Sweden resulted in less environmental impacts than importing them from New Zealand, despite production efficiencies in the latter country. Similarly, Sim and colleagues (2007) found that apples produced and stored in the U.K. for ten months were less impactful than those imported from Italy, Chile or Brazil; while Blanke \& Burdick (2005) found that apples produced in Germany and cold stored for five months yielded more favourable results than importing the fruit from New Zealand. Discrepancies in methodological choices made in these studies, however, have been identified, including lack of accounting for country specific variations in production, timing of consumption and length of storage (Mila i Canals et al., 2007a), and the use of outdated data sets (e.g., Blanke \& Burdick, 2005). Problems of methodological inconsistencies are further highlighted when results from Jones (2002) and Saunders et al. (2008) are examined. Indeed, Jones (2002) suggests that apples produced, stored, and consumed in the U.K. have a more favourable environmental profile than those shipped from New Zealand, while Saunders and Barber (2008) come to the opposite conclusion. These studies emphasize the need to employ comprehensive system boundaries when comparisons are being made (Edward-Jones et al., 2008), as well as the usefulness in following ISO-standardized LCA guidelines.

Mila i Canals and colleagues (2007a) consider these methodological shortcomings in their comparison of primary energy consumption of domestic and imported apples. Using a cradle-to-retail-gate system delimitation, the authors accounted for country specific energy inputs of apple provision and associated variability, as well as storage and seasonality, and transport mode and distance. Their findings indicate that impacts are 
highly dependent on these input variables. For instance, the energetic requirements of storage increase as storage time lengthens and associated wastage occurs; as such, the relative benefits of consuming locally produced apples are reduced as storage time increases. Likewise in Nova Scotia, as would be expected, apples that do not require storage result in fewer impacts than those requiring storage year round, as the electricity requirements are a major driver of life cycle burdens (Tables $6 \& 7$ ). Findings from Mila i Canals and colleagues (2007a) also indicate that transportation is a significant cause of primary energy use, with emphasis placed on both distance and mode. For example, the relative impacts of shipping apples between European countries by transport truck is similar to the impact intensity of those sent to Europe by ship from countries in the Southern hemisphere (especially during the northern spring and summer), highlighting efficiencies in transport by freight ship. Similarly in Nova Scotia, differences in transport methods have been identified as important to environmental impacts (Table 8).

Consequently, recommendations that emerge from Mila i Canals et al. (2007a) suggest that on an energetic basis it may be environmentally preferable to eat a combination of domestic and imported apples, rather than advocating for procurement of locally produced apples as previous studies have done (e.g., Sim et al., 2007; Blanke \& Burdick, 2007). While it is beyond the scope of this research to determine whether consuming locally produced apples in Nova Scotia is more environmentally benign than imports, results produced are of value in further understanding the environmental impacts of fruit production in the province. More importantly, though, review of previous studies highlight the need to consider all supply chain inputs, and to be aware of methodological assumptions before drawing conclusions on the relative environmental benefits of local or imported apple consumption.

\subsubsection{Choice of functional unit}

As Basset-Mens and van der Werf (2005), Mouron et al. (2006a,b), and De Backer et al. (2009) have observed, LCA results are dependent on the functional unit employed in studies. Here, the use of both mass and area based units of analysis served to effectively represent two important agricultural concerns, including production efficiency and impact intensity of orchards. These functional units have been employed in previous 
LCA studies (e.g., Charles et al., 2006; Mouron et al., 2006a,b; De Backer et al., 2009), and are essential to consider in developing environmentally superior food systems. Indeed, if land quality considerations, calculated through an area based functional unit, were considered more frequently it may facilitate the development of more ecologically oriented policies regarding land use and regional development (Berlin \& Uhlin, 2004). Production efficiency, meanwhile, covered through calculations using a mass based FU, may have more relevance to consumers and could be used for comparability more readily (Brentrup, 2003, as cited in De Backer et al., 2009), and can facilitate comparisons between production regions. Employing both area and mass based units of analysis is therefore essential in representing the multifunctional nature of agriculture, allowing us to better address both local and global scale agro-related environmental impacts.

Previous analyses (e.g., Basset-Mens \& van der Werf, 2005; Hayer et al., 2008; De Backer et al., 2009) have found superior environmental profiles for conventional agricultural systems using a mass based functional unit, while analyses per hectare have found organic production to cause less environmental burdens, similar to findings in Nova Scotia. These results reflect reduced productivity of organic orchard production, which may be associated with less input intensity, while increased inputs on conventional production can lead to both increased yields and greater impacts per area. These findings relate to broader debates, such as how to balance biodiversity and agriculture through land sparing (e.g., agricultural intensification) or land sharing (e.g., wildlife-friendly farming) (see Green et al., 2005; Fisher et al., Phalan et al., 2011, Tscharntke et al., 2012), further emphasizing the importance of using multiple units of analysis.

\subsubsection{Cradle-to-farm gate analyses}

Several hotspots of environmental burdens arose in the cradle-to-farm-gate analyses that suggest opportunities for management actions to improve environmental outcomes. Some of these have been suggested in previous apple LCA research (Mila i Canals et al., 2006; Mouron et al., 2006b), but apply in a Nova Scotian context as well. 


\subsubsection{Fuel use}

Up to the farm gate, combustion of diesel fuel was found to be a major driver of life cycle impacts on both conventional and organic orchards, a finding consistent with past apple LCAs (e.g., Mila i Canals et al., 2006). Reducing diesel inputs would therefore lead to decreased burdens across all impact categories. This might be accomplished by decreasing the amount of mechanization on orchards, for less tractor use would reduce the amount of fuel needed for their operation. To do so, previous research (Mila i Canals et al., 2006) has suggested the possibility of replacing machinery with human labour, so long as the economic viability of orchards is not jeopardized. However, the assumption that labour is a low energy input substitute has not been proven, and the possibility for increased costs to producers is problematic, especially for growers with financial constraints. A strategy that may be more readily implemented is a well-planned organization of picking activities that optimizes use of tractors and human labour, as most fuel use is consumed during harvest on the majority of orchards (Mouron et al., 2006b). Prior studies have also suggested using alternative fuels such as bio-diesel (Powlson et al., 2005; Mila i Canals et al., 2006), however substantial problems associated with its provision have been identified (Dias de Oliveira et al., 2005; Crutzen et al., 2008; Lardon et al., 2009) and therefore their use is not recommended. Finally, fuel efficiency could be improved by ensuring that tractor tires are not over inflated, which can save up to 20 percent of fuel use on farms (Lancas et al., 1996); using tractors with smaller, fuelefficient engines; ensuring that machinery is well maintained (Mouron et al., 2006b); changing oil and filters according to manufacturer's suggestions; and avoiding long periods of idling (Desir, 2006).

\subsubsection{Synthetic and natural crop inputs}

Similar to previous agricultural LCAs (e.g., Mila i Canals, 2006; De Backer et al., 2009), synthetic chemicals contributed significantly to several impact categories in the conventional apple farming system modeled. Energetic provision and production of chemicals, along with subsequent emissions to air, water and soil were the cause of the majority of impacts caused by these inputs, which originated primarily from fungicides, 
growth regulators, and herbicides. If chemical pesticide application could be reduced or, when possible, excluded - without affecting yield and quality - on orchards, non-trivial environmental improvements could be achieved.

A range of improvement techniques exist that could help to realize this objective, as producers could employ integrated pest management (IPM) practices on orchards.

While IPM tactics are used in Nova Scotia, the degree to which they are employed ranges significantly between producers, similar to other apple growing regions (Mouron et al., 2012). Indeed, chemical-based models involving targeted spraying regimes and insect trapping are more widely employed than programs that integrate behavioral, biological and chemical tactics to control pests (MacHardy, 2000). As such, education on IPM tactics, sharing of spray reduction techniques between orchardists, and the use of lowimpact and less toxic pesticides is essential (see Canadian Horticulture Council, 2009; Craig, 2010). Other options for reducing the use of chemicals on orchards include planting disease resistant cultivars, and employing new technologies such as drift reducing measures (Mouron et al., 2012).

In terms of organic production, permitted mineral-based pesticides are also substantial drivers to life cycle impacts, caused primarily from the manufacture and supply of sulphur and copper inputs. While further research is required to assess the toxicological impacts of these inputs and incorporate them into LCA methodology (De Backer et al., 2009), the materials and energy needed for their production nevertheless led to burdens across several impact categories. As a result, organic producers should take caution in the use of sulphur and copper treatments. To do so, orchardists could focus on promoting an ecological balance and facilitating overall tree health (e.g., by use of foliar nutrients; organized orchard architecture) to help reduce susceptibility to disease (Phillips, 2005), as well as move to less susceptible apple varieties.

Taking a non-allopathic approach to pest and disease management can be beneficial for both conventional and organic production systems (Appendix A). Reducing the amount of pesticide treatments may not only decrease environmental burdens, it can also lead to less toxicological exposure to both humans and natural systems, which is becoming of increasing concern to consumers in terms of personal and ecological health, as well as food safety and quality (Bourn \& Prescott, 2002). Furthermore, economic 
incentives exist for reducing such inputs, in terms of monetary costs for their purchase and labour for their application.

\subsubsection{Synthetic and manure fertilizers}

The provision of nitrogen and phosphorus based fertilizers (i.e. synthetic and manure) and their related emissions to air and water were the cause of the majority of eutrophication and acidifying impacts on both conventional and organic orchards, and also led to noteworthy contributions to global warming potential. On top of reducing the overall volume of fertilizers used on orchards, additional options for decreasing impacts associated with fertilizers include planting nitrogen fixing cover crops (Pelletier et al., 2008); expansion of cultivars with high nutrient uptake capacities, as well as varieties with low nitrogen requirements (e.g. Cortland, McIntosh, Gravenstein, and Golden Delicious); ensuring a balanced and properly executed nutrient management regime (e.g. lower volumes applied at well-planned and seasonally sensitive times) (Mila i Canals et al., 2006); and choosing fertilizers and manures with less nitrogen content and those less prone to subsequent field-level emissions (Brentrup et al., 2001). Fertilizer improvement, however, must be undertaken in parallel with the maintenance of fruit quality and optimal yields, as these are all essential factors in successful apple production.

\subsubsection{Cradle-to-retail gate and scenario analyses}

Cradle-to-retail gate analyses and scenario modeling revealed sub-system areas of concern in the life cycle of Nova Scotia apples. These are reviewed next, with associated recommendations for improvement possibilities.

\subsubsection{Electricity}

The importance of how energy is generated in Nova Scotia is revealed in the cradle-to-Halifax retail analyses for both conventional and organic production, as results show that the contribution of electricity for controlled atmosphere and cold room storage (where $\sim 70 \%$ and $\sim 30 \%$ of total apples are stored, respectively) is substantial. Despite the fact that packing and storage facilities in the province are state of the art and operate in a highly efficient manner in terms of inputs to production, the electricity needed for their 
operations reflects a poor environmental profile. This highlights the challenge of extending local seasons through storage when electricity generation is produced primarily using coal, the reality of which is highlighted in scenario F. This finding is not novel; the government of Nova Scotia is well aware of the problems inherent in coal-based electricity production and has designed policy changes to ameliorate the issue, which can be seen in their renewable energy targets for 2020 and beyond (see Nova Scotia Department of Energy, 2009, 2010 \& 2012). Unfortunately, scenarios E1 and E2 show that even with the actualization of these targets, electricity generation will continue to be a hotspot in the life cycle of apple production, albeit on a reduced scale.

In lieu of these findings, it is crucial that provincial energy targets currently in place are achieved and further advancements made for environmental improvements to be realized. Politically, this can be assisted by policies and investments in renewable energy, energy efficiency and conservation. Not only may environmental improvements be achieved through such measures, additional benefits may also be realized, including employment opportunities for renewable and energy efficient projects (Haley, 2010); improving energy security by reducing dependence on energy imports; and ensuring the energy remains affordable as prices for imports from conventional oil and coal may change (Federal Ministry, 2007). Importantly, economic incentives exist for the implementation of such measures, for reduced and efficient energy use is also costeffective for industries and should thus be integrated into practice. To this end, storage facilities should take advantage of incentive programs offered by Efficiency Nova Scotia, who provide financial and technical assistance through rebates (e.g., for lighting, alternative heating options), consultations for energy efficiency improvements, as well as installation of energy saving equipment.

\subsubsection{Transportation}

Expanding from the singular focus on distance travelled in the 'food miles' paradigm, present cradle-to-retail LCA findings emphasized the importance of food distribution in terms of efficiency of transport mode. Indeed, when transport trucks are used to carry apples to different locations across North America (scenarios A, B1 and C), the relative contribution of transport increases in conjunction with distance of retail 
location. Consequently, reliance on long truck transport for food distribution is not the most environmentally preferable course of action, for along with airfreight, these methods are considerably more damaging than transport by rail or freight ship (EdwardJones et al, 2008; MacRae, 2010). Indeed, transport of apples to Montreal by rail (scenario B2) resulted in lower impacts across all categories under investigation. Likewise, transport via freight ship to London (scenario D) was substantially less impactful than shipment of apples to Houston by transport truck (scenario C), even though distances are similar. In fact, exporting to London resulted in reduced burdens in most impact categories, even in comparison to trucking apples to the much closer Montreal destination (scenario B1). Further studies are needed to make a comprehensive assessment of whether domestic consumption or imported apples are environmentally superior, integrating cultivation and storage data from other counties. Results do indicate, however, that eating local apples when in season, thus avoiding long-distance transport, is an environmentally favourable course of action.

\subsubsection{Organic output}

Compared to conventional orchard production, lower yields were found on organic orchards surveyed, negatively impacting their environmental profile when assessed using a mass based functional unit. Reduced output on organic apple orchards can be caused by various factors, including inadequate crop load management (e.g. poor thinning due to lack of organically certified thinners), nutrient deficiencies due to lack of zinc and low fertilizer applications, and increased pressure of pathogens, pests and weeds (Peck et al., 2006; do Amarante et al., 2008). In fact, weed control has been identified as one of the central problems in organic apple production in Nova Scotia. Moreover, organic apple production in the province is relatively incipient, which further affects productivity, as it takes an average of ten years for orchards to reach full production (Phillips, 2005). Finally, annual yields may also vary as the result of weather conditions and pest and disease outbreaks.

Low output has been identified as central drawback of organic production (Gomiero et al. 2008; MacRae et al. 2010; De Backer et al. 2009; Kirchmann et al., 2009), and thus raising yields has been identified as critically important (Cederberg \& 
Mattsson, 2000; MacRae et al., 2010). Several researchers have addressed this issue, offering both optimistic and pessimistic positions on whether yields can rival those realized in conventional production (e.g., Pretty et al., 2003; Badgley et al., 2007; Kirchmann et al., 2009). Leaving such predictions aside, improvement practices exist for increased yields to be achieved, including planting high yielding (e.g. Golden delicious) and disease resistant varieties; organizing high-density planting arrangements; ensuring consistent and well planned thinning and pruning routines; employing proper orchard floor management (e.g. composted manure, companion plant covers) that accentuates conditions needed for optimal output; and implementing full and balanced nutrition treatment regimes (Phillips, 2005; do Amarante et al., 2008).

\subsection{Conclusion}

The vulnerabilities of global food systems and their deleterious effects on the Earth have been identified for decades, amplifying the impetus for research on ways to improve methods of production, distribution, and consumption (Ehrlich \& Ehrlich, 2013). Indeed, ensuring that food systems are both resource and energy efficient is crucial in reducing the environmental impacts they produce. LCA is well positioned to aid in this process, providing a robust evaluation of environmental performance so that sound policy and praxis decisions can be made. Further, as life cycle thinking has been declared a prerequisite for any rigourous sustainability assessment (Klöpffer, 2003), the application of LCA to apple production systems in Nova Scotia is important given the value of the industry in the province. Indeed, this evaluation could help ensure the apple industry is in line with objectives expressed in the province's Environmental Goals and Sustainable Prosperity Act and greenhouse gas emission reduction targets. More broadly, results of agricultural LCAs can aid in reducing the ecological impacts of food supply chains by identifying hotspots in production and developing improvement recommendations, which could ultimately assist in establishing more productive and resilient food systems.

This LCA investigated the environmental performance of conventional and organic apple production systems in Nova Scotia in order to understand how life cycle subsystems contribute to relevant environmental impact categories. By quantifying and assessing the materials and energy used in production, storage, and transportation, 
associated emissions were identified in relation to environmental burdens. Additional scenario models were built to understand how changes to distance and mode of transport affected overall life cycle impacts and the relative role of transportation. Further, scenarios were constructed to explore future and hypothetical changes to the Nova Scotia electricity grid and their effects related to apple storage. Evaluation of modeled apple systems revealed life cycle hotspots and allowed for the establishment benchmark results. Findings indicate that fuel use, $\mathrm{N}$ and P-fertilizers, and inputs for pest and disease management on both conventional and organic orchards were the drivers of burdens to impact categories under investigation, similar to past apple LCAs (e.g., Mila i Canals et al., 2006; Mouron et al., 2006b). When system boundaries were extended to retail locations, attention is drawn to the electricity used for storage and the role of transportation, highlighting problems of coal-based electricity generation in Nova Scotia, as well as the efficiency of freight ship and rail when compared to trucking over long distances.

Taking these hotspots into consideration, improvement recommendations were developed with the goal of reducing the environmental impacts of apple supply chains in the province. Strategies to reduce fuel use and improve fuel efficiency, options to help lower impacts of fertilizers, and ways to decrease application of chemical and nonchemical pesticides on conventional and organic orchards were identified. While further studies are needed to unearth the impacts of consuming imported apples versus those grown domestically in a Nova Scotia context, this study identified that eating locally produced apples when in season is environmentally preferable when compared to consuming those transported over long distances or stored year round due to the province's coal-based electricity source. Meanwhile, the importance of increasing yield in organic operations was examined and options for achieving this objective identified to improve impacts when analyzed per tonne. Conversely, lowering the input intensity of conventional orchards was highlighted as a way to lower per hectare impacts. The importance of differentiating between area and mass based units of analysis was emphasized herein, showing the value of considering the multi-functionality of agriculture and the importance of communicating results from multiple functional units. 
In line with conclusions drawn by Mila i Canals and colleagues (2006), we argue that while the scientific evidence provided by LCA studies is essential, of perhaps equal importance is the implementation of improvement recommendations, for mitigating the impacts of global food systems means that real world changes must be made. As such, effective dissemination of LCA results is paramount, producing and communicating improvement possibilities in ways that are relevant to producers, industry, and government they affect. To do so, presenting results in such ways that relate to socioeconomic and political needs is crucial, contextualizing improvements so that benefits can be understood beyond the ecological realm (Mila i Canals et al., 2006). Although beyond the scope of this article, this is an avenue for future research endeavors. 


\section{Chapter 3. Discussion ANd Conclusion}

Given that life cycle thinking has been prescribed as a precondition for any comprehensive sustainability assessment (Klöpffer, 2003), the application of LCA to Nova Scotia apple systems is an important project for one of the province's principal industries. Comprehensively examining apple production, storage and distribution chains in relation to relevant environmental impact categories produced valuable insights in terms of identifying life cycle hotspots, as well as creating a baseline for future research. More broadly, such knowledge may help to ensure that the apple industry in the province is in line with Nova Scotia's Environmental Goals and Sustainable Prosperity Act, as well as move apple production towards provincial greenhouse gas reduction targets. Moreover, Nova Scotia recognizes farmers engaging in sustainable practices through the Environmental Stewardship Award and accompanying publicity and payment, which provides incentive to ensure that production practices are in line with environmental considerations. Finally, agricultural LCA can assist wider aims of developing resilient production systems that are capable of remaining productive in the long-term, making certain that current production does not further outstrip the productive capacity of the biosphere and thus the ability to produce food in the future.

This thesis (Chapter 2) assessed the environmental performance of conventional and organic apple production in Nova Scotia in order to understand how life cycle subsystems contribute to global-scale environmental impact categories. The objectives of this research were to quantify and evaluate the materials and energy used in production, storage, and transportation, determining how associated emissions result in potential contributions to relevant environmental burdens. Additionally, models were constructed to identify how distance and mode of transport affected overall life cycle impacts, and how the relative role of transportation changed according to different scenarios. Scenarios were also modeled to explore how possible improvements to key supply chain inputs may result in environmental benefits, looking specifically at changes to the Nova Scotia electricity grid, as well as hypothetical storage of apples in Quebec. In doing so, hotspots were identified and improvement recommendations made with the aim of minimizing environmental impacts associated with both orchard and post-production activities (section 2.5). 
Results of analysis show that primary drivers to environmental burdens on-farm were fuel use, fertilizers, and inputs for pest and disease management on both conventional and organic orchards. When system boundaries were extended to cradle-toretail locations, attention is drawn to the electricity used for storage, highlighting problems of coal-based electricity generation in the province, as well as efficiencies of different transport modes. Complete results appear in Tables $6-8$ in Chapter 2.

Discussion of the significance of findings in relation to past apple LCAs is found in Chapter 2, 2.5.1.

\subsection{Food for thought on organic and local production systems}

Akin to studies in the past (e.g., Basset-Mens \& van der Werf, 2005; Hayer et al., 2008; De Backer et al., 2009), results for organic apple production in Nova Scotia were more favourable when analyzed per hectare than per tonne, reflecting lower inputs per land area. While less use of intensive inputs (e.g., agro-chemicals) may be beneficial in terms of landscape health in this regard, they are also one likely explanation for reduced

yields on organic orchards. As noted in Chapter 2, the debate of land sharing versus land sparing is highlighted herein: should agricultural production be intensified (e.g., increased inputs per production area) to ostensibly boost productivity, allowing for the preservation of species rich areas nearby (i.e. land sparing), or should agriculture be integrated with surrounding ecosystems, where more land would be required to produce similar yields, resulting in lower levels of productivity to conserve biodiversity (i.e. land sharing) (Green et al., 2005; Fischer et al., 2008). While these two perspectives represent "the endpoints of a continuum of separation between agriculture and biodiversity" (Fischer et al., 2008, p. 381), the question remains of how to move forward with efficient use of agricultural land - minimizing inputs while achieving high levels of productivity, and at the same time being successful at biodiversity conservation. Since evidence exists that agricultural intensification negatively affects biodiversity, thus putting ecosystem services such as biological pest control, crop pollination (Geiger et al., 2010; Tscharnke et al., 2012), and soil protection (Brussaard et al., 1997) at risk, less input intensive practices (e.g., organic) have been recommended as more prudent agricultural models 
(Scialabba \& Hattam, 2002; Geiger et al., 2010). ${ }^{6}$ Issues of yield remain, however, for despite encouraging findings of output capabilities in organic production (e.g., Pretty et al., 2006; Badgley et al., 2007; Chappell \& LaValle, 2010), productivity varies depending on crops, regions, and technologies employed (Pimentel et al., 2005).

While biodiversity considerations and other land use variables (e.g., habitat and soil quality, aesthetic values of landscapes, etc.) are highly relevant when assessing the environmental impacts of agriculture, this impact category in notably absent from not only the present study, but also most food-related LCAs. ${ }^{7}$ Although the development of the land use impact category has been underway for over a decade (Haas et al., 2000; Lindeijer, 2000; Anton et al., 2007; Milà i Canals et al., 2007b; De Schryver et al., 2010; Curran et al., 2011), the continued absence of a consensus based-model represents a substantial gap in the LCA methodology. Disagreement regarding its characterization and quantification is due to lack of adequate impact indicators and insufficient data on its parameters (Anton et al., 2007). For example, parameters for soil quality indicators are not agreed upon, as well as ways to adequately account for changes in biodiversity (Mungkung \& Gheewala, 2007). Moreover, difficulties in characterizing land use impacts arise due to the site-specific and time dependent nature of agriculture, and as such modeling of these localized impacts is challenging (Mattsson, 2000).

As we move forward in the development of alternative agricultural systems both the benefits and drawbacks of conventional and organic production must be taken into account; lacking parameters to evaluate impacts to agricultural landscapes represents a shortcoming in LCA methodology. Barring this exclusion, however, LCA results are nonetheless important, contributing to our understanding of other globally relevant impact categories affected by agriculture, as shown in the present apple LCA. As methodological advancements continue to progress, inclusion of additional land/landscape impacts will be highly beneficial, allowing for more comprehensive environmental evaluations. Research committed to developing representative models for

\footnotetext{
${ }^{6}$ For example, organic production has been found to enhance pollinator diversity on agricultural landscapes (Holzschuh et al., 2008).

${ }^{7}$ Important ecological functions of agricultural land such as nutrient cycling, water and carbon capture and storage, as well as habitat provision for human and non-human organisms are encompassed in the land use impact assessment category, yet missing in most applications due to methodological gaps (Mila i Canals et al., 2007b).
} 
land use is underway, particularly through collaboration of LCA experts in the UNEPSETAC Life Cycle Initiative.

Turning to a discussion of local food and the significance of transportation, results for Nova Scotia apple production indicate that the relative impact of transportation is dependent on both distance and mode of transport. Within Nova Scotia, the contribution of transport to life cycle impacts was negligible (Chapter 2, Tables $6 \& 7$ ). Shipping apples outside of the province to Montreal, the closest large Canadian metropolitan area to N.S., by transport truck increased the relative contribution of transport from 4 to 50 percent from the Halifax baseline depending on the impact category (Chapter 2, Table 8). As would be expected, therefore, as travel distance via transport truck increases in additional scenarios, the relative impact of transport becomes more pronounced. Assuming that apple systems elsewhere have similar inputs to production and storage as in Nova Scotia, and thus comparable environmental impacts, these findings suggest that eating apples grown closer to home will have less environmental impacts than those shipped by transport truck from other areas. However, when apples are shipped using more efficient means of transport results differ. In fact, findings indicate that the relative impact of transportation is 3 to 33 percent higher across impact categories when apples are shipped to Montreal by transport truck compared to shipping them by freight ship to London, even though the distance to London is $>3000 \mathrm{~km}$ further. Pending data on production and storage from areas of import, however, it is beyond the scope of this research to conclusively speak to the environmental superiority of domestic versus imported apples. Corresponding with past apple LCAs (Mila i Canals et al., 2007a), findings demonstrate that the relative impact of transport is dependent upon other supply chain inputs, as production, storage and time of consumption, and method of transportation must all be considered when making such judgments. Meanwhile, results from this study indicate that eating locally produced apples when in season is environmentally preferable when compared to consuming in-season apples transported over long distances, or those stored year round, due primarily the impact electricity needed for storage (Chapter 2, Tables $6 \& 7$ ).

Around the world, support for developing local food systems is gaining momentum as initiatives from urban gardens, to farmers markets, to CSAs, to regional 
foodsheds take off. At the outset, the 'food miles' concept was the environmental rationale for buying local, which argued that fewer transport related $\mathrm{CO}_{2}$ emissions are produced the closer consumption takes place to production. Although this reasoning was advanced as sound, recent LCA studies have shown that this concept fails to include important differences in emissions that are produced at each stage of the supply chain. Indeed, analyses using the sole proxy of 'distance travelled' does not account for important variables including inputs to production, storage, processing, mode of transport and consumer phases (Mila i Canals, 2007; Edwards-Jones et al., 2008; Pelletier et al., 2011; Point et al., 2012), all of which influence the relative impact of transportation. Claims of the environmental superiority of local foods that rely on the 'food miles' rationale are justified only when all other factors are equal, which usually is not the case, and therefore, such claims are often not justified. Indeed, local and imported food can be produced using both environmentally benign and ecologically intrusive production techniques.

Importantly, the proclivity of the 'food miles' arguments in the academic realm have begun to diminish as such evidence continues to mount. Recently, in fact, Scott and McLeod (2010) affirm that reasons to buy local are not necessarily rooted in environmental claims, as more persuasive arguments rest in social and economic considerations. While results of the present work speak to environmental impacts, they do not address potential socio-economic benefits and drawbacks of local food systems, a methodological limitation that is expanded upon in section 3.2. Past research using nonLCA analyses, however, has taken up such analyses. A cursory examination of this literature has found that cited rationale for local purchasing rests largely in the financial viability of local economies and producers, while environmental and health considerations of local food were found to be less important (Purslow, 2000 as cited in Winter, 2003). By paying farmers directly, costs of production can be more readily reimbursed instead of money being displaced through lengthier food supply chains (Allen, 2003), helping to fostering the economic viability of local farms. Local food interactions are assumed to add social capital to communities as well, where interactions between producers and consumers can assist in facilitating trusting relationships, helping overcome the facelessness of industrialized food commodity chains (Allen, 2003). 
Moreover, local food initiatives such as farmers markets and CSAs are seen as opportunities to not only cultivate community engagement, but also allow for support of farmers who have production methods in line with the environmental values of the consumer. Local food can provide improvements in terms of freshness and taste, reducing reliance on processed foods, and expanding consumer experiences beyond the grocery store (Allen, 2010).

Meanwhile, some recent research has taken aim at the claims of local food enthusiasts and academics who equate local food systems with sustainable agriculture (e.g., Pretty, 1998), reinforcing life cycle type thinking that to be local does not necessarily mean systems are sustainable (Winter, 2003). This conflation is regarded as misplaced as local consumption is founded primarily on the economic viability of farms rather than support for sustainable agriculture and/or issues of social justice (Winter, 2003; Dupuis \& Goodman, 2005). Indeed, as Winter (2003) asserts,

Far from heralding an alternative post-global green future, as promoted by a range of proponents of sustainable agriculture (e.g., Pretty, 1998), the turn to local food may cover many different forms of agriculture, encompassing a variety of consumer motivations and giving rise to a wide range of politics (p. 30).

Further, speaking to the differences of circumstance, it has been shown that local food initiatives tend to be dominated by white, middle class consumers, and therefore threaten to be exclusionary, as programs unintentionally exclude low-income people who do not have the money or access to these initiatives (Allen, 2003; Guthman, 2006). As such, critics argue that local food initiatives have the potential to increase farm security by increasing incomes for farmers, yet may be an insufficient response to larger issues of food security (Guthman, 2006).

Taking these viewpoints into consideration is critical, yet it is beyond the scope of this research to delve into such a discussion in more depth. Debate continues over whether local food networks have the ability to fully overcome the social and environmental injustices associated with the global industrial agri-business, or if they are only treading lightly without addressing larger embedded problems of production and consumption, which limits their transformative abilities (Allen, 2003). Perhaps putting 
power back into the hands of local consumers and producers is a step in the right direction, but is it enough to transform the entire system? Food for thought and future research endeavors indeed.

\subsection{Research challenges and project limitations}

Similar to many LCA studies, the data collection phase brought with it both practical and temporal difficulties. A challenge at the outset was the lack of an orchard directory for the province, which meant the pool of potential participants was limited to producers who sell directly at local markets and those with public contact information (i.e. available through Internet searches). Additional contacts were made with the aid of an industry informant. Of producers contacted, most were unaware of LCA methodology, which curtailed initial support for the project. This challenge was overcome by the construction of a detailed information package that described the project's objectives, methods, data requirements, and intended outcomes. Upon commitment to participate, survey completion took lengthy periods of time in some cases, dependent upon human resource capacities, time of year, and schedules of producers. Personal contact by phone ultimately provided the most effective means of survey completion. Further, despite a thorough survey design, several follow-ups for clarification were required. As such, data acquisition took several months, causing a significant challenge for timely analysis.

Being a novice LCA practitioner, constructing a representative model of the apple supply chain for Nova Scotia also presented research challenges. Not only was the life cycle software program SimaPro new, conceptual modeling of agricultural production systems was not an area of former expertise. Since results are contingent on how models are designed and which materials and processes are selected within the modeling software, significant attention was devoted to this phase, making sure all relevant inputs to supply chains sub-systems were included and simplifying assumptions adequately justified. Minor difficulties also arose during the quantification of orchard inputs, specifically in terms of calculating foreground inventory data using Excel given the lack of familiarity with the program initially. Finally, given my previous academic focus in the social sciences, entering into the LCA realm required some theoretical adjustments 
and exploration at the outset. While this proved challenging at times, it was ultimately an extremely important scholarly attainment.

Research limitations also arose during the course of this project. To begin, temporal constraints were experienced in regards to system boundaries. Although whole tree life cycles and full crop rotations are preferable in agricultural LCAs (Cowell, 1998 in Mila i Canals, 2003), production and storage data was collected solely for the 2010 season given both time and financial restrictions of this practitioner. Despite most producers indicating that 2010 inputs were 'typical' of past growing years, future analyses may produce different results, corresponding with evolving management practices and changing yields. This may be noteworthy for organic producers in Nova Scotia in particular, for yields and resulting impacts will likely change as the industry continues to grow. Furthermore, certain spatial factors were not specifically accounted for, as analysis was conducted using aggregated data instead of comparison on a case-bycase basis. For example, while taking note of differences in orchard management practices and farm locations, these factors were not distinctively examined, for they were not pertinent to the project's research objectives. On this subject, however, Nemecek \& Gaillard (2010) argue that large samples can serve to obtain representative and reliable LCA data to account for variability amongst farms, a requirement that was fulfilled in the present assessment of Nova Scotia apple production (Chapter 2, section 2.4).

Regarding further issues of system delimitation, this LCA did not conduct a full cradle-to-grave analysis. Decisions to exclude processing, consumer (e.g., transport and storage at the household level) and disposal methods were supported by boundaries of agricultural LCAs in the past (e.g., Stadig, 1997; Mila i Canals et al., 2007a; Sim et al., 2007; Saunder \& Barber 2008), and were not required given the project's research aims. Moreover, such post-retail system boundary extension can be problematic for practitioners in terms of uncertainties in modeling and assumptions of processes required (e.g., allocation of consumer transport for apple purchases at retail outlets) (CarlssonKanyama et al., 2003). Similarly, data on food waste was not included in analysis, for not only was information on apple wastage rates not available, food wastage rates vary considerably dependent on the specific supply chain under investigation (Sonesson et al., 2005). Indeed, Lynch (2009) notes that fruit and vegetable losses can range from 10 to 
70 percent. Wastage rates for storage were also omitted, as less than 1 percent of apples from the Nova Scotia storage facility surveyed are discarded, sent instead to processing facilities.

Furthermore, while LCA methodology allows for an environmental evaluation of products and production systems, poignantly absent are socio-economic considerations and methods for their evaluation. Given the current agricultural situation in Nova Scotia, financial factors are of upmost importance, as producers in the province are facing several budget-related challenges. For instance, the net income of small-scale farming operations has been steadily declining in recent years, decreasing 91 percent since 1971, as farm debt has increased by 146 percent during the same period (Scott \& Coleman, 2008). For four years between 2000 and 2006, Nova Scotia farms recorded a negative net farm income, where income no longer covered operating expenses (Scott \& Coleman, 2008). Warnings from GPIAtlantic were issued in 2001 and 2008 reports, contending that several agricultural sectors (including apples) are in crisis as farming is no longer an economically viable industry. Further, although the number of farms and farm area in Nova Scotia had increased by 2.9 and 2.2 percent respectively between 2006 and 2011, apple farm area decreased by 13.8 percent during this period. Moreover, the number of jobs in the agricultural sector had also been reduced by 40 percent between 1976 and 2006 (Scott \& Coleman, 2008).

Such socio-economic considerations are important, for without including cost factors it is difficult to assess the overall sustainability of orchards. ${ }^{8}$ As noted by EdwardJones \& Howell (2001),

Within agricultural systems, the ability to provide an economic return to the manager is one critical characteristic related to the system's ability to continue. Unprofitable agricultural systems will not continue. Related to this are issues concerned with maintaining output, such as soil fertility and reducing losses to weeds and pests (p. 32).

\footnotetext{
${ }^{8}$ LCA findings, including present results, show that many variables are important to consider when evaluating the environmental impacts of products or production systems. This is true for alternative systems as well, for just because a system is local or organic does not guarantee its sustainability. Indeed, further than environmental considerations, it is also necessary to look at an orchard system's ability to produce sufficient yields, be profitable, conserve resources, create employment, and be managed in line with societal values (do Amarante et al., 2008).
} 
Indeed, previous economic analyses of conventional and organic costs of production in Washington State (Glover et al., 2002) determined that the absence of certified thinning substances causes difficulties for organic producers in the region, as higher input costs are required to obtain similar yield and fruit size to those of conventional growers.

Evaluation of the economic viability of orchard systems in Nova Scotia could also help in encouraging producers to adopt alternative production practices. Reasons for conversion to organic production, for instance, have shifted from 'committed' to pragmatic rationale, centered primarily on economic and agronomic factors (Rigby et al., 2001).

Fostering economically viable farms is arguably just as important as improving the environmental sustainability of them. In addition to financial considerations, social factors were not addressed in this study. This is a drawback given that the agricultural sector is the second largest contributor to employment worldwide, with the labour force concentrated primarily in developing countries (Kruse, 2010). As food-related employment is often accompanied by high fatality rates, low wages, and physically hazardous conditions (Kruse, 2010), conducting a parallel social life cycle analysis would be beneficial. Such factors are important, as links between pesticide use and other toxic substances (e.g., fertilizers, diesel fumes, excessive sunlight) and health problems of agricultural workers have been made (Mills \& Yang, 2007; Mills et al., 2009). Meanwhile, positive social externalities that could be achieved through orchard production include employment opportunities, contributions to local economies, and social factors in rural communities (Pretty, 2001). Further, as identified in section 3.2, positive environmental externalities (e.g., landscape and aesthetic value, water supply, carbon control and sequestration, biodiversity habitats, soil formation and nutrient supply: Pretty, 2001) are also left out of LCA studies, causing a further methodological limitation.

Given the importance of socio-economic factors in overall sustainability assessments, life cycle tools that focus on such aspects are being developed to complement LCA studies. For example, it has been suggested that life cycle costing (LCC) be used with LCA either by applying the tool separately or by assessing the material flows of the life cycle inventory in monetary terms (Settanni, 2010). LCC expands from typical economic accounting by incorporating use and end of life phases, as 
well as hidden costs into analyses. If the same system boundaries are used, therefore, as Klöpffer and Renner (2009) argue, LCC is the logical counterpart to LCA for the economic assessment of production systems. Practitioners are also attempting to develop a social LCA tool, which has been difficult due to lack of data available to quantify and assess these parameters, which has been limited by the absence of reporting on social indicators throughout the food industry and as well as social life cycle databases (Kruse, 2010). ${ }^{9}$ Moreover, it can be difficult to quantify value-based parameters, as their qualitative nature does not lend well to typically quantitative methods used in LCA studies. Additional problems in methodological development have been how to relate social indicators to the functional unit of the production system, and how to create regional life cycle inventories to account for the variation in social conditions geographically (Klöpffer \& Renner, 2009).

\subsection{Current and on-going LCA research}

Given that LCA methodology is ISO-standardized, Kruse (2010) argues that it would be redundant to create new assessment tools if LCA can be modified to include social and economic aspects. Again, the UNEP-SETAC Life Cycle Initiative has been crucial in the development of these methodologies. Indeed, many different research projects are underway under this program, ranging from the integration of socioeconomic aspects into LCA, to capacity building in terms of conducting LCA in developing countries, to characterization of land and water use impact categories (UNEP, 2002). Moreover, several groups around the world are tackling problems in LCA by sharing information and experiences with each other in hopes of overcoming these issues (Roy et al., 2009). In addition to UNEP and SETAC, the International Organization for Standardization (ISO), the European Commission, and Denmark's Directorate for Food, Fisheries and Agri-Business are all working to develop practical tools to evaluate products and services in a life cycle perspective, as well as ways to standardize the LCA methodology (Roy et al., 2009). Further, CALCAS (Coordination Action for innovation in Life Cycle Analysis for Sustainability), coordinated by the European Commission in

\footnotetext{
${ }^{9}$ Green Delta has recently developed and published the first social life cycle database (http://socialhotspot.org/). How this will be incorporated and applied to life cycle studies will be both interesting and important to follow.
} 
2006, has been successful in establishing a framework for Life Cycle Sustainability Analysis (LCSA) (Guinee et al., 2011). ${ }^{10}$ In order for these and other initiatives to succeed, strong international collaboration is necessary to overcome differences in approaches and methods in LCA (see Hauschild et al., 2008). Moreover, dialogue with experts outside the LCA field is also crucial to provide insight to methodological and model development (e.g., assessing the impacts of land use) (Mila i Canals et al., 2007b; Hauschild et al., 2008).

\subsection{Future research opportunities}

Several ideas for future research endeavors emerged upon reflection of the Nova Scotia study. To begin, subsequent research could take a comparative analysis approach to assess management techniques on an orchard-to-orchard level, examining how different on-farm practices, inputs to production, and yields result in distinctive environmental profiles. Evaluations of different management techniques on orchards have taken place in other fruit growing regions such as New Zealand (Mila i Canals et al., 2006) and Switzerland (Mouron et al., 2006b). Although observation of variability in management practices emerged from participating orchardists, the decision to characterize 'typical' apple production in the province was made with the aim of producing average impacts of apple orchards in the province. In doing so, improvement recommendations may be relevant to apple producers across Nova Scotia; while some producers may already be adhering to management practices that are environmentally benign, results of the current study may aid others in developing less impactful production regimes. Nevertheless, it could be beneficial to conduct analysis on individual orchard levels, for results and improvement possibilities could also be useful to the industry.

In a similar vein, differences in orchard size could be included in future analyses, comparing the impacts of both small-scale and larger production systems, as orchards

\footnotetext{
${ }^{10}$ LCSA framework links questions of sustainability to information required to address them, identifies available knowledge and models in relation to LCA, as well as shows gaps in knowledge and ways in which they can be overcome (Guinee et al., 2011). LCSA development will be important to take note of, for understanding the trade-offs that exist between social, economic and environmental spheres is crucial in conducting full-scale sustainability assessments.
} 
varied from $<1$ to over 50 hectares in size. As well, a future research project could reexamine organic apple production in five or more years, comparing baseline findings from the present study to those from future analysis, which could uncover whether and how environmental burdens change as the industry expands and potentially becomes more productive. In terms of future apple LCAs, additional studies could be performed in other fruit growing regions in Canada and the U.S., as the majority of research in the past has been conducted for European and Southern hemisphere countries (Mila i Canals et al., 2006; Mouron et al., 2006a,b; Sim et al., 2007; Mila i Canals et al., 2007a). Collaboration with these LCA practitioners would be useful, for access to data from countries of import could be used to understand the relative environmental impacts of consuming local versus imported apples. Meanwhile, it would be both pertinent and interesting to conduct an apple LCA in China given that they are responsible for over half of total global apple production at present.

Finally, an area of research inquiry that is of significant interest to this practitioner is examination of whether and how improvement recommendations borne from LCA results are successfully implemented both on-farm and in post-harvest supply chains. Being relatively new to the LCA world, it is unknown whether follow ups are commonly made with participants to investigate such changes, and if so whether additional studies are conducted to compare impacts of new management practices to prior benchmark results. Discussion of such topics is lacking in the LCA literature, which may indicate that such subsequent communication and analyses are not routine. Of related inquiry is how practitioners effectively disseminate conclusions to non-experts in their field of study. Since it is the responsibility of the individual LCA practitioner to effectively communicate results, the availability of findings to industries, government, and consumers likely varies in each instance. A future research project, therefore, could explore these questions, which would likely take place through a qualitative study drawing on experiences of LCA practitioners, incorporated with a discussion of barriers (e.g., practical, socio-economical, political, etc.) that prevent farmers from transitioning to alternative practices (see Rodriguez, 2008; Horne \& Grant, 2009; Chappell \& LaValle, 2011) as well as transition opportunities (e.g., through policy mechanisms, incentive 
programs, price premiums). This would be of value, as highlighted by Horne and Grant (2009),

Even where LCA suggests that lower overall impacts may arise from a particular application of organic farming, this conclusion combined with a growing interest in organic and other less intensive agriculture may not be enough to change practice effectively and quickly.... The need for LCA in agriculture is perhaps greater than in other sectors, given the complexity, variability and lack of previous attention, and new LCA will be most effective in driving change when it is linked to applied socioeconomic assessment and research techniques to support policy development (pp. 121).

Additional research endeavors in LCA and beyond will be pertinent in the development of food systems that are environmentally innocuous, as they are able to facilitate a more thorough understanding of food production and networks of supply and consumption. With the incorporation of socio-economic models in the future, life cycle methodology will have the potential to assess the overall sustainability of products and production systems, a crucial undertaking given the ecological, social, and economic constraints of our modern world.

\subsection{Conclusion}

This LCA investigated the environmental performance of conventional and organic apple systems in Nova Scotia in order to understand how life cycle sub-systems contribute to environmental impact categories. In doing so, hotspots were identified and improvement recommendations made with the aim of minimizing environmental impacts associated with both orchard and post-production activities. Results indicate that the combustion of diesel fuel, fertilizer provision and resulting emissions air and water, and inputs for pest and disease management were the primary drivers of burdens in terms of both conventional and organic orchard production. Cradle-to-retail analyses revealed that electricity for storage contributed significantly to life cycle impacts, attributed specifically to Nova Scotia's coal-based electricity source. Further, long-haul transport truck delivery was found to be a hotspot in scenarios modeled, while delivering apples by freight ship caused negligible burdens in comparison. Although additional studies are needed to examine the impact of local versus imported apple procurement, findings revealed that consuming local apples when in season, thereby avoiding long-term transport and storage, led to fewer environmental impacts. Finally, the importance of 
differentiating between area and mass based units of analysis was highlighted herein, emphasizing the value in considering the multi-functionality of agriculture, as this is crucial when addressing local and global environment impacts of agricultural systems. 


\section{APPENDiX A: PestiCides ON APPLE ORCHARDS}

Whether farming using conventional, integrated, or organic standards, pesticides are used on apple orchards, albeit on different scales and causing different effects. Table A1 displays the U.S. Environmental Protection Agency (EPA) acute human toxicity classification of most pesticides used on Nova Scotian orchards. ${ }^{11}$

Table A1: US EPA acute human toxicity classification of active ingredients (AI) of substances applied to conventional and organic apple orchards in Nova Scotia in 2010

\begin{tabular}{|l|l|l|r|}
\hline Active Ingredient (AI) & $\begin{array}{l}\text { US EPA Toxicity } \\
\text { Classification* }\end{array}$ & Chemical Type & $\begin{array}{l}\text { kg of AI per tonne of } \\
\text { apples }\end{array}$ \\
\hline Captan & & & 0.71 \\
\hline Telone/1,3-dichloropropene & I & Fungicide & 0.31 \\
\hline Paraquat dichloride & I & Fumigant & 0.03 \\
\hline 2,4-D-Dichlorophenoxyacetic acid & I & Herbicide & 0.09 \\
\hline Carbaryl & II & Herbicide & 0.06 \\
\hline Mineral oil & III & Herbicide & 1.00 \\
\hline Glyphosate & III & Herbicide & 0.37 \\
\hline Metiram & III & Fungicide & 0.19 \\
\hline Ammonium Thiosulphate & III & Growth & 0.07 \\
\hline Calcium Polysulfide (lime sulphur) & III & Fungicide (organic) & 1.13 \\
\hline Copper sulphate & III & Fungicide (organic) & 0.16 \\
\hline Terbacil & IV & Herbicide & 0.06 \\
\hline Mancozeb & IV & Fungicide & 0.02 \\
\hline Sulphur & IV & Fungicide (organic) & 10.01 \\
\hline
\end{tabular}

*Note: US EPA toxicity classification: I - Highly toxic; II - Moderately toxic; III - Slightly toxic; IV - Not acutely toxic (Kegley et al., 2010).

In addition to problems associated with acute toxicity exposure, pesticides can cause further threats to both humans and ecosystems (e.g. carcinogenity, neurotoxicity; endocrine system disruption; soil and water contamination, etc.) (Heaton, 2002). Indeed, application of pesticides to agricultural landscapes results in certain exposure to nontarget organisms, potentially leading to deleterious consequences for surrounding flora and fauna, as well as severe ailments to humans (van der Werf, 1996; Margni et al., 2002; Mills \& Yang, 2007). The impacts of pesticides used in conventional agriculture have long been documented (e.g. Carson, 1962; van der Werf, 1996; Margni et al., 2002), motivating the development of alternative pest and disease control management techniques, particularly in terms of IPM and organic production.

\footnotetext{
${ }^{11}$ Table F1 shows all pesticides with $>0.01$ of AI applied to orchards.
} 
While organic agriculture prohibits the use of synthetically based pesticides, a small number of inorganic compounds are permitted (e.g. copper-based fungicides, sulphur, lime sulphur, etc). Generally, such mineral-based chemicals require less processing than their synthetic counterparts and tend to dissociate more rapidly in the environment (Heaton, 2002), thereby presenting low risk for humans and the environment. However, they are not completely free from toxicological effects, causing primarily problems of phytotoxicity (Pottorff, 2010). Specifically, copper-based fungicides have been flagged as potentially hazardous in terms of ecosystem contamination: being a heavy metal, copper persists in the environment by accumulating in surface soils, and has been classified as very toxic to aquatic wildlife and slightly toxic to other organisms (PMEP, 2008; Smith, 2008). In response, the E.U. has been attempting to phase out this substance since 2002 (Smith, 2008). Due to a lack of adequate replacements the use of copper nevertheless persists, as research has shown that successfully producing scab-resistant cultivars without its application on organic orchards is highly difficult (Holb \& Heijne, 2001).

However, while taking these points into consideration, organic pesticides continue to show less toxicological potential than their synthetic counterparts and are not considered carcinogenic (Table A1, Slattery et al., 2011). Further, it has also been argued that copper accumulation in deciduous fruit crops is not a likely problem (Rosenberger, 2012). Moreover, copper, sulphur, and lime sulphur do not exceed maximum levels of pesticide residues legally permitted in and on foods according to the U.S. EPA's 'pesticide residue tolerance' (Slattery et al., 2011). Indeed, research has shown that permissible organic compounds are rarely found to be residual in food that has been tested, and when are present, have lower levels than in food produced using synthetic chemicals (Heaton, 2002). Nevertheless, environmental impacts are associated pesticides used on both organic and conventional orchards, and as such it is essential that their use be minimized. 


\section{APPENDIX B: APPLE INVENTORY SURVEY}

\section{Section 1. General Orchard Information}

1.1 What is the total area of your orchard in acres?

1.2 How many years has your orchard been producing apples?

1.3 How many acres of apples were grown in your orchard in 2010?

1.4 What proportion of your apple trees were bearing and non-bearing in 2010?

Bearing: $\%$ Non-bearing: $\%$

1.5 What was the total yield of apples produced in 2010 ?

1.6 What proportion of your apples went to export for processing $\%$, or other (please indicate) $\%$, local markets $\%$,

1.7 Please indicate the cultivars grown in 2010 and the acreage that each cultivar represents in your orchard. Check all that apply.

\begin{tabular}{||l|l|l|r|}
\hline Cultivar & $\begin{array}{l}\text { Proportion of } \\
\text { orchard }\end{array}$ & Cultivar & $\begin{array}{l}\text { Proportion of } \\
\text { orchard }\end{array}$ \\
\hline$\square$ Cortland & $\%$ & $\square$ McIntosh & $\%$ \\
\hline$\square$ Red Delicious & $\%$ & $\square$ Novaspy & $\%$ \\
\hline$\square$ Golden Delicious & $\%$ & $\square$ Paulared & $\%$ \\
\hline$\square$ Gala & $\%$ & $\square$ Russet & $\%$ \\
\hline$\square$ Gravenstein & $\%$ & $\square$ Spy & $\%$ \\
\hline$\square$ Honeycrisp & $\%$ & $\square$ Various & $\%$ Other: \\
\hline$\square$ Jonagold & $\%$ & $\square$ \\
\hline
\end{tabular}

1.8 Please indicate the spacing of your apple trees and rows of trees for each of the cultivars grown.

\begin{tabular}{|l|l|l|}
\hline Cultivar & Spacing of trees & Spacing of rows of trees \\
\hline & & \\
\hline & & \\
\hline & & \\
\hline & & \\
\hline & & \\
\hline & & \\
\hline & & \\
\hline
\end{tabular}




\section{Section 2. Land preparation}

2.1 What existed on your orchard prior to apples?

2.2 Please indicate the soil amendments and their quantities that were applied while prepping the land (see table below). Use the blank spaces for any additional amendments. *Volume of application - e.g., pickup/dump truck loads, tons, kg, etc.

\begin{tabular}{|l|c|c|}
\hline \multicolumn{1}{|c|}{$\begin{array}{c}\text { Product } \\
\text { Check all that apply) }\end{array}$} & $\begin{array}{c}\text { Volume of } \\
\text { Application* }\end{array}$ & $\begin{array}{c}\text { Frequency of } \\
\text { Application }\end{array}$ \\
\hline$\square$ Manure & & \\
\hline$\square$ Compost & & \\
\hline$\square$ Limestone & & \\
\hline$\square$ Wood chips & & \\
\hline$\square$ Sawdust & & \\
\hline$\square$ Fertilizers - Brand Name \& & & \\
N P K (if known) & & \\
\hline$\square$ Fumigant - Brand Name (if & & \\
known) & & \\
& & \\
\hline Other: & & \\
\hline Other: & & \\
\hline
\end{tabular}

2.3 Did you apply an herbicide prior to planting?

Yes $\square$ No $\square$

2.3.1 If yes, please indicate which herbicides were used, as well as their volume and frequency of application.

\begin{tabular}{|l|l|l|}
\hline Product & $\begin{array}{c}\text { Volume per } \\
\text { Application }\end{array}$ & $\begin{array}{c}\text { Frequency of } \\
\text { Application }\end{array}$ \\
\hline & & \\
\hline & & \\
\hline & & \\
\hline
\end{tabular}




\section{Section 3. Irrigation}

3.1 Do use an irrigation system on your orchard?

Yes $\square$ No

- If no please proceed to Section 4

3.1.1 If yes, please indicate the type of irrigation system you have, what proportion of your orchard that you apply it to, and the frequency of irrigation use for 2010.

\begin{tabular}{|l|r|r|}
\hline Irrigation System & Proportion of orchard & Frequency of use \\
\hline$\square$ Under-tree dripper & $\%$ & \\
\hline$\square$ Micro-sprinkler system & $\%$ & \\
\hline$\square$ Overhead system & $\%$ & \\
\hline$\square$ Other: & $\%$ & \\
\hline
\end{tabular}

3.2.1 What is the total length of your irrigation lines?

3.2.2 From where did you purchase/rent your irrigation equipment?

\section{Section 4. Trellising and Fencing system}

4.1 Does your orchard have a trellising system?

Yes $\square$ No

- If no, proceed to question 4.5

4.1.1 If yes, what proportion of your apple trees include trellising?

Trees with trellising

$\% \quad$ Trees without trellising $\%$

4.2 Please indicate what type of trellising system you have, including the type, the amount of acres it is applied to, what the materials the posts are made from, as well as the type, length and gauge of wires.

\begin{tabular}{|c|c|c|c|c|}
\hline Type & $\begin{array}{c}\text { Acres of } \\
\text { Orchard }\end{array}$ & $\begin{array}{c}\text { Materials of } \\
\text { Posts (e.g. } \\
\text { wood, metal, } \\
\text { bamboo etc.) }\end{array}$ & $\begin{array}{c}\text { Type of Wire } \\
\text { (material) }\end{array}$ & $\begin{array}{c}\text { Length and } \\
\text { gauge of wires }\end{array}$ \\
\hline$\square$ V-system & & & & \\
\hline$\square$ Super Spindle & & & & \\
\hline$\square$ Central leader & & & & \\
\hline$\square$ Free standing & & & & \\
\hline$\square$ Other: & & & & \\
\hline
\end{tabular}

4.3 What materials are used to hold the wires to the poles and how much of these materials are used in your trellising system? 
4.4 Please indicate what apple varieties the trellising system is used on.

4.5 Do you have fencing around the trees in your orchard?

Yes $\square$ No $\square$

4.5.1 If yes, please indicate the type of material used for your fencing, the size of fencing, and what proportion of your orchard has fencing around it. Please be as specific as possible (e.g. type of wood).

\begin{tabular}{|c|c|c|}
\hline $\begin{array}{c}\text { Material of fencing } \\
\text { (e.g. wood, metal etc.) }\end{array}$ & $\begin{array}{c}\text { Size (e.g. height/width of } \\
\text { posts) }\end{array}$ & Proportion \\
\hline & & $\%$ \\
\hline
\end{tabular}

4.6 How much tape and twine did you use in 2010 ? (e.g. \# of rolls, etc.)

Tape:

Twine:

\section{Section 5. Pruning and Non-chemical Orchard Floor Management Practice}

5.1 Please indicate the instruments used to prune your apple trees, how many are owned, their brand name, and approximately what percentage of your trees is pruned using each method. Select all that apply.

\begin{tabular}{|l|r|r|r|}
\hline \multicolumn{1}{|c|}{ Pruning Instrument } & \# Owned & $\begin{array}{c}\text { Brand Name } \\
\text { (If known) }\end{array}$ & $\begin{array}{c}\text { Proportion } \\
\text { of trees }\end{array}$ \\
\hline$\square$ Hand-operated loppers and & & & $\%$ \\
saws & & & $\%$ \\
\hline$\square$ Ladders & & $\%$ \\
\hline$\square$ Motorized air pruners & & $\%$ \\
\hline (Pneumatic pruner) & & & $\%$ \\
\hline$\square$ Power saw / pole pruner & & & $\%$ latform \\
\hline$\square$ Hydraulic lift / platform & & & $\%$ \\
\hline$\square$ Other: & & & $\%$ \\
\hline
\end{tabular}

5.2 What is done with your prunings once they are removed?

5.3 Please indicate what type of orchard floor management you do. If applicable, indicate the specific type of management or name of product, along with the volume and frequency of application. Select all that apply. (Continued on next page)

\begin{tabular}{||c|c|c|c|}
\hline $\begin{array}{c}\text { Type of } \\
\text { management }\end{array}$ & Type/Name of product & $\begin{array}{c}\text { Volume per } \\
\text { application }\end{array}$ & $\begin{array}{c}\text { Frequency of } \\
\text { application } \\
\text { (per year) }\end{array}$ \\
\hline$\square$ Mulching & & & \\
\hline$\square$ Compost & & \\
\hline
\end{tabular}




\begin{tabular}{|l|l|l|l|}
\hline $\begin{array}{c}\text { Type of } \\
\text { management }\end{array}$ & Type/Name of product & $\begin{array}{c}\text { Volume per } \\
\text { application }\end{array}$ & $\begin{array}{c}\text { Frequency of } \\
\text { application } \\
\text { (per year) }\end{array}$ \\
\hline$\square$ Ground covers & & & \\
\hline$\square$ Mowing & & \\
\hline $\begin{array}{l}\square \text { Hand-weeded } \\
\text { control }\end{array}$ & & & \\
\hline $\begin{array}{l}\square \text { Animal } \\
\text { grazing }\end{array}$ & & & \\
\hline$\square$ Other & & & \\
\hline
\end{tabular}

5.4 If you applied a mildew spray or cover spray to your orchard in 2010, please indicate what product you used, along the volume and frequency of its application (per year). In the last column please indicate if the 2010 application was typical, more or less than what is usually applied to your orchard each year.

\begin{tabular}{|c|c|c|c|}
\hline Material & $\begin{array}{c}\text { Volume per } \\
\text { Application }\end{array}$ & $\begin{array}{c}\text { Frequency of } \\
\text { Application }\end{array}$ & Typical, more or less \\
\hline & & & \\
\hline & & & \\
\hline & & & \\
\hline
\end{tabular}

\section{Section 6. Annual Nutrient Management}

6.1 Please indicate the soil amendments / nutrients that were applied to your orchard in 2010. Check all that apply. In the last column please indicate if the 2010 application was typical, more or less than what is usually applied to your orchard each year. Use the blank spaces on next page for any additional nutrients used.

\begin{tabular}{|l|c|c|c|c|c|}
\hline \multicolumn{1}{|c|}{ Product } & $\begin{array}{c}\text { Active } \\
\text { Ingredient }\end{array}$ & $\begin{array}{c}\text { N.P.K. } \\
\text { (If known/ } \\
\text { applicable) }\end{array}$ & $\begin{array}{c}\text { Volume per } \\
\text { Application }\end{array}$ & $\begin{array}{c}\text { Frequency of } \\
\text { Application } \\
\text { (per year) }\end{array}$ & $\begin{array}{c}\text { Typical, } \\
\text { more or } \\
\text { less }\end{array}$ \\
\hline Manure & $\mathrm{X}$ & & & & \\
\hline Compost & $\mathrm{X}$ & & & & \\
\hline Limestone & $\mathrm{X}$ & & & & \\
\hline Copper & $\mathrm{X}$ & & & & \\
\hline Iron & $\mathrm{X}$ & & & & \\
\hline $\begin{array}{l}\text { Rock } \\
\text { phosphate }\end{array}$ & Phosphorus & & & & \\
\hline Bone Meal & Phosphorus & & & & \\
\hline $\begin{array}{l}\text { Potassium } \\
\text { sulfate }\end{array}$ & Potassium & & & & \\
\hline Sul-Po-Mag & Sulfur,potash & & & & \\
\hline Solubor & Boron & & & & \\
\hline Epsom salts & Magnesium & & & & \\
\hline
\end{tabular}




\begin{tabular}{|l|c|c|c|c|c|}
\hline \multicolumn{1}{|c|}{ Product } & $\begin{array}{c}\text { Active } \\
\text { Ingredient }\end{array}$ & $\begin{array}{c}\text { N.P.K. } \\
\text { (If known/ } \\
\text { applicable) }\end{array}$ & $\begin{array}{l}\text { Volume per } \\
\text { Application }\end{array}$ & $\begin{array}{c}\text { Frequency of } \\
\text { Application } \\
\text { (per year) }\end{array}$ & $\begin{array}{c}\text { Typical, } \\
\text { more or } \\
\text { less }\end{array}$ \\
\hline Urea & Nitrogen & & & & \\
\hline CaC12 flake & Calcium & & & & \\
\hline Zinc sulphate & Zinc & & & & \\
\hline & & & & & \\
\hline & & & & & \\
\hline
\end{tabular}

6.2 Did you use growth regulators or thinners in 2010 ?

Yes $\square$ No $\square$

6.2.1 If yes, please indicate which products were used, their volume and frequency of application, and if the application in 2010 was typical, more, or less than what is usually applied to your orchard each year. Use the blank spaces for any additional products used.

\begin{tabular}{|l|c|c|c|c|}
\hline $\begin{array}{c}\text { Product } \\
\text { Name }\end{array}$ & Active Ingredient & $\begin{array}{c}\text { Volume per } \\
\text { Application }\end{array}$ & $\begin{array}{c}\text { Frequency of } \\
\text { Application } \\
\text { (per year) }\end{array}$ & $\begin{array}{c}\text { Typical, } \\
\text { more or } \\
\text { less }\end{array}$ \\
\hline ATS & Ammonium-Thisulphate & & & \\
\hline $\begin{array}{l}\text { Amid- } \\
\text { Thin }\end{array}$ & Naphthaleneacetatamide & & & \\
\hline Frutone-N & Naphthalene Acetic Acid & & & \\
\hline $\begin{array}{l}\text { Sevin } \\
\text { XLR }\end{array}$ & Carbaryl & & & \\
\hline MaxCel & 6-benzyladenine & & & \\
\hline Cilis Plus & 6-benzyaminepurine & & & \\
\hline & & & & \\
\hline & & & & \\
\hline
\end{tabular}

6.3 If any machinery was used to thin your apple trees please answer the following:

\begin{tabular}{|c|c|c|}
\hline $\begin{array}{c}\text { Type and name of machine } \\
\text { (e.g. Darwin machine) }\end{array}$ & Frequency of use & $\begin{array}{c}\text { Proportion of trees } \\
\text { thinned using machine }\end{array}$ \\
\hline & & $\%$ \\
\hline
\end{tabular}

\section{Section 7. Weed and pest management}

* Note: If you have a spray log for 2010 please attach it to this questionnaire.

7.1. Please indicate all miticides and fungicides applied to your orchard in 2010 , as well as their volume and frequency of application (times per year), and if the application in 2010 was typical, more, or less than what is usually applied to your orchard each year.

\begin{tabular}{|c|c|c|c|}
\hline Product Name & $\begin{array}{c}\text { Volume per } \\
\text { Application }\end{array}$ & $\begin{array}{c}\text { Frequency of } \\
\text { Application }\end{array}$ & $\begin{array}{c}\text { Typical, more or } \\
\text { less }\end{array}$ \\
\hline & & & \\
\hline & & & \\
\hline
\end{tabular}


7.2 Please indicate all herbicides applied to your orchard in 2010, their volume and frequency of application (times per year), and if the application in 2010 was typical, more, or less than what is usually applied to your orchard each year. Only include herbicides that have not already been listed in question 5.4.

\begin{tabular}{|l|l|l|}
\hline Product Name & $\begin{array}{c}\text { Volume per } \\
\text { Application }\end{array}$ & $\begin{array}{c}\text { Frequency of } \\
\text { Application }\end{array}$ \\
\hline & & \\
\hline & & \\
\hline & & \\
\hline & & \\
\hline
\end{tabular}

7.5 Do you use pheronome traps / dispensers on your orchard?

Yes $\square$ No $\square$

7.5.1 If yes, please indicate what materials the dispensers are made of and how many you have in your orchard.

Section 8. Harvesting and Storage

8.1 Please indicate the material of the bins into which the apples are harvested in 2010, along with their dimensions and total number of bins used on the orchard.

\begin{tabular}{|c|c|c|}
\hline Material & Dimensions & Total number of bins \\
\hline & & \\
\hline
\end{tabular}

8.2 Please indicate the type of vehicle used to transfer apples to your storage facility in 2010, as well as the approximate distance travelled, and how often per year transfers take place.

\begin{tabular}{|c|c|c|c|}
\hline \multicolumn{1}{|c|}{ Vehicle } & Make/model & Distance travelled & Times per year \\
\hline$\square$ Tractor & & & \\
\hline$\square$ Road vehicle & & & \\
\hline$\square$ Other: & & & \\
\hline
\end{tabular}

8.3 Please indicate the type of storage facility used for your apples, and what proportion of apples are stored in them.

\begin{tabular}{l}
$\square$ Controlled storage $\ldots \ldots \ldots \ldots \ldots \ldots \ldots \ldots \ldots$ \\
\hline$\square$ Regular storage..........................
\end{tabular}

8.4 Please indicate the number of employees that worked in your orchard in 2010

8.4.1 What was the approximate number of "people hours" employed on your orchard in 2010 ? 
8.4.2 If your employees had to travel from abroad (out of province or country) to work in your orchard, please indicate their province/country(ies) of origin. Please indicate the most specific locations known (e.g. city of province, region of country etc.)

\section{Section 9. Energy use on farm}

9.1 What is the total amount of fuel typically used in your orchard machinery per year?

Diesel

Gasoline

9.2 Please indicate how this energy is used in orchard operations. For each piece of machinery indicate approximately what percentage of the total amount or the actual amount of gas/diesel they use, and whether they are gas or diesel driven. Use the blank space for additional machinery not listed.

\begin{tabular}{|l|l|l|l|l|}
\hline \multicolumn{1}{|c|}{$\begin{array}{c}\text { Machinery } \\
\text { equipment }\end{array}$} & $\begin{array}{c}\text { Make/Model (if } \\
\text { known) }\end{array}$ & $\begin{array}{c}\text { Proportion of total } \\
\text { energy used / } \\
\text { actual amount }\end{array}$ & Gasoline & Diesel \\
\hline Tractor & & & & \\
\hline Hydra-ladder & & & & \\
\hline Sprayer & & & & \\
\hline Mower & & & & \\
\hline Wind machine & & & & \\
\hline Under-tree dripper & & & & \\
\hline Sprinkler systems & & & & \\
\hline & & & & \\
\hline
\end{tabular}

Additional comments or questions:

\section{A most sincere thank-you for taking the time to participate in this study.}




\section{APPENDix C: EMisSiON CALCULATIONS}

Table C1: Illustrates $\mathrm{N}_{2} \mathrm{O}, \mathrm{NH}_{3}, \mathrm{NO}, \mathrm{NO}_{3}, \mathrm{P}_{2} \mathrm{O}_{5}$, and $\mathrm{CO}_{2}$ emission calculations from fertilizers and liming materials applied on conventional apple orchards in Nova Scotia.

\begin{tabular}{|c|c|c|c|}
\hline Calculation Step & Unit & Per tonne & Per ha \\
\hline \multicolumn{4}{|l|}{ Direct emissions of $\mathbf{N}$ species to atmosphere } \\
\hline $\mathrm{N}$ from Fertilizer & $\mathrm{kg}$ & $* 1.15$ & $* * 27.30$ \\
\hline Percent Fertilizer $\mathrm{N}$ lost as Ammonia $\left(\mathrm{NH}_{3}\right)^{\mathrm{a}}$ & $\%$ & 9 & \\
\hline $\mathrm{NH}_{3}-\mathrm{N}$ lost to atmosphere: Per tonne $X=(1.15 * 0.09)$ & $\mathrm{kg}$ & 0.10 & 2.46 \\
\hline Percent Fertilizer $\mathrm{N}$ lost as Nitric Oxide (NO) ${ }^{\mathrm{a}, \mathrm{b}}$ & $\%$ & 1 & \\
\hline NO-N lost to atmosphere: Per tonne $X=(1.15 * 0.01)$ & $\mathrm{kg}$ & 0.01 & 0.27 \\
\hline Percent Fertilizer $\mathrm{N}$ lost as Nitrous Oxide $\left(\mathrm{N}_{2} 0\right)^{a}$ & $\%$ & 1 & \\
\hline $\mathrm{NH}_{3}-\mathrm{N}$ lost to atmosphere: Per tonne $X=(1.15 * 0.01)$ & $\mathrm{kg}$ & 0.01 & 0.27 \\
\hline Percent Fertilizer N lost as Nitrogen Gas $\left(\mathrm{N}_{2}\right)^{\mathrm{b}}$ & $\%$ & 9 & \\
\hline $\mathrm{NH}_{3}-\mathrm{N}$ lost to the atmosphere: Per tonne $X=(1.15 * 0.09)$ & $\mathrm{kg}$ & 0.10 & 2.46 \\
\hline Additional $\mathrm{NH}_{3}-\mathrm{N}$ Emissions per hectare ${ }^{\mathrm{c}}$ & $\mathrm{kg} / \mathrm{h}$ & 5.00 & 5.00 \\
\hline Crop Yield & tonne/ha & 23.66 & \\
\hline Additional $\mathrm{NH}_{3}-\mathrm{N}$ Emissions per tonne: & & & \\
\hline Per tonne $X=(5 / 23.66)$ & $\mathrm{kg} /$ tonne & 0.21 & \\
\hline
\end{tabular}

\begin{tabular}{|llrr|}
\hline Total N Inputs to System & & & \\
\hline N from Fertilizer & $\mathrm{kg}$ & 1.15 & 27.30 \\
Rate of Atmospheric N deposition $^{\mathrm{b}}$ & $\mathrm{kg} / \mathrm{ha}$ & 7.5 & 7.5 \\
Crop Yield & tonnes/ha & 23.66 & \\
Atmospheric N Deposition per tonne of crop: & & & \\
Per tonne and per ha $X=(7.5 / 23.66)$ & $\mathrm{kg} /$ tonne & 0.32 & \\
Total N Inputs: Per tonne $X=(1.15+0.32)$ & $\mathrm{kg}$ & 1.47 & 34.80 \\
\hline
\end{tabular}

\begin{tabular}{|c|c|c|c|}
\hline \multicolumn{4}{|l|}{ Total N Outputs from System } \\
\hline Fertilizer $\mathrm{N}$ lost as $\mathrm{NH}_{3}$ to atmosphere (as above) & $\mathrm{kg}$ & 0.10 & 2.46 \\
\hline Fertilizer N lost as NO to atmosphere (as above) & $\mathrm{kg}$ & 0.01 & 0.27 \\
\hline Fertilizer $\mathrm{N}$ lost as $\mathrm{N}_{2} 0$ to atmosphere (as above) & $\mathrm{kg}$ & 0.01 & 0.27 \\
\hline Fertilizer $\mathrm{N}$ lost as $\mathrm{N}_{2}$ to atmosphere (as above) & $\mathrm{kg}$ & 0.10 & 2.46 \\
\hline $\begin{array}{l}\text { Additional } \mathrm{NH}_{3}-\mathrm{N} \text { to atmosphere (as above): } \\
\text { Per tonne } X=(5 / 23.66)\end{array}$ & $\begin{array}{l}\mathrm{kg} / \text { tonne; } \\
\mathrm{kg} / \mathrm{ha}\end{array}$ & 0.21 & 5.00 \\
\hline Nitrogen Removed with Crop ${ }^{d}$ & $\begin{array}{l}\mathrm{kg} / \text { tonne; } \\
\mathrm{kg} / \mathrm{ha}\end{array}$ & 0.62 & 14.63 \\
\hline $\begin{array}{l}\text { Total N outputs: } \\
\text { Per tonne } X=\sum(0.1+0.01+0.01+0.1+0.21+0.62)\end{array}$ & $\mathrm{kg}$ & 1.05 & 24.84 \\
\hline
\end{tabular}




\section{Table C1: Continued}

\begin{tabular}{|llrl|}
\hline $\begin{array}{l}\text { Total N Surplus Remaining: } \\
\text { Per tonne } X=(\text { Total } N \text { inputs - Total N outputs: } 1.47-1.05)\end{array}$ & $\mathrm{kg}$ & 0.42 & 9.96 \\
\hline Percent leached as $\mathrm{NO}_{3}$ a,b & $\%$ & 30 & \\
\hline $\begin{array}{l}\text { Nitrogen Surplus for } \mathrm{NO}_{3} \text { Loss: Per tonne } X=(\text { Total } N \\
\left.\text { Surplus * percent leached as } \mathrm{NO}_{3}: 0.42 * 0.3\right)\end{array}$ & $\mathrm{kg}$ & 0.13 & 2.99 \\
\hline
\end{tabular}

\begin{tabular}{|c|c|c|c|}
\hline Indirect Nitrogen Emissions from Volatilization a & d I & & \\
\hline Total $\mathrm{NH}_{3}-\mathrm{N}($ Ammonia from $\mathrm{N})$ & & & \\
\hline $\begin{array}{l}\text { Per tonne } \mathrm{X}=\sum\left(\mathrm{NH}_{3^{-}} \mathrm{N} \text { lost to atmosphere }+ \text { additional } \mathrm{NH}_{3^{-}}\right. \\
\mathrm{N}: 0.10+0.21)\end{array}$ & $\mathrm{kg}$ & 0.31 & 7.43 \\
\hline Indirect $\mathrm{N}_{2} \mathrm{O}$ Volatilization Emissions from $\mathrm{NH}_{3}-\mathrm{N}^{\mathrm{a}}$ & $\%$ & 1 & \\
\hline $\begin{array}{l}\text { Indirect } \mathrm{N}_{2} 0 \text { Emissions from } \mathrm{NH}_{3}-\mathrm{N} \text { : } \\
\text { Per tonne } X=(0.31 * 0.01)\end{array}$ & $\mathrm{kg}$ & 0.003 & 0.074 \\
\hline
\end{tabular}

$\mathrm{NO}_{3}$ Emissions:

Per tonne $\mathrm{X}=$ Nitrogen Surplus for $\mathrm{NO}_{3}$ Loss $0.13 \quad 2.99$ Indirect $\mathrm{N}_{2} \mathrm{O}$ Leaching/Runoff Emissions from $\mathrm{NO}_{3}{ }^{\mathrm{a}} \quad \% \quad 0.75$ Indirect $\mathrm{N}_{2} \mathrm{O}$ Emissions from $\mathrm{NO}_{3}$ :

Per tonne $X=(0.13 * 0.0075)$ $\mathrm{kg}$ $0.001 \quad 0.022$

\begin{tabular}{|c|c|c|c|}
\hline \multicolumn{4}{|c|}{ Total Nitrogen Emissions from Direct and Indirect Calculation Steps (above) } \\
\hline $\begin{array}{l}\text { Total } \mathrm{N}_{2} \mathrm{O}-\mathrm{N} \text { to } \mathrm{Air}^{\mathrm{a}} \text { : } \\
\text { Per tonne } \mathrm{X}=\sum \text { (Indirect } \mathrm{N}_{2} \mathrm{O} \text { Emissions from } \mathrm{NO}_{3}+\text { Indirect } \\
\mathrm{N}_{2} \mathrm{O} \text { Emissions from } \mathrm{NH}_{3}-\mathrm{N}+\text { Fertilizer lost as } \mathrm{NO}_{2}: \\
0.001+0.003+0.01) *\left(44 / 28: \mathrm{N}_{2} \mathrm{O}-\mathrm{N} \text { conversion to } \mathrm{N}_{2} \mathrm{O}\right)\end{array}$ & $\mathrm{kg}$ & 0.02 & 0.52 \\
\hline $\begin{array}{l}\text { Total } \mathrm{NH}_{3}-\mathrm{N} \text { to } \mathrm{Air}^{\mathrm{a}}: \\
\text { Per tonne } X=\left(\text { Total } \mathrm{NH}_{3}-\mathrm{N}: 0.31\right) *\left(1.21: \mathrm{NH}_{3}-\mathrm{N} \text { conversion }\right)\end{array}$ & $\mathrm{kg}$ & 0.38 & 9.02 \\
\hline $\begin{array}{l}\text { Total NO-N to Air }{ }^{a}: \text { Per tonne } X= \\
\text { (Fertilizer lost as NO: } 0.01) *(30 / 14: N O-N \text { conversion) }\end{array}$ & $\mathrm{kg}$ & 0.02 & 0.51 \\
\hline $\begin{array}{l}\text { Total } \mathrm{NO}_{3}-\mathrm{N} \text { to Water }{ }^{\text {a }}: \text { Per tonne } X= \\
\left(\mathrm{NO}_{3} \text { Emissions: } 0.13\right) *\left(62 / 14: \mathrm{NO}_{3}-N \text { conversion }\right)\end{array}$ & $\mathrm{kg}$ & 0.56 & 13.23 \\
\hline
\end{tabular}

Note: * Nitrogen and phosphorus values per tonne and per hectare include combined inputs from land preparation and annual nutrient management $(\mathrm{N}$ from synthetic fertilizer and $\mathrm{N}$ from urea application). Per hectare results have been calculated as a function of the crop yield (tonne/ha) for conventional orchard production. 


\section{Table C1: Continued}

\begin{tabular}{|c|c|c|c|}
\hline \multicolumn{4}{|l|}{ Phosphorus Emissions from Fertilizer } \\
\hline P from Fertilizer & $\mathrm{kg}$ & $* 0.99$ & $* 23.40$ \\
\hline $\begin{array}{l}\text { Phosphate Fertilizer Conversion to Phosphorus }{ }^{\mathrm{e}} \text { : } \\
\text { Per tonne } X=(0.99 / 2.3)\end{array}$ & $\mathrm{kg}$ & 0.43 & 10.17 \\
\hline Phosphorus content of crop ${ }^{d}$ & $\%$ & 0.05 & \\
\hline $\begin{array}{l}\text { Phosphorus Removed/tonne and hectare of crop }{ }^{\mathrm{d}} \text { : } \\
\text { Per tonne } X=(0.9 * 2.47105) / 6691.68\end{array}$ & $\begin{array}{l}\mathrm{kg} / \text { tonne; } \\
\mathrm{kg} / \mathrm{ha}\end{array}$ & 0.0003 & 0.01 \\
\hline $\begin{array}{l}\text { Total Remaining Phosphorus: } \\
\text { Per tonne } X=\text { (Total Phosphorous in Phosphate Fertilizer- } \\
\text { Phosphorus Removed: } 0.43-0.0003 \text { ) }\end{array}$ & $\mathrm{kg}$ & 0.43 & 10.17 \\
\hline Leaching rate of phosphorus ${ }^{f}$ & $\%$ & 2.9 & \\
\hline
\end{tabular}

\section{Total Phosphorus Emissions from Calculations Steps (above)}

\section{Total $\mathrm{P}_{2} \mathrm{O}_{5}-\mathrm{P}$ to water ${ }^{\mathrm{g}}$ :}

$\begin{array}{llll}\text { Per tonne } X=(\text { Total Remaining Phosphorus * Leaching rate of } & \mathrm{kg} & 0.029 & 0.68\end{array}$

phosphorus: $0.43 * 0.029) *\left(2.29: \mathrm{P}_{2} \mathrm{O}_{5}-\mathrm{P}\right.$ conversion to $\left.\mathrm{P}_{2} \mathrm{O}_{5}\right)$

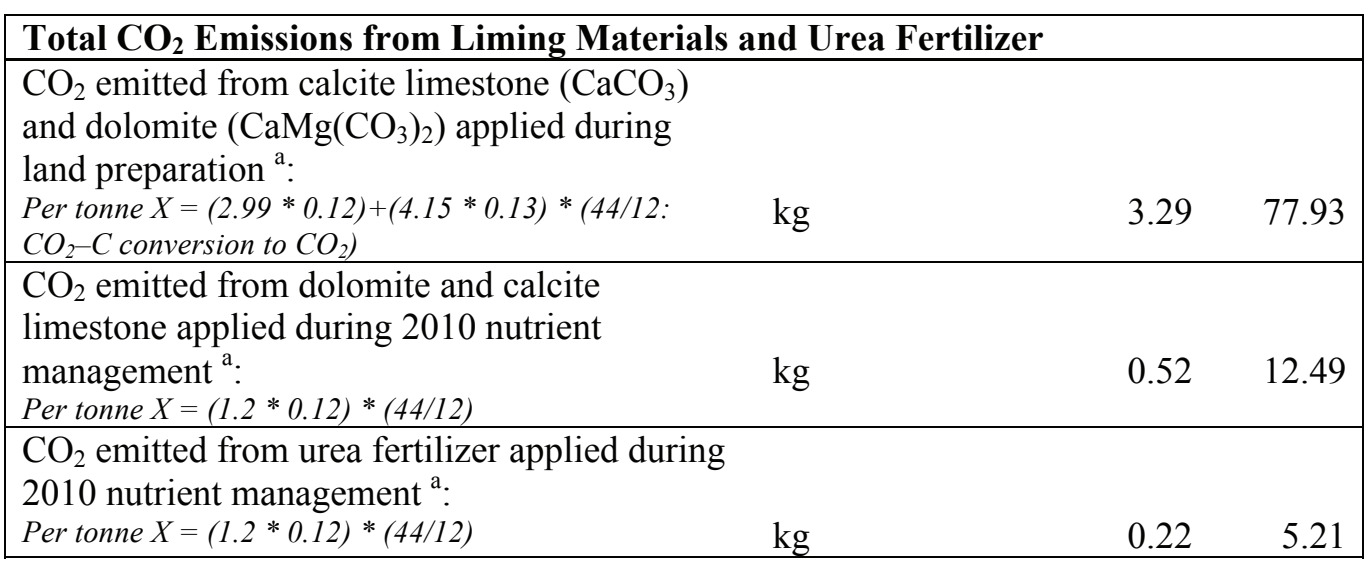


Table C2: Illustrates $\mathrm{N}_{2} \mathrm{O}, \mathrm{NH}_{3}, \mathrm{NO}, \mathrm{NO}_{3}, \mathrm{P}_{2} \mathrm{O}_{5}$, and $\mathrm{CO}_{2}$ emission calculations from manure and liming materials applied on organic apple orchards in Nova Scotia.

\begin{tabular}{|c|c|c|c|}
\hline Calculation Step & Unit & Per tonne & Per ha \\
\hline \multicolumn{4}{|l|}{ Direct emissions of $\mathrm{N}$ species to atmosphere } \\
\hline $\mathrm{N}$ from Manure ${ }^{\mathrm{g}}$ & $\mathrm{kg}$ & 1.60 & $* 19.01$ \\
\hline Percent Manure $\mathrm{N}$ lost as Ammonia $\left(\mathrm{NH}_{3}\right)^{\mathrm{a}}$ & $\%$ & 18 & \\
\hline $\mathrm{NH}_{3}-\mathrm{N}$ lost to atmosphere: Per tonne $X=(1.6 * 0.18)$ & $\mathrm{kg}$ & 0.29 & 3.42 \\
\hline Percent Manure $\mathrm{N}$ lost as Nitric Oxide $(\mathrm{NO})^{\mathrm{a}, \mathrm{b}}$ & $\%$ & 1 & \\
\hline NO-N lost to atmosphere: Per tonne $X=(1.6 * 0.01)$ & $\mathrm{kg}$ & 0.02 & 0.19 \\
\hline Percent Manure $\mathrm{N}$ lost as Nitrous Oxide $\left(\mathrm{N}_{2} 0\right)^{\mathrm{a}}$ & $\%$ & 1 & \\
\hline $\mathrm{N}_{2} \mathrm{O}-\mathrm{N}$ lost to atmosphere: Per tonne $X=(1.6 * 0.01)$ & $\mathrm{kg}$ & 0.02 & 0.19 \\
\hline Percent Manure N lost as Nitrogen Gas $\left(\mathrm{N}_{2}\right)^{\mathrm{b}}$ & $\%$ & 9 & \\
\hline $\mathrm{N}_{2}-\mathrm{N}$ lost to the atmosphere: Per tonne $X=(1.6 * 0.09)$ & $\mathrm{kg}$ & 0.14 & 1.71 \\
\hline $\mathrm{NH}_{3}-\mathrm{N}$ Emissions per hectare ${ }^{\mathrm{c}}$ & $\mathrm{kg} / \mathrm{ha}$ & 5.00 & 5.00 \\
\hline Crop Yield & tonne/ha & 11.88 & \\
\hline $\begin{array}{l}\text { Total Additional } \mathrm{NH}_{3}-\mathrm{N} \text { Emissions: } \\
\text { Per tonne } X=(5 / 11.88)\end{array}$ & $\mathrm{kg} /$ tonne & 0.42 & \\
\hline
\end{tabular}

\begin{tabular}{|llrr|}
\hline Total N Inputs to System & & & \\
\hline N from Manure & $\mathrm{kg}$ & 1.6 & 19.01 \\
Rate of Atmospheric N deposition $^{\mathrm{b}}$ & $\mathrm{kg} / \mathrm{ha}$ & 7.5 & 7.5 \\
Crop Yield & tonnes/ha & 11.88 & \\
Atmospheric N Deposition per tonne of crop: & & & \\
Per tonne and per ha $X=(7.5 / 11.88)$ & $\mathrm{kg} /$ tonne & 0.63 & \\
Total N Inputs: Per tonne $X=(1.6+0.63)$ & $\mathrm{kg}$ & 2.23 & 26.51 \\
\hline
\end{tabular}

\begin{tabular}{|c|c|c|c|}
\hline \multicolumn{4}{|l|}{ Total N Outputs from System } \\
\hline Manure $\mathrm{N}$ lost as $\mathrm{NH}_{3}$ to atmosphere (as above) & $\mathrm{kg}$ & 0.29 & 3.42 \\
\hline Manure N lost as NO to atmosphere (as above) & $\mathrm{kg}$ & 0.02 & 0.19 \\
\hline Manure $\mathrm{N}$ lost as $\mathrm{N}_{2} 0$ to atmosphere (as above) & $\mathrm{kg}$ & 0.02 & 0.19 \\
\hline Manure $\mathrm{N}$ lost as $\mathrm{N}_{2}$ to atmosphere (as above) & $\mathrm{kg}$ & 0.14 & 1.71 \\
\hline $\begin{array}{l}\text { Additional } \mathrm{NH}_{3}-\mathrm{N} \text { Emissions lost from crop: } \\
\text { Per tonne } X=(5 / 11.88)\end{array}$ & $\begin{array}{l}\mathrm{kg} / \text { tonne; } \\
\mathrm{kg} / \mathrm{ha}\end{array}$ & 0.42 & 5.00 \\
\hline Nitrogen Removed with Crop ${ }^{d}$ & $\begin{array}{l}\mathrm{kg} / \text { tonne; } \\
\mathrm{kg} / \mathrm{ha}\end{array}$ & 0.62 & 7.37 \\
\hline $\begin{array}{l}\text { Total } \mathrm{N} \text { outputs: } \\
\text { Per tonne } X=\sum(0.29+0.02+0.02+0.14+0.42+0.62)\end{array}$ & $\mathrm{kg}$ & 1.50 & 17.84 \\
\hline
\end{tabular}




\section{Table C2: Continued}

\begin{tabular}{|llrl|}
\hline $\begin{array}{l}\text { Total N Surplus Remaining: } \\
\text { Per tonne } X=(\text { Total } N \text { inputs - Total N outputs: } 2.23-1.50)\end{array}$ & $\mathrm{kg}$ & 0.73 & 8.66 \\
\hline Percent leached as $\mathrm{NO}_{3}^{\text {a,b }}$ & $\%$ & 30 & \\
\hline $\begin{array}{l}\text { Nitrogen Surplus for } \mathrm{NO}_{3} \text { Loss: Per tonne } X=(\text { Total } N \\
\left.\text { Surplus * percent leached as } \mathrm{NO}_{3}: 0.73 * 0.3\right)\end{array}$ & $\mathrm{kg}$ & 0.22 & 2.60 \\
\hline
\end{tabular}

\begin{tabular}{|llrl|}
\hline Indirect Nitrogen Emissions from Volatilization and Leaching/Runoff & \\
\hline Total $\mathrm{NH}_{3}-\mathrm{N}($ Ammonia from $\mathrm{N})$ : & & & \\
Per tonne $X=\sum\left(\mathrm{NH}_{3}-\mathrm{N}\right.$ lost to atmosphere + additional $\mathrm{NH}_{3}{ }^{-}$ & $\mathrm{kg}$ & 0.71 & 8.41 \\
N lost from Crops: $0.29+0.42)$ & $\mathrm{kg}$ & 1 & \\
\hline Indirect $\mathrm{N}_{2} \mathrm{O}$ Volatilization Emissions from $\mathrm{NH}_{3}-\mathrm{N}^{\mathrm{a}}$ & $\%$ & & \\
\hline $\begin{array}{l}\text { Indirect } \mathrm{N}_{2} \mathrm{O} \text { Emissions from } \mathrm{NH}_{3}-\mathrm{N}: \\
\text { Per tonne } X=(0.71 * 0.01)\end{array}$ & $\mathrm{kg}$ & 0.007 & 0.08 \\
\hline
\end{tabular}

$\mathrm{NO}_{3}$ Emissions:

$\begin{array}{llll}\text { Per tonne } X=\text { Nitrogen Surplus for } \mathrm{NO}_{3} \text { Loss } & \mathrm{kg} & 0.22 & 2.60\end{array}$

Indirect $\mathrm{N}_{2} \mathrm{O}$ Leaching/Runoff Emissions from $\mathrm{NO}_{3}{ }^{\mathrm{a}} \quad \% \quad 0.75$

Indirect $\mathrm{N}_{2} 0$ Emissions from $\mathrm{NO}_{3}$ :

$\begin{array}{llll}\text { Per tonne } X=(0.22 * 0.0075) & \mathrm{kg} & 0.002 & 0.02\end{array}$

\begin{tabular}{|c|c|c|c|}
\hline Total Nitrogen Emissions from Direct and Indire & $\mathrm{Ca}$ & (abo) & \\
\hline $\begin{array}{l}\text { Total } \mathrm{N}_{2} \mathrm{O}-\mathrm{N} \text { to } \mathrm{Air}^{\mathrm{a}}: \\
\text { Per tonne } \mathrm{X}=\sum \text { (Indirect } \mathrm{N}_{2} \mathrm{O} \text { Emissions from } \mathrm{NO}_{3}+\text { Indirect } \\
\mathrm{N}_{2} \mathrm{O} \text { Emissions from } \mathrm{NH}_{3}-\mathrm{N}+\text { Manure } \mathrm{N} \text { lost as } \mathrm{NO}_{2}: \\
0.002+0.007+0.02) *\left(44 / 28: \mathrm{N}_{2} \mathrm{O}-\mathrm{N} \text { conversion to } \mathrm{N}_{2} \mathrm{O}\right)\end{array}$ & $\mathrm{kg}$ & 0.04 & 0.46 \\
\hline $\begin{array}{l}\text { Total } \mathrm{NH}_{3}-\mathrm{N} \text { to } \mathrm{Air}^{\mathrm{a}} \text { : } \\
\text { Per tonne } \mathrm{X}=\left(\text { Total } \mathrm{NH}_{3}-\mathrm{N}: 0.71\right) *\left(1.21: \mathrm{NH}_{3}-\mathrm{N} \text { conversion }\right)\end{array}$ & $\mathrm{kg}$ & 0.86 & 10.19 \\
\hline $\begin{array}{l}\text { Total NO-N to Air }{ }^{\text {aa }}: \text { Per tonne } X=(\text { Manure lost as NO: } \\
0.02) *(30 / 14: \text { NO-N conversion })\end{array}$ & $\mathrm{kg}$ & 0.03 & 0.41 \\
\hline $\begin{array}{l}\text { Total } \mathrm{NO}_{3}-\mathrm{N} \text { to Water }{ }^{\text {a }} \text { : } \\
\text { Per tonne } \mathrm{X}=\left(\mathrm{NO}_{3} \text { Emissions: } 0.22\right) *\left(62 / 14: \mathrm{NO}_{3}-\mathrm{N}\right. \\
\text { conversion })\end{array}$ & $\mathrm{kg}$ & 0.97 & 11.51 \\
\hline
\end{tabular}




\section{Table C2: Continued}

\begin{tabular}{|c|c|c|c|}
\hline \multicolumn{4}{|l|}{ Phosphorus Emissions from Manure } \\
\hline $\mathrm{P}$ from Fertilizer & $\mathrm{kg}$ & 1.05 & 12.47 \\
\hline $\begin{array}{l}\text { Phosphate Manure Conversion to Phosphorus }{ }^{\mathrm{e}} \text { : } \\
\text { Per tonne } X=(1.05 / 2.3)\end{array}$ & $\mathrm{kg}$ & 0.46 & 5.42 \\
\hline Phosphorus content of crop ${ }^{d}$ & $\%$ & 0.05 & \\
\hline $\begin{array}{l}\text { Phosphorus Removed/tonne and hectare of crop }{ }^{\mathrm{d}} \\
\text { Per tonne } X=(0.45 * 2.47105) / 225.82\end{array}$ & $\begin{array}{l}\mathrm{kg} / \text { tonne; } \\
\mathrm{kg} / \mathrm{ha}\end{array}$ & 0.005 & 0.06 \\
\hline $\begin{array}{l}\text { Total Remaining Phosphorus: } \\
\text { Per tonne } X=(\text { Total Phosphorous in Manure - Phosphorus } \\
\text { Removed: } 0.46-0.0005)\end{array}$ & $\mathrm{kg}$ & 0.45 & 5.36 \\
\hline Leaching rate of phosphorus ${ }^{f}$ & $\%$ & 2.9 & \\
\hline
\end{tabular}

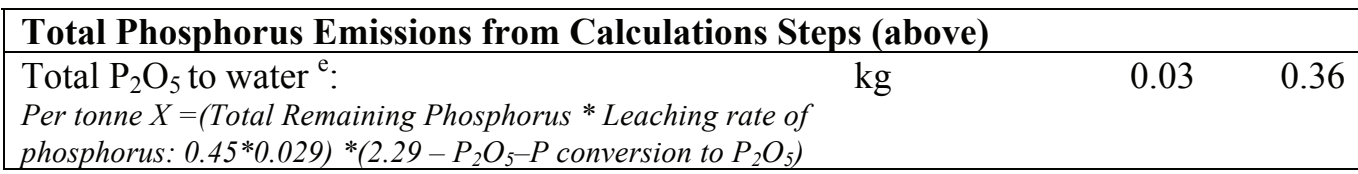

\section{Total $\mathrm{CO}_{2}$ Emissions from Liming Materials}

$\mathrm{CO}_{2}$ emitted from dolomite $\left(\mathrm{CaMg}\left(\mathrm{CO}_{3}\right)_{2}\right)$ applied during land preparation ${ }^{\mathrm{a}}$ :

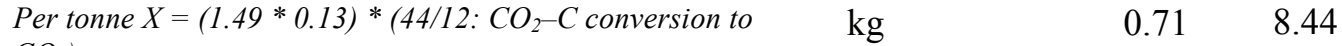
$\left.\mathrm{CO}_{2}\right)$

*Note: Per hectare results have been calculated as a function of the crop yield (tonne/ha) for organic orchard production.

\footnotetext{
a. Intergovernmental Panel on Climate Change, 2006

b. Brentrup et al., 2000

c. Andersson et al., 2001, as cited in Schmidt, 2007

d. National Resources Conservation Service, 2007

e. McKenzie \& Middleton, 1997

f. Dalgaard et al., 2006

g. ATTRA, 2003.
} 


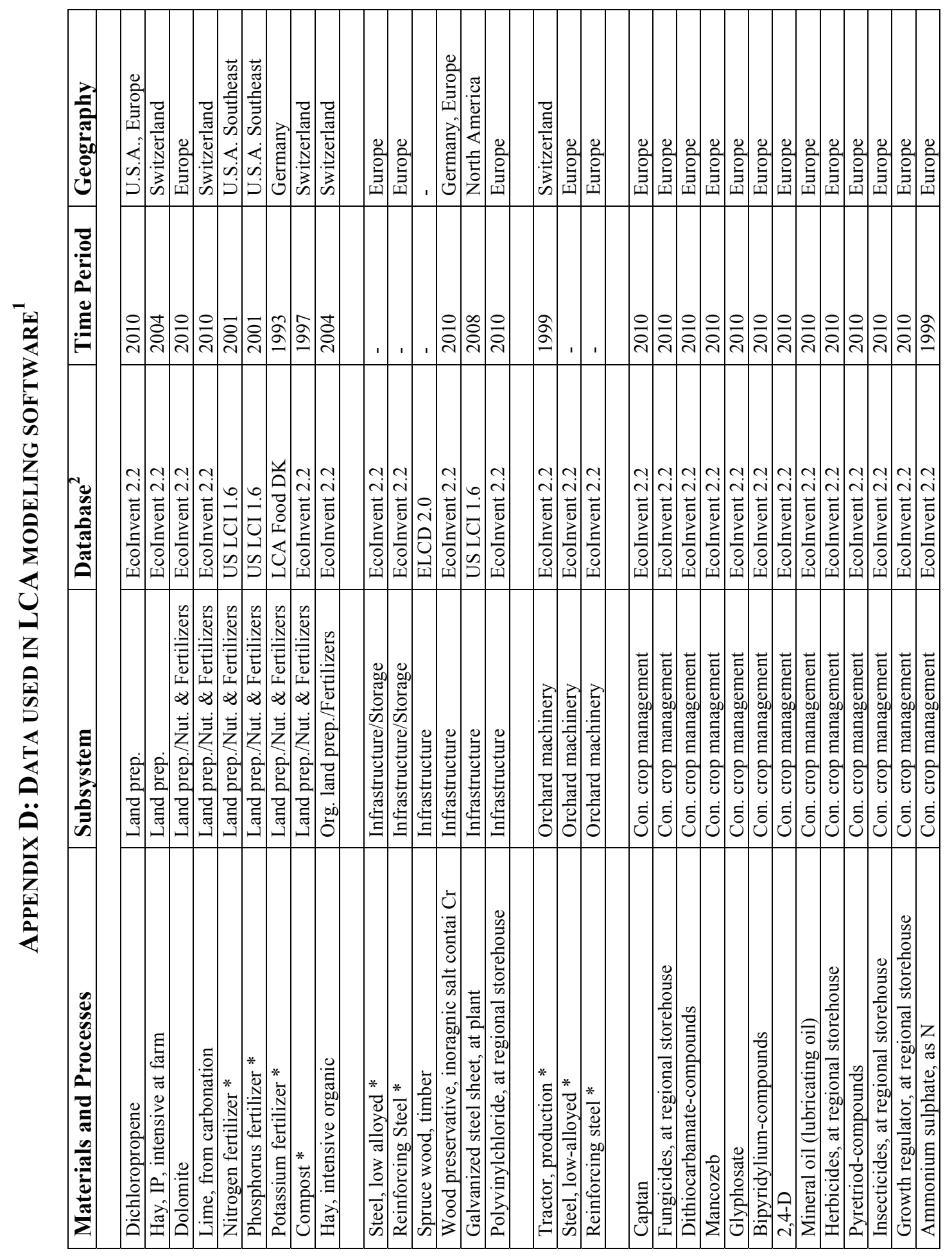




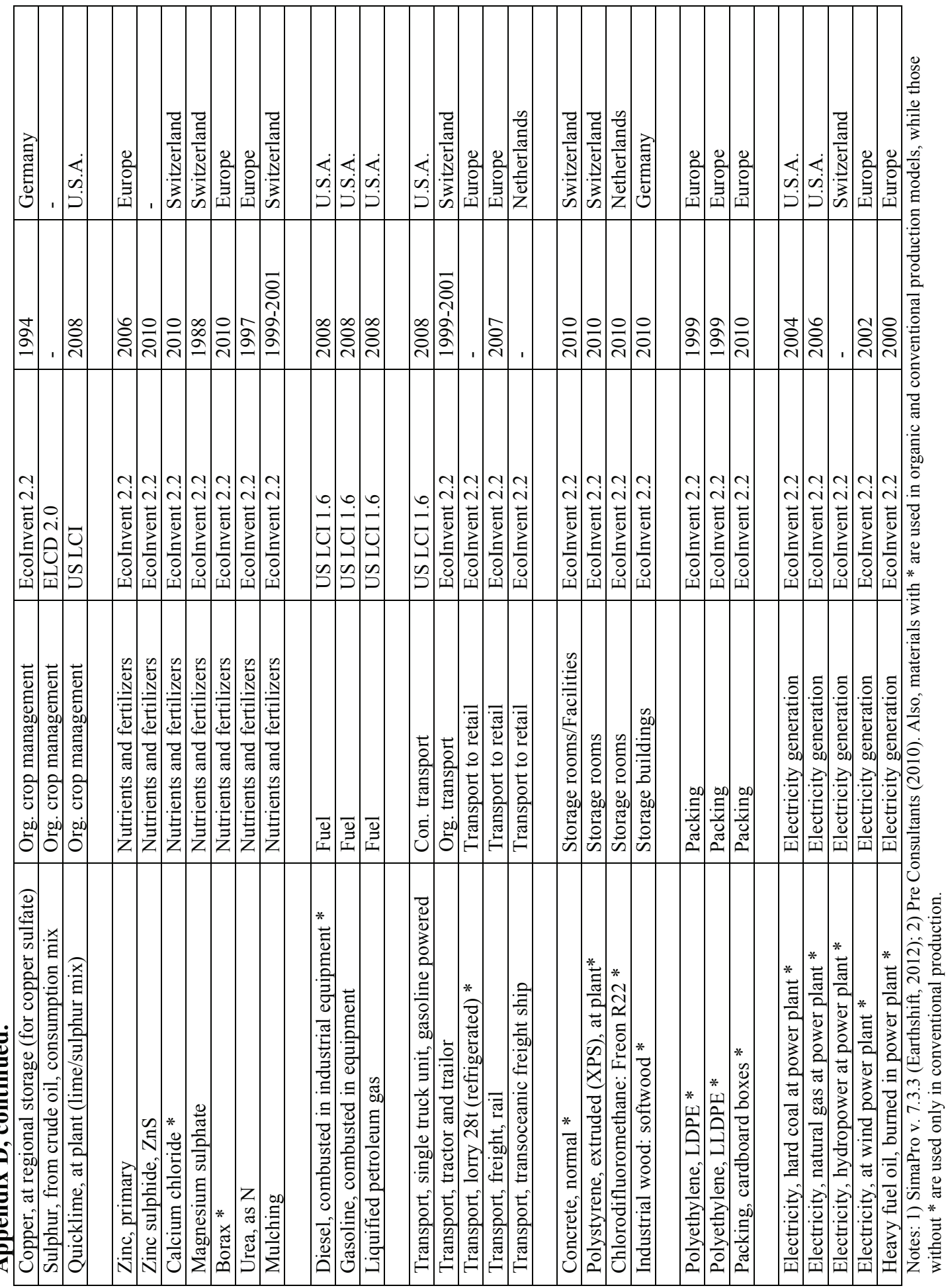




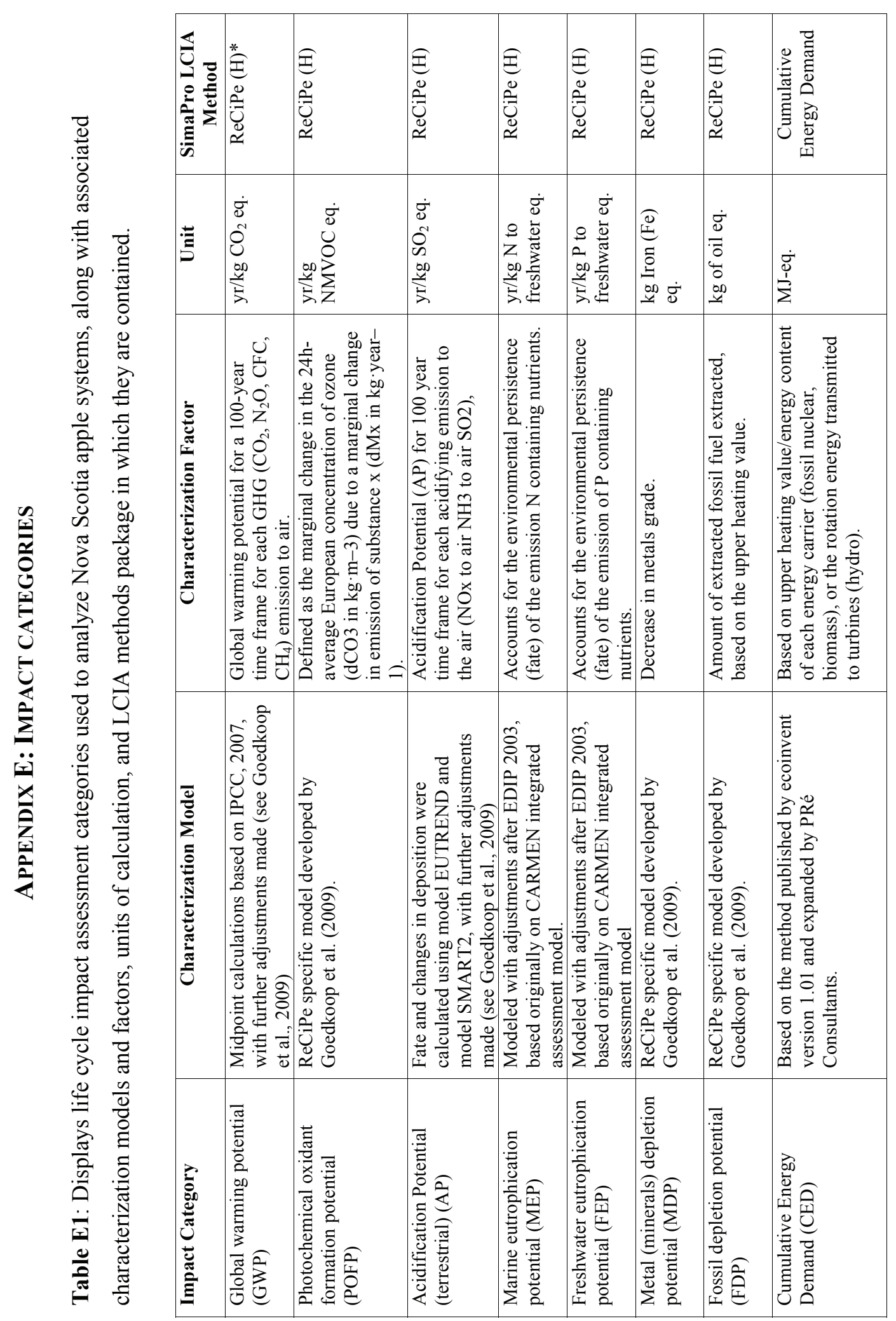




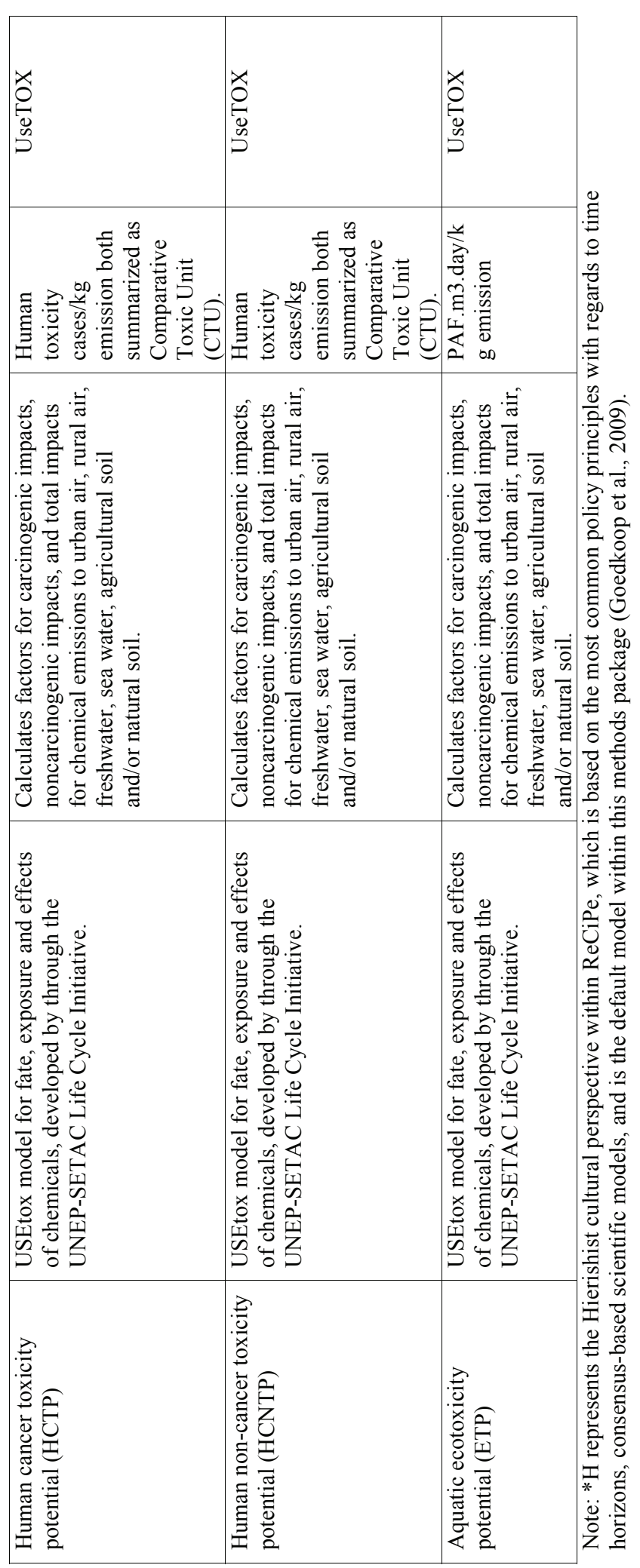




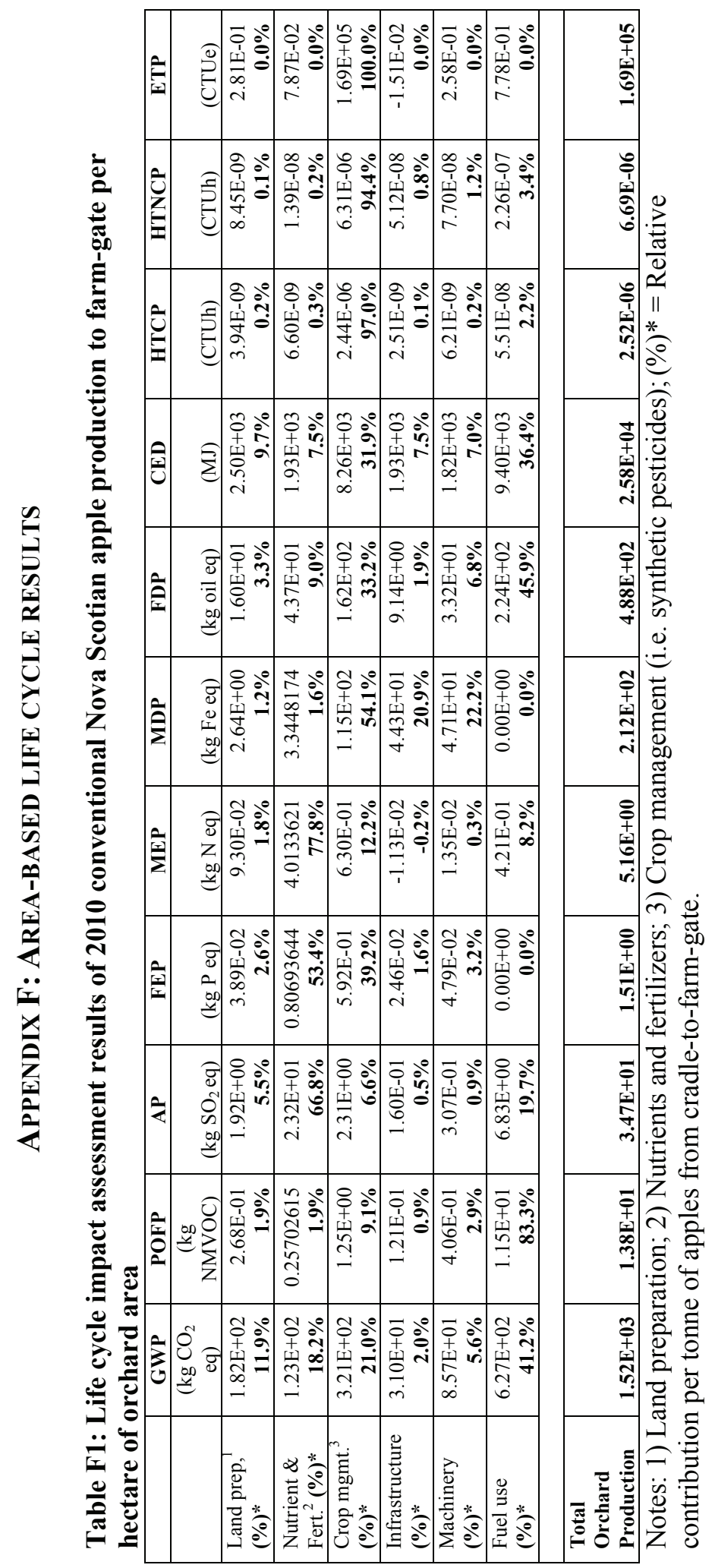




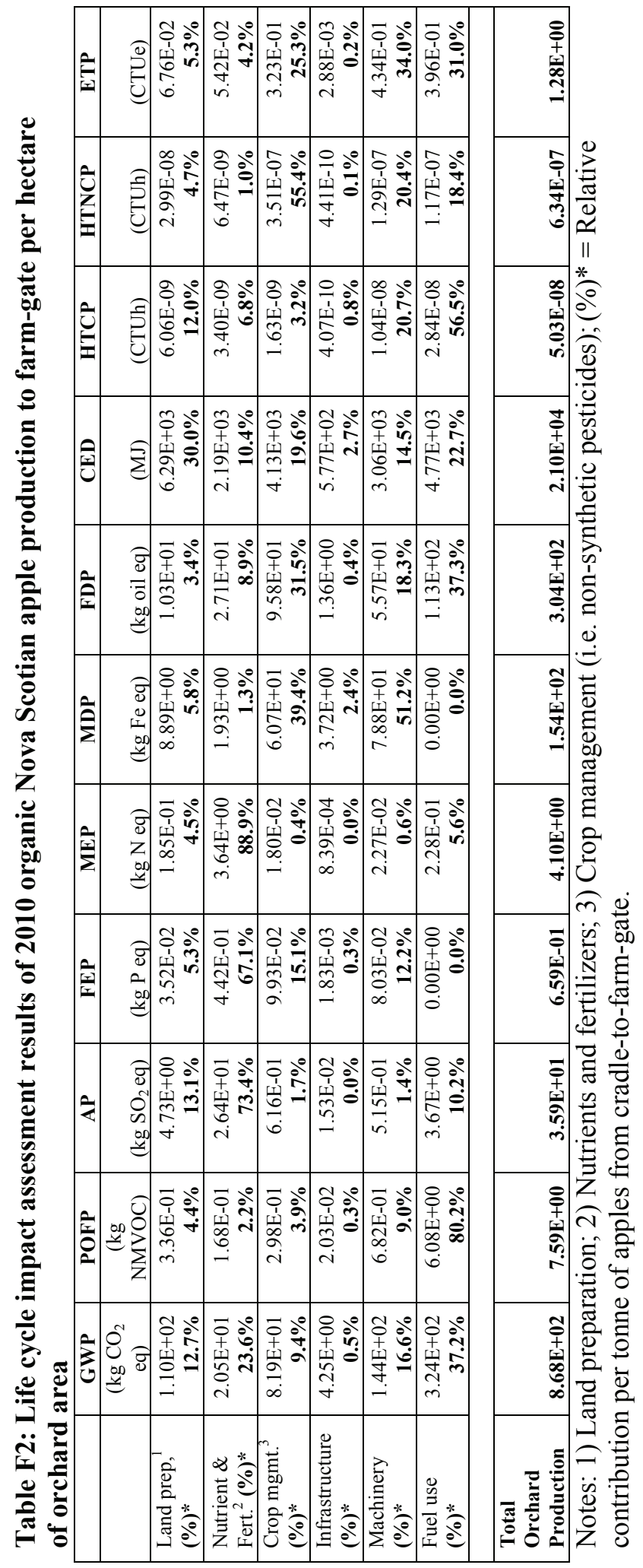




\section{REFERENCES}

AgraPoint International Inc. (2006). Orchard fertility. Atlantic Committee on Fruit Crops Publication ACC 1201. Retrieved from http://perennia.ca/Fact\%20Sheets/Horticulture/Fruit/Orchard\%20Fruit/ORCHAR D_FERTILITY.pdf

AgraPoint International Inc. (2009). Nova Scotia Tree Fruit Industry Vitalization: Program Review. Nova Scotia Fruit Growers Association. Kentville, Nova Scotia, $3-140$

Agriculture and Agri-Food Canada. (2007). Canadian Apple Industry Research and Development Strategy (Final). Retrieved from http://www.hortcouncil.ca/uploads/file/English/Apple\%20and\%20Fruit/Apple_Re search_Priorities_Workshop_Report_2007_Eng.pdf

Agriculture and Agri-Food Canada. (2012). A snapshot of the Canadian apple industry, 2010. Retrieved from http://www4.agr.gc.ca/AAFC-AAC/displayafficher.do?id=1334147419910\&lang=eng

Allen, P., FitzSimmons, M., Goodman, M., \& Warner, K. (2003). Shifting plates in the agrifood landscape: the tectonics of alternative agrifood initiatives in California. Journal of rural studies, 19(1), 61-75.

Allen, P. (2010). Realizing justice in local food systems. Cambridge Journal of Regions, Economy and Society, 3(2), 295-308. doi:10.1093/cjres/rsq015

Altieri, M. (2009). Agroecology, small farms, and food sovereignty. Monthly Review, 61(3), 102-113.

Andersson, K. (2000). LCA of food products and production systems. International Journal of LCA, 5 (4), 239-248.

Andersson, K., \& T. Ohlsson. (1999). Life cycle assessment of bread produced at different scales. International Journal of Life Cycle Assessment, 4, 25-40.

Anton, A., Catells, F., \& Montero, J.I. (2007). Land use indicators in life cycle assessment. Case study: The environmental impact of Mediterranean greenhouses. Journal of Cleaner Production 15, 432-438. doi:10.1016/j.jclepro.2005.10.001

Atlantic Canada Opportunities Agency (2011). Harper Government Supports Nova Scotia Fruit Growers Association. News Release. Retrieved from http://mediaroom.acoa-apeca.gc.ca/e/media/press/press.shtml?5055 
Appropriate Technology Transfer for Rural Areas (ATTRA). (2003). Manures for organic crop production: Soil system guide. Retrieved from:

http://counties.cce.cornell.edu/washington/Ag/Haymanual/Hay\%20Manual/11Organic-Hay/Manures\%20for\%20Organic\%20Production.pdf

Avilla, J., \& Riedl, H. (2003). Integrated Fruit Production for Apples - Principles and Guidelines. In Apples: Botany, Production and Uses. D. C. Ferree \& I. J. Warrignton (Eds.) New York, NY: CABI Pub. 539-549.

Audsley, E. (2003). Harmonisation of Environmental Life Cycle Assessment for Agriculture: Final Report, Concerted Action AIR3-CT94-2028. CE DG VI-Centre de documentation.

Badgley, C., Moghtader, J., Quintero, E., Zakem, E., Chappell, M. J., Aviles-Vazquez, K., Samulon, A., et al. (2007). Organic agriculture and the global food supply. Renewable Agriculture and Food Systems, 22(2), 86-108. doi:10.1017/S1742170507001640

Bailey, J. (2010). Farm Energy: Resource Kit for Nova Scotia Farmers. Think Farm: Nova Scotia Department of Agriculture. Retrieved from http://www.gov.ns.ca/agri/thinkfarm/fsheets/09-farm-energy.pdf

Basset-Mens, C., \& Van der Werf, H. M. G. (2005). Scenario-based environmental assessment of farming systems: the case of pig production in France. Agriculture, Ecosystems \& Environment, 105(1-2), 127-144. doi:10.1016/j.agee.2004.05.007

Baumann, H., \& Tillman, A.M. (2004). The Hitch Hiker's Guide to LCA. Lund: Studentlitteratur

Beers, E. H., Suckling, D. M., Prokopy, R. J., \& Avilla, J. (2003). Ecology and Management of Apple Arthropod Pests. In Apples: Botany, Production and Uses. D. C. Ferree \& I. J. Warrignton (Eds.) New York, NY: CABI Pub. 539-549.

Berlin, D., \& Uhlin, H.E. (2004). Opportunity cost principles for life cycle assessment: Toward strategic decision making in agriculture. Progress in Industrial Ecology, An International Journal, 1, 187-202.

Bertschinger, L., Mouron, P., Dolega, E., Höhn, H., Holliger, E., Husistein, A., Schmid, A., et al. (2004). Ecological apple production: A comparison of organic and integrated apple-growing. Acta Hort., 638, 321-332.

Binder, C., Feola, G., \& Steinberger, J. (2010). Considering the normative, systemic and procedural dimensions in indicator-based sustainability assessments in agriculture. Environmental Impact Assessment Review 30, 71-81. doi:10.1016/j.eiar.2009.06.002 
Biswas, W. K., Barton, L., \& Carter, D. (2008). Global warming potential of wheat production in Western Australia: a life cycle assessment. Water and Environment Journal, 22(3), 206-216. doi:10.1111/j.1747-6593.2008.00127.x

Björklund, A. (2002). Survey of approaches to improve reliability in LCA. Int J LCA $7(2), 64-72$.

Blanke M.M., \& Burdick, B. (2005). Food (miles) for thought. Energy balance for locally-grown versus imported apple fruit. Env. Sci. Pollut. Res., 12(3), 125-27.

Bonti-Ankomah, S., \& Yiridoe, E. (2006). Organic and Conventional Food: A Literature Review of the Economics of Consumer Perceptions and Preferences. Organic Agriculture Centre of Canada, Nova Scotia Agricultural College, Canada.

Bourn, D., \& Prescott, J. (2002). A comparison of the nutritional value, sensory qualities and food safety of organically and conventionally produced foods. Critical Reviews in Food Science and Nutrition, 42(1), 1-34.

Brentrup, F. (2003) Life Cycle Assessment to Evaluate the Environmental Impact of Arable Crop Production. Doctoral dissertation. University of Hannover, Göttingen, Germany.

Brentrup, F., Küsters, J., Lammel, J., \& H. Kuhlmann. (2000). Methods to Estimate Onfield Nitrogen Emissions from Crop Production as an Input to LCA Studies in the Agricultural Sector. International Journal of Life Cycle Assessment, 5, 349-357.

Brentrup, F., Küsters, J., Kuhlmann, H., Lammel, J., (2001). Application of the life cycle assessment methodology to agricultural production: an example of sugar beet production with different forms of nitrogen fertilizers. European Journal of Agronomy 14(3), 221-233.

Brentrup, F., Küsters, J., Kuhlmann, H., \& Lammel, J. (2004). Environmental impact assessment of agricultural production systems using the life cycle assessment methodology. European Journal of Agronomy, 20(3), 247-264.

doi:10.1016/S1161-0301(03)00024-8

Brown, L. (2009). Plan B 4.0: Mobilizing to save civilization. Earth Policy Institute. New York: W.W. Norton \& Company

Bruinsma, J. (ed.). (2003). World agriculture: Towards 2015/2030 - An FAO perspective. London: Earthscan Publications Ltd

Bruinsma, J. (2009). Proceedings from FAO Expert Meeting '09: The Resource Outlook to 2050: By how much do land, water and crop yields need to increase by 2050? FAO, Rome, Italy. Retrieved from http://www.fsnnetwork.org/sites/default/files/the_resource_outlook_to_2050by_h ow_much_do_land_water_and_crop_yields_need_to_increase_by_2050_pdf 
Brussaard, L., Behan-Pelletier, V. M., Bignell, D. E., Brown, V. K., Didden, W., Folgarait, P. et al. (1997). Biodiversity and ecosystem functioning in soil. Ambio, 26, 563-570,

Butler, S.J., Vickery, J.A., \& Norris, K. (2007). Farmland biodiversity and the footprint of agriculture. Science 315(5810), 381-384. DOI: 10.1126/science.1136607

Canadian Horticultural Council. (2009). Crop Protection - A Better Future for Canada Retrieved from http://www.hortcouncil.ca/uploads/file/English/Crop\%20Plant\%20Protection\%20 and\%20Environment/Integrated_Pest_Management_Strategies_Eng.pdf

Carlsson-Kanyama, A. (1998). Climate change and dietary choices: How can emissions of greenhouse gases from food consumption be reduced? Food Policy, 23(3-4), 277- 293.

Carlsson-Kanyama, A., Ekström, M. P., \& Shanahan. H. (2003). Food and life cycle energy inputs: Consequences of diet and ways to increase efficiency. Ecological Economics, 44(2-3), 293-307.

Carson, R. (1962). Silent spring. Boston: Houghton Mifflin.

Cederberg, C., \& Mattson, B. (2000). Life cycle assessment of milk production- a comparison of conventional and organic farming. Journal of Cleaner Production, 8, 49-60.

Cederberg, C., \& Stadig, M. (2003). System expansion and allocation in life cycle assessment of milk and beef production. Int $J L C A, 8(6), 350-356$. doi: 10.1007/BF02978508

Chappell, M., \& LaValle, L. (2011). Food security and biodiversity: can we have both? An agroecological analysis. Agric Hum Values, 2, 3-26. doi: 10.1007/s10460009-9251-4

Cowell, S.J., \& Clift, R. (1997). Impact assessment for LCAs involving agricultural production. Int. J. of LCA 2(2), 99-103.

Craig, B. (2010). Best Management Practices for Nova Scotia Apple Production. AgraPoint International Inc. Retrieved from http://perennia.ca/Fact\%20Sheets/Horticulture/Fruit/Orchard\%20Fruit/REV_Best $\% 20$ Management $\% 20$ Practices $\% 20$ for $\% 20$ Nova $\% 20$ Scotia $\% 20$ Apple $\% 20$ Produc tion.pdf

Cross, J.V. (2002).Guidelines for Integrated Production of Pome Fruits in Europe: IOBC Technical Guideline III. $3^{\text {rd }}$ edition. IOBC/WPRS Bulletin 25(8), 1-8. Retrieved from http://www.iobc-wprs.org/pub/bulletins/iobc-wprs_bulletin_2002_25_08.pdf 
Crutzen, P. J., Mosier, A. R., Smith, K. A., Winiwarter, W., Jolla, L., \& Pleasant, M. (2008). $\mathrm{N}_{2} \mathrm{O}$ release from agro-biofuel production negates global warming reduction by replacing fossil fuels. Atmos. Chem. Phys. 8, 389-395.

Curran, M., De Baan, L., De Schryver, A. M., Van Zelm, R., Hellweg, S., Koellner, T., Sonnemann, G., et al. (2011). Toward meaningful end points of biodiversity in life cycle assessment. Environmental science \& technology, 45(1), 70-9. doi:10.1021/es101444k

Dalgaard, R., Halberg, N., Kristensen, I. S. \& I. Larsen. (2006). Modeling Representative and Coherent Danish Farm Types Based on Farm Accountancy Data for Use in Environmental Assessments. Agriculture, Ecosystems and Environment, 117, 223237.

De Backer, E., Aertsens, J., Vergucht, S., \& Steurbaut, W. (2009). Assessing the ecological soundness of organic and conventional agriculture by means of life cycle assessment. British Food Journal, 111(10).

doi:10.1108/00070700910992916

De Schryver, A. M., Goedkoop, M. J., Leuven, R. S. E. W., \& Huijbregts, M. a. J. (2010). Uncertainties in the application of the species area relationship for characterisation factors of land occupation in life cycle assessment. The International Journal of Life Cycle Assessment, 15(7), 682-691. doi:10.1007/s11367-010-0205-2

DeEll, J.R. \& Prange, R.K. (1992). Postharvest quality and sensory attributes of organically and conventionally grown apples. HortScience 27, 1096-1099.

Delate, K., Mckern, A., Turnbull, R., Walker, J. T. S., Volz, R., White, A., Bus, V., et al. (2008). Organic apple Systems : Constraints and opportunities for producers in local and global markets : Introduction to the colloquium. HortScience, 43(1), 611 .

Desir, F. (2006). Energy Opportunities: Tips to reduce fuel consumption, fact sheet. Ontario Ministry of Agriculture, Food, and Rural Affairs, 06-091. Retrieved from http://www.omafra.gov.on.ca/english/engineer/facts/06-091.pdf

Dias de Oliveira, M., Vaughan, B., \& Rykiel E. (2005). Ethanol as fuel: Energy, carbon dioxide balances, and ecological footprint. BioScience, 55(7), 593-602.

do Amarante, C., Steffens, C. A., \& Mafra, Á. L. (2008). Yield and fruit quality of apple from conventional and organic production systems. Pesq. agropec. bras., Brasília, 43(3), 333-340.

DuPuis, E. M., \& Goodman, D. (2005). Should We Go "Home" to Eat?: Toward a Reflexive Politics of Localism. Journal of Rural Studies, 21, 3, 359-371. 
Duram, L., \& Oberholtzer, L. (2010). A geographic approach to place and natural resource use in local food systems. Renewable Agriculture and Food Systems: 25(2); 99-108. Doi:10.1017/S1742170510000104

Edwards, J., Kleinschmit, J., \& Schoonover, H. (2009). Identifying our Climate "Foodprint" Assessing and Reducing the Global Warming Impacts of Food and Agriculture in the U.S. Institute for Agriculture and Trade Policy, Minneapolis, Minnesota

Edwards-Jones, G., \& Howells, O. (2001). The origin and hazard of inputs to crop protection in organic farming systems: are they sustainable? Agricultural Systems, 67(1), 31-47.

Edwards-Jones, G., Milà i Canals, L., Hounsome, N., Truninger, M., Koerber, G., Hounsome, B., Cross, P., et al. (2008). Testing the assertion that "local food is best": the challenges of an evidence-based approach. Trends in Food Science \& Technology, 19(5), 265-274. doi:10.1016/j.tifs.2008.01.008

Ehrlich, P. R., \& Ehrlich, A. H. (2013). Can a collapse of global civilization be avoided? Proc. R. Soc. B, 280(20122845). doi:doi.org/10.1098/rspb.2012.2845

Eichner, M. (1990). Nitrous oxide emissions from fertilized soils: Summary of available data. Journal of Environmental Quality 19, 272-280.

Elliot, S. L., \& Mumford, J. D. (2002). Organic, integrated and conventional apple production: why not consider the middle ground? Crop Protection, 21(5), 427429. doi:10.1016/S0261-2194(02)00036-4

Ellis, M.A., Ferree, D.C., Funt, R.C., \& Madden, L.V. (1998). Effects of an apple scabresistant cultivar on use patterns of inorganic and organic fungicides and economics of disease control. Plant Dis. 82, 428-433.

FAO. (2009). FAO Expert Meeting: "How to Feed the World in 2050". The Resource Outlook to 2050: By how much do land, water and crop yields need to increase by 2050? FAO, Rome, Italy. Retrieved from

ftp://ftp.fao.org/docrep/fao/012/ak542e/ak542e00.pdf

Federal Ministry of the Environment, Nature Conservation, and Nuclear Safety. (2007). EEG-The Renewable Energy Sources Act: The Success Story of Sustainable Policies in Germany. Germany. Retrieved from http://www.folkecenter.net/mediafiles/folkecenter/pdf/eeg_success_brochure_eng 1.pdf

Finnveden, G. (2000). On the limitations of life cycle assessment and environmental systems analysis tools in general. Int. J. LCA 5(4) 229-238. 
Finnveden, G., \& Moberg, A. (2005). Environmental systems analysis tools - an overview. Journal of Cleaner Production 13, 1165-1173.

doi:10.1016/j.jclepro.2004.06.004

Fischer, J., Brosi, B., Daily, G. C., Ehrlich, P. R., Goldman, R., Goldstein, J., Lindenmayer, D. B., et al. (2008). Should agricultural policies encourage land sparing or wildlife-friendly farming? Frontiers in Ecology and the Environment, 6(7), 380-385. doi:10.1890/070019

Foster, C., Green, K., Belda, M., Dewick, P., Evans, B., Flynn, A. \& J. Mylan. (2006). Environmental Impacts of Food Production and Consumption: a report to the Department for Environment, Food and Rural Affairs. Manchester Business School. Defra, London.

Friedrich, H., Delate, K., Domoto, P., Nonnecke, G., \& Wilson, L. (2003). Effect of organic pest management practices on apple productivity and apple food safety. Biol. Agr. Hort. 21, 1-14.

Geiger, F., Bengtsson, J., Berendse, F., Weisser, W. W., Emmerson, M., Morales, M. B., Ceryngier, P., ... Inchausti, P. (2010). Persistent negative effects of pesticides on biodiversity and biological control potential on European farmland. Basic and Applied Ecology, 11(2), 97-105.

Giovannucci, D., Scherr, S., Nierenberg, D., Hebebrand, C., Shapiro, J., Milder, J., \& Wheeler, K. (2012). Food and agriculture: The future of sustainability. A strategic input to the Sustainable Development in the 21st Century (SD21) project. New York: United Nations Department of Economic and Social Affairs, Division for Sustainable Development.

Glover, J., Hinman, H., Reganold, J., \& Andrews, P. (2002). A cost of production analysis of conventional vs. integrated vs. organic apple production systems. Agricultural Research Center Publication, Washington State University, WA January.

Goedkoop, M., Heijungs, R., Huijbregts, M. A. J., De Schryver, A. M., Struijs, J., \& van Zelm, J, R. (2009). ReCiPe 2008 - A life cycle impact assessment method which comprises harmonised category indicators at the midpoint and the endpoint level, 1st ed.; Report I: Characterisation, 2009. Retrieved from http://www.lcia-recipe.

Gomiero, T., Paoletti, M. G., \& Pimentel, D. (2008). Energy and Environmental Issues in Organic and Conventional Agriculture. Critical Reviews in Plant Sciences, 27(4), 239-254.

Gomiero, T., Pimentel, D., \& Paoletti, M. (2011). Is there a need for more sustainable agriculture? Critical Reviews in Plant Sciences 30, 6-23. DOI: 10.1080/07352689.2011.553515 
Government of Nova Scotia. (2012). Pest and pesticides: Frequently asked questions. Retrieved from http://www.gov.ns.ca/nse/pests/ipmfaq.asp

Granatstein, D. (2013). Organic \& integrated tree fruit production. Washington State University Tree Fruit Research \& Extension Center. Retrieved from http://www.tfrec.wsu.edu/pages/organic/Introduction

Green, R.E., Cornell, S.J., Scharlemann, P.W., \& Balmford, A. (2005). Farming and the fate of wild nature. Science 307, 550-55.

Guinée, J. B., Gorée, M., Heijungs, R., Huppes, G., Kleijn, R. \& A. De Koning., et al. (2001). An Operational Guide to the ISO Standards, Final Report. The Netherlands: Ministry of Housing, Spatial Planning and the Environment (VROM) and the Centre for Environmental Studies, Leiden University.

Guinée, J.B.; Gorrée, M.; Heijungs, R.; Huppes, G.; Kleijn, R.; Koning, A. de; Oers, L. van; Wegener Sleeswijk, A.; Suh, S.; Udo de Haes, H.A.; Bruijn, H. de; Duin, R. van \& Huijbregts, M.A.J. (2002). Handbook on life cycle assessment. Operational guide to the ISO standards. I: LCA in perspective. IIa: Guide. IIb: Operational annex. III: Scientific background. Kluwer Academic Publishers, ISBN 1-40200228-9, Dordrecht.

Guinée, J., Heijungs, R., Huppes, G., Zamagni, A., Masoni, P., Buonamici, R., Ekvall, T., et al. (2011). Life Cycle Assessment: Past, Present, and Future. Environmental science \& technology, 45(1), 90-96.

Guthman, J. (2006). Squaring farm security and food security in two types of alternative food institutions. Rural Sociology, 71(4), 662-684.

Haas, G., Wetterich, F., \& Geier, U. (2000). Life cycle assessment framework in agriculture on the farm level. The International Journal of Life Cycle Assessment, 5(6), 345-348.

Haas, G., Wetterich, F., \& Kopke, U. (2001). Comparing intensive, extensified and organic grassland farming in southern Germany by process of life cycle assessment. Agriculture, Ecosystems and Environment, 83, 43-53.

Haley, B. (2010). Energy Cost Politics and the Environment in Nova Scotia: Reflections on the Government's Backtrack on Mercury Emissions. Canadian Centre for Policy Alternatives. Retrieved from http://www.policyalternatives.ca/sites/default/files/uploads/publications/Nova\%20 Scotia\%20Office/2010/10/NS\%20Energy\%20Cost\%20Politics\%2010.pdf 
Hauschild, M. Z., Huijbregts, M., Jolliet, O., MacLeod, M., Margni, M., van de Meent, D., ... \& McKone, T. E. (2008). Building a model based on scientific consensus for life cycle impact assessment of chemicals: the search for harmony and parsimony. Environmental science \& technology, 42(19), 7032-7037.

Hayashi, K., Gaillard G., \& Nemecek T. (2007). Life Cycle Assessment of Agricultural Production Systems: Current Issues and Future Perspectives. National Agricultural Research Center 3-1-1 Kannondai, Tsukuba, Ibaraki 305-8666, Japan Agroscope FAL Reckenholz Swiss Research Station for Agroecology and Agriculture Reckenholzstr. 191 CH-8046 Zurich, Switzerland, 2007- 05-16. Available online at: http://www.agnet.org/library/bc/54011/

Hayer, F., Kägi, T., Casado, D., Czembor, E., Delval, P., Gaillard, G., Jensen, J., Otto, S., \& Strassemeyer, J. (2008). Life Cycle Assessment of Wheat and Apple Production Systems within the ENDURE Project. ENDURE International Conference: Diversifying crop protection. Oral presentation. La Grande-Motte, France

Heaton, S. (2002). Organic farming, food quality and human health: a review of the evidence. Soil Association, Bristol, UK. Retrieved from http://www.soilassociation.org/LinkClick.aspx?fileticket=cY8kfP3Q\%2BgA\%3D \&tabid $=388$

Herdt, R.W., \& Steiner, R.A. (1995). Agricultural sustainability: concepts and conundrums. In: Barnett, V., Payne, R., Steiner, R. (eds.), Agricultural sustainability: Economic, Environmental and Statistical considerations. Wiley, UK, 3-13.

Hokazono, S., Hayashi, K., \& Sato, M. (2009). Potentialities of organic and sustainable rice production in Japan from a life cycle perspective. Agronomy Research 7, $257-262$.

Holb, I. J., \& Heijne, B. (2001). Evaluating primary scab control in organic apple production. Gartenbauwissenschaft 66(5), 254-261.

Holzschuh, A., Steffan-Dewenter, I., \& Tscharntke, T. (2008). Agricultural landscapes with organic crops support higher pollinator diversity. Oikos 117, 354-361.

Horne, R., \& Grant, T. (2009). Life cycle assessment and agriculture: challenges and prospects. In R. Horne, T. Grant \& K. Verghese (eds.) Life Cycle Assessment: Principles, Practice and Prospects. Melbourne, CSIRO Publishing

Horrigan, L., Lawrence, R.S., \& Walker, P. (2002). How sustainable agriculture can address the environmental and human health harms of industrial agriculture. Environmental Health Perspectives, 110, 445-456. 
Hospido, A., \& Tyedmers, P. (2005). Life cycle environmental impacts of Spanish tuna fisheries. Fisheries Research, 76(2), 174-186.

IPCC. (2006). 2006 IPCC Guidelines for National Greenhouse Gas Inventories, Volume 4 - Agriculture, Forestry and Other Land Use, Chapter 11: N2O Emissions fro Managed Soils, and CO2 Emissions from Lime and Urea Application. Retrieved from: http://www.ipcc- nggip.iges.or.jp/public/2006gl/index.html.

ISO. (2006a). ISO 14040 Environmental Management - Life Cycle Assessment Principles and Framework. Geneva, Switzerland.

ISO. (2006b). ISO 14044 Environmental Management - Life Cycle Assessment Requirements and Guidelines. Geneva, Switzerland.

Jones, A. (2002). An environmental assessment of food supply chains: a case study on dessert apples. Environmental Management, 30(4), 560-567.

Kegley, S.E., Hill, B.R., Orme S., \& Choi A.H. (2010). PAN Pesticide Database, Pesticide Action Network, North America. San Francisco, CA. Retrieved from http://www.pesticideinfo.org/Search_Chemicals.jsp

Kirby, E., \& Granatstein, D. (2009). Recent Trends in Organic Tree Fruit Production. WSU-CSANR. Retrieved from http://csanr.wsu.edu/publications/techreports/wa_orgtreefr_11_09_final.pdf

Kirchmann, H., Bergstrom, L., Kätterer, T., Andrén, O., \& Andersson, R. (2009). Can Organic Crop Production Feed the World? In: H. Kirchmann, L. Bergstrom (Eds.), Organic Crop Production - Ambitions and Limitations. Springer Netherlands. DOI 10.1007/978-1-4020-9316-6 3

Klöpffer, W. (2003). Life-cycle based methods for sustainable product development. International Journal of LCA, 8(3), 157-159.

Klöpffer, W., \& Renner, I. (2009). Life-cycle based sustainability assessment of products. In Environmental Management Accounting for Cleaner Production, 91-102. Springer Netherlands.

Kortbech-Olesen, R. (2004). The Canadian market for organic food and beverages. International Trade Centre UNCTAD/WTO. Geneva, Switzerland

Kruse, S.A. (2010). Inclusion of social aspects in life cycle assessment of food. In: U. Sonesson, J. Berlin \& F. Ziegler (eds.). Environmental Assessment and management in the food industry: Life cycle assessment and related approaches. Woodhead publishing limited, Cambridge, UK. 
Lancas, K., Upadhyaya, S., Sime, M., \& Shafii, S. Overinflated tractors tires waste fuel, reduce productivity. California Agriculture 50(2). Retrieved from ucce.ucdavis.edu/files/repositoryfiles/ca5002p28-69753.pdf

Lardon, L., Helias, A., Sialve, B., Steyer, J.-P., \& Bernard, O. (2009). Life-Cycle Assessment of Biodiesel Production from Microalgae. Environmental science \& technology, 43(17), 6475-6481.

LaTrobe, H.L., \& Acott, T.G. (2000). Localising the global food system. International Journal of Sustainable Development and World Ecology 7(4), 309-320.

Lindeijer, E. (2000). Biodiversity and life support impacts of land use in LCA. Journal of Cleaner Production, 8(4), 313-319.

Loureiro, M. L., Mccluskey, J. J., \& Mittelhammer, R. C. (2001). Assessing consumer preferences for organic, eco-labeled, and regular apples. Journal of Agriculture and Resource Economics, 26(2), 404-416.

Luby, J. J. (2003). Taxonomic Classification and Brief History. In Apples: Botany, Production and Uses. D. C. Ferree \& I. J. Warrignton (Eds.) New York, NY: CABI Pub. 539-549.

Lynch, D. (2009). Environmental impacts of organic agriculture: A Canadian perspective. Canadian Journal of Plant Science, 89(4), 621-628.

Lynch, D., MacRae, R., \& Martin, R. C. (2011). The carbon and global warming potential impacts of organic farming: does it have a significant role in an energy constrained world?. Sustainability, 3(2), 322-362.

MacRae, R. J., Lynch, D., \& Martin, R. C. (2010). Improving Energy Efficiency and GHG Mitigation Potentials in Canadian Organic Farming Systems. Journal of Sustainable Agriculture, 34(5), 549-580. doi:10.1080/10440046.2010.484704

MacHardy, W. E. (2000). Current status of IPM in apple orchards. Crop Protection, 19(8-10), 801-806. doi:10.1016/S0261-2194(00)00107-1

Margni, M., Rossier, D., Crettaz, P., \& Jolliet, O. (2002). Life cycle impact assessment of pesticides on human health and ecosystems. Agric. Ecosyst. Environ. 93, 379392.

Matson, P.A., Parton, W.J., Power, A.G., \& Swift, M.J., (1997). Agricultural intensification and ecosystem properties. Science, 277, 504-509.

Mattsson, B., Cederberg, C., \& Blix, L. (2000). Agricultural land use in life cycle assessment (LCA): case studies of three vegetable oil crops. Journal of cleaner production, $8(4)$, 283-292. 
Mattsson, B., \& Wallén, E., (2003). Environmental LCA of organic potatoes. In: Proceedings of the 26th International Horticultural Congress, ISHS, Acta Horticulturae, 691.

Mckenna, M., Roche, M., \& Heron, R. Le. (1998). Sustaining the fruits of labour : A comparative localities analysis of the integrated fruit production programme in New Zealand' s apple industry. Journal of Rural Studies, 14(4), 393-409.

McKenzie, R. \& Middleton, A. (1997). Phosphorus Fertilizer Application in Crop Production. Government of Albert, Agriculture and Rural Development. Retrieved from http://www1.agric.gov.ab.ca/\$department/deptdocs.nsf/all/agdex920

McLaren, S. (2010). Life Cycle Assessment (LCA) of food production and processing: an introduction. In: U. Sonesson, J. Berlin \& F. Ziegler (eds.). Environmental Assessment and management in the food industry: Life cycle assessment and related approaches. Woodhead publishing limited, Cambridge, UK.

Mila i Canals, L.M. (2003). Contributions to LCA methodology for agricultural systems: Site-dependency and soil degradation impact assessment. Ph.D. Thesis. Universitat Autònoma de Barcelona. Retrieved from http://www.tdx.cesca.es/TDX-1222103-154811/

Mila i Canals, L., \& Polo, G.C. (2003). Life cycle assessment of fruit production. In B.Mattsson \& U. Sonesson (eds.) Environmentally -friendly food processing. Woodhead publishing Ltd. Cambridge, England.

Mila i Canals, L., Burnip, G., \& Cowell, S. (2006). Evaluation of the environmental impacts of apple production using life cycle assessment (LCA): Case study New Zealand. Agriculture, Ecosystems and Environment, 114 (2-4), 226-238.

Mila i Canals, L., Cowell, S. J., Sim, S., \& Basson, L. (2007a). Comparing domestic versus imported apples: A focus on energy use. Environ. Sci. Pollut. Res., 14(5), 338-344. Retrieved from http://www.ncbi.nlm.nih.gov/pubmed/17722769

Mila i Canals, L. M., Muller-Wenk, R., Bauer, C., Depestele, J., Dubreuil, A., Knuchel, R. F., Gaillard, G., ... Rydgren, B. (2007b). Key Elements in a Framework for Land Use Impact Assessment Within LCA. International Journal of Life Cycle Assessment, 12, 1, 2-4.

Mills, P., \& Yang, R. (2007). Agricultural exposures and gastric cancer risk in Hispanic farm workers in California. Environmental Research, 104(2), 282-289.

Mills, P. K., Dodge, J., \& Yang, R. (2009). Cancer in migrant and seasonal hired farm workers. Journal of agromedicine, 14(2), 185-191. 
Mon, P. N., \& Holland, D. W. (2007). Organic apple production in Washington State: An input-output analysis. Renewable Agriculture and Food Systems, 21(2), 134-141. doi:10.1079/RAF2005142

Mouron, P., Scholz, R.W., Nemecek, T., \& Weber, O. (2006a). Life cycle management on Swiss fruit farms: Relating environmental and income indicators for applegrowing. Ecological Economics, 58(3), 561-578

Mouron, P., Nemecek, T., Scholz, R. W., \& Weber, O. (2006b). Management influence on environmental impacts in an apple production system on Swiss fruit farms: Combining life cycle assessment with statistical risk assessment. Agriculture, Ecosystems \& Environment, 114(2-4), 311-322. doi:10.1016/j.agee.2005.11.020

Mouron, P., Heijne, B., Naef, A., Strassemeyer, J., Hayer, F., Avilla, J., Alaphilippe, A., et al. (2012). Sustainability assessment of crop protection systems: SustainOS methodology and its application for apple orchards. Agricultural Systems, 113, 115. doi:10.1016/j.agsy.2012.07.004

Mundler, P., \& Rumpus, L. (2012). The energy efficiency of local food systems: A comparison between different modes of distribution. Food Policy, 37, 609-615.

Mungkung, R., \& Gheewala, S. (2007). Use of life cycle assessment (LCA) to compare the environmental impacts of aquaculture and agri-food products. In D.M. Bartley, C. Brugere, D. Soto, P. Gerber and B. Harvey (eds.) Comparative assessment of the environmental costs of aquaculture and other food production sectors: methods for meaningful comparisons. FAO/WFT Expert Workshop. 2428 April 2006, Vancouver, Canada. FAO Fisheries Proceedings. No. 10. Rome, FAO. 87-96.

National Resources Conservation Service (2007). Nutrient Content of Crops: Nutrients Removed by Harvest. Retrieved from http://plants.usda.gov/npk/main

Nemecek, T., \& Gaillard, G. (2010). Challenges in assessing the environmental impacts of crop production in horticulture. In: U. Sonesson, J. Berlin \& F. Ziegler (eds.) Environmental Assessment and management in the food industry: Life cycle assessment and related approaches. Woodhead publishing limited, Cambridge, UK.

Nemecek, T., Dubois, D., Huguenin-Elie, O., \& Gaillard, G. (2011). Life cycle assessment of Swiss farming systems: I. Integrated and organic farming. Agricultural Systems, 104(3), 217-232. doi:10.1016/j.agsy.2010.10.002

Ngo, M. \& Dorff, E. (2009) Fork in the road: Canadian agriculture and food on the move. Statistics Canada. Retrieved from http://www.statcan.gc.ca/pub/96-325x/2007000/article/10646-eng.htm 
Nova Scotia Department of Energy. (2009). Toward a Greener Future: Nova Scotia's 2009 Energy Strategy, 1-40. Retrieved from www.gov.ns.ca/energy/energystrategy

Nova Scotia Department of Energy. (2010). Renewable Electricity Plan: A path to good jobs, stable prices, and a cleaner environment, 1-32. Retrieved from www.gov.ns.ca/energy.

Nova Scotia Department of Energy. (2012). Statement of Mandate 2012-2013, 1-22. Retrieved from http://www.gov.ns.ca/energy/resources/spps/statement-ofmandate/Energy-Statement-of-Mandate-2012.pdf.

NSDA (Nova Scotia Department of Agriculture). (2009). Business planning and economics of apple orchard establishment and cost of production in Nova Scotia. NSDA: Business Development and Economics Division. Retrieved from http://perennia.ca/Fact\%20Sheets/Horticulture/Fruit/Orchard\%20Fruit/AppleProd uctionReport.pdf

NSDA (Nova Scotia Department of Agriculture). (2013). Apple industry: Industry overview. Retrieved from http://growingnovascotia.ca/opportunity-profiles/appleindustry

Orange Pippin. (2013). Apple Production Facts. Retrieved from http://www.orangepippin.com/resources/apple-facts/apple-facts

Parker, R. W. R., \& Tyedmers, P. H. (2012). Life cycle environmental impacts of three products derived from wild-caught Antarctic krill (Euphausia superba). Environmental science \& technology, 46(9), 4958-65. doi:10.1021/es2040703

Peck, G. M., Andrews, P. K., Richter, C., \& Reganold, J. P. (2005). Internationalization of the organic fruit market: The case of Washington State's organic apple exports to the European Union. Renewable Agriculture and Food Systems, 20(2), 101112. doi:10.1079/RAF2004102

Peck, G. M., Andrews, P. K., Reganold, J. P., \& Fellman, J. K. (2006). Apple Orchard Productivity and Fruit Quality under Organic , Conventional, and Integrated Management, HortScience, 41(1), 99-107.

Pelletier, N. (2006). Life cycle measures of biophysical sustainability in feed production for conventional and organic salmon aquaculture in the Northeast Pacific. Thesis (M.E.S.), Dalhousie University

Pelletier, N. \& P.H. Tyedmers. (2007). Feeding Farmed Salmon: is organic better? Aquaculture, 272, 399-416. 
Pelletier, N. (2008). Environmental performance in the US broiler poultry sector: Life cycle energy use and greenhouse gas, ozone depleting, acidifying and eutrophying emissions. Agriculture Systems, 98(2), 67-73. doi: 10.1016/j/agsy/2008/03/007

Pelletier, N., Arsenault, N., \& Tyedmers, P. (2008). Scenario Modeling Potential EcoEfficiency Gains from a Transition to Organic Agriculture: life cycle perspectives on Canadian canola, corn, soy and wheat production. Journal of Environmental Management, 42, 989-1001. DOI: 10.1007/s00267-008-9155-x

Pelletier, N., Pirog, R., \& Rasmussen, R. (2010). Comparative life cycle environmental impacts of three beef production strategies in the Upper Midwestern United States. Agricultural Systems, 103(6), 380-389. doi:10.1016/j.agsy.2010.03.009

Pelletier, N., Audsley, E., Brodt, S., Garnett, T., Henriksson, P., Kendall, A., Kramer, K. J., et al. (2011). Energy Intensity of Agriculture and Food Systems. Annual Review of Environment and Resources, 36(1), 223-246. doi:10.1146/annurevenviron-081710-161014

Phillips, M. (2005). The Apple Grower: A guide for the organic orchardists. Chelsea Green Publishing Company, Vermont

Pimentel, D., \& Wilson, A. (2005). World Population, Agriculture, and Malnutrition. Worldwatch Institute. Retrieved from http://www.energybulletin.net/node/3834

Pimentel, D., Hurd, L., Bellotti, A., Forster, M., Oka, I., Sholes, O., \& Whitman, R. (1973). Food production and the energy crisis. Science, 182, 443-449.

Pimentel, D., Hepperly, P., Hanson, J., Douds, D., \& Seidel, R. (2005). Environmental, Energetic, and Economic Comparisons of Organic and Conventional Farming Systems. Bioscience, 55(7), 573-582.

Phalan, B., Onial, M., Balmford, A., \& Green, R. E. (2011). Reconciling food production and biodiversity conservation: land sharing and land sparing compared. Science 333(6047), 1289-91. doi:10.1126/science.1208742

Phillips, M. (2005). The Apple Grower: A guide for the organic orchardists. Chelsea Green Publishing Company, Vermont

PMEP (Pesticide Management Education Program). (2008). Extoxnet: Extension Toxicological Network. Cornell University. Retrieved from http://pmep.cce.cornell.edu/profiles/extoxnet/

Point, E. (2008). Life cycle environmental impacts of wine production and consumption in Nova Scotia, Canada. Thesis (M.E.S.), Dalhousie University 
Point, E., Tyedmers, P., \& Naugler, C. (2012). Life cycle environmental impacts of wine production and consumption in Nova Scotia, Canada. Journal of Cleaner Production, 27, 11-20. doi:10.1016/j.jclepro.2011.12.035

Pottorff, L.P., (2010). Some Pesticides Permitted in Organic Gardening. Colorado State University Cooperative Extension. Retrieved from http://www.colostate.edu/Depts/CoopExt/4DMG/VegFruit/organic.htm

Powlson, D., Riche, A., \& Shield, I. (2005). Biofuels and other approaches for decreasing fossil fuel emissions from agriculture. Annals of Applied Biology, 146, 193-201.

Pretty, J. (1998). The Living Land: Agriculture, Food and Community Regeneration in Rural Europe. Earthscan, London Hinricks.

Pretty, J. (2008). Agricultural sustainability: concepts, principles and evidence. Philosophical transactions of the Royal Society of London. Series B, Biological sciences, 363(1491), 447-65. doi:10.1098/rstb.2007.2163

Pretty, J., Brett, C., Gee, D., Hine, R., Mason, C., Morison, J., ... \& Dobbs, T. (2001). Policy challenges and priorities for internalizing the externalities of modern agriculture. Journal of Environmental Planning and Management, 44(2), 263283.

Pretty, J.N., Morison, J.L.L., \& Hine, R.E. (2003). Reducing food poverty by increasing agricultural sustainability in developing countries, Agric. Ecosyst. Environ, 95, 217-234.

Pretty, J.N.; Noble, A.D.; Bossio, D.; Dixon, J.; Hine, R.E.; Penning de Vries, F.W.T. \& Morison, J.I.L. (2006). Resource-conserving agriculture increases yields in developing countries. Environmental Science and Technology, 40,1114-1119.

Reap, J., Roman, F., Duncan, S., \& Bras, B. (2008). A survey of unresolved problems in life cycle assessment Part 2: impact assessment and interpretation. Int J LCA, 13, 374-388. doi: 10.1007/s11367-008-0009-9

Rebizter, G., Ekball, T., Frischknecht, R., Hunkeler, D., Norris, G., Rydberg, T., Schmidt, W.-P., Suh., S., Weidema, B.P., \& Pennington, D.W. (2004). Life cycle assessment Part 1: Framework, goal and scope definition, inventory analysis, and applications. Environmental International, 30, 701-720.

Reganold, J. P., Glover, J. D., Andrews, P. K., \& Hinman, H. R. (2001). Sustainability of three apple production systems. Nature, 410(6831), 926-30. doi: $10.1038 / 35073574$

Rigby, D., Young, T., \& Burton, M. (2001). The development of and prospects for organic farming in the UK. Food Policy, 26, 6, 599-613. 
Rodriguez, J., Molnar, J., Fazio, R., Sydnor, E., \& Lowe, M. (2008). Barriers to adoption of sustainable agriculture practices: Change agent perspectives.

Renewable Agriculture and Food Systems 24(1), 60-71

doi:10.1017/S1742170508002421

Rosenberger, D. (2012). What Copper Formulations are Best for Tree Fruit Applications? 2012 Mid-Atlantic Fruit and Vegetable Convention. Hershey, PA. [Powerpoint slides]. Retrieved from http://shaponline.org/wpcontent/uploads/2012/03/Rsnbrgr-Wed-945am-copper.pdf

Roukhkian, G. (2011). The Canadian retail food sector: Opportunities for Swiss companies. OSEC, Business Network Switzerland. Swiss Business Hub Canada. Retrieved from http://www.osec.ch/sites/default/files/bbf_Canada_FoodRetail_Feb2011.pdf

Roussos, P., \& Gasparatos, D. (2009). Apple tree growth and overall fruit quality under organic and conventional orchard management. Scientia Horticulturae, 123(2), 247-252. doi:10.1016/j.scienta.2009.09.011

Roy, P., Shimizu, N., Kimura, T., (2005). Life cycle inventory analysis of rice produced by local processes. Journal of the Japanese Society of Agricultural Machinery 67(1), 61-67.

Roy, P., Nei, D., Orikasa, T., Xu, Q., Okadome, H., Nobutaka, N., \& Shiina, T. (2009). A review of life cycle assessment (LCA) on some food products Journal of Food Engineering 90, 1-10.

Saunders, C., \& Barber, A. (2008). Carbon footprints, life cycle analysis, food miles: Global trade trends and market issues. Political Science, 60(1), 73-88. doi: $10.1177 / 003231870806000107$

Sahota, A. (2009). The global market for organic food \& drink. In: H. Willer \& L. Kilcher (Eds.). The World of Organic Agriculture. Statistics and Emerging Trends 2009, IFOAM, Bonn, and FiBL, Frick

Schau, E.M., \& Fet, A.M. (2007). LCA studies of food products as background for environmental product declarations. Int J LCA, 13(2), 255-264.

Schlich, E., \& Fleissner, U. (2005). The Ecology of Scale: Assessment of Regional Energy Turnover and Comparison with Global Food. International Journal of Life Cycle Assessment, 10 (3), 219 - 223.

Scialabba, N. El-H., \& Hattam, C. (eds). (2002). Organic Agriculture, Environment, and Food Security. FAO, Rome. Retrieved from http://www.fao.org/docrep/005/y4137e/y4137e00.htm 
Schmidt, J.H. (2007). Life Cycle Assessment of Rapeseed Oil and Palm Oil. Ph.D. thesis. Department of Development and Planning, Aalborg University.

Scott, J., \& Coleman, R. (2008). The GPI Soils and Agricultural Accounts: Economic Viability of Farms and Farm communities in Nova Scotia and Prince Edward Island - An Update. 3rd Data Release: Kings County Genuine Progress Index. Retrieved from http://www.gpiatlantic.org/pdf/agriculture/farmviability08.pdf

Scott J., \& MacLeod, M. (2010). Is Nova Scotia eating local? And if not... where is our food coming from? Ecology Action Centre \& the Nova Scotia Federation of Agriculture.

Settanni, E. (2010). Combining life cycle assessment of food products with economic tools. In: U. Sonesson, J. Berlin \& F. Ziegler (eds.). Environmental Assessment and management in the food industry: Life cycle assessment and related approaches. Woodhead publishing limited, Cambridge, UK.

Sim, S., Barry, M., Clift, R., \& Cowell, S.J. (2007). The Relative Importance of Transport in Determining an Appropriate Sustainability Strategy for Food Sourcing: A Case Study of Fresh Produce Supply Chains. Int. J. Life-Cycle Assess., 12(6), 422-431.

Simon, S., Bouvier, J.-C., Debras, J.-F., \& Sauphanor, B. (2010). Biodiversity and pest management in orchard systems. A review. Agronomy for Sustainable Development, 30(1), 139-152. doi:10.1051/agro/2009013

Slattery, E., Livingston, M., Greene, C., \& Klonsky, K. (2011). Characteristics of Conventional and Organic Apple Production in the United States / FTS-347-01. Economic Research Service/USDA. Retrieved from http://www.ers.usda.gov/media/118496/fts34701.pdf

Smith, A., Watkiss, P., Tweddle, G., McKinnon, A., Browne, M., Hunt, A., et al. (2005). The validity of food miles as an indicator of sustainable development. Defra, ED50254(7). Oxon, U.K.

Smith, J. (2008). Fungicides revisited: A critical look at copper and sulphur-based fungicides in organic agriculture. Farm Start. Retrieved from http://www.farmstart.ca/wp-content/uploads/2008/06/smith-2008-fungicidesrevisited.pdf

Sonesson, U., Anteson, F., Davis, J., \& Sjödén, P. O. (2005). Home transport and wastage: environmentally relevant household activities in the life cycle of food. AMBIO: A Journal of the Human Environment, 34(4), 371-375.

Stadig, M. (1997). Life cycle assessment of apple production-Case studies for Sweden, New Zealand and France. SIK report 630. Gothenburg, Sweden: SIK 
Statistics Canada. (2008). Guide to the Labour Force Survey 2008. Cat No. 71-543-G.

Retrieved from http://www.statcan.ca/cgi-bin/downpub/listpub.cgi?catno=71-543GIE2008001.

Statistics Canada. (2012). Table 1:Estimate of area, commercial production and farm gate value of fruits in Canada, by province, 2010. Retrieved from http://www.statcan.gc.ca/pub/22-003-x/2011002/t029-eng.htm

Tassou, S.A., De-Lille, G., \& Ge, Y.T. (2008). Food transport refrigeration - approaches to reduce energy consumption and environmental impacts of road transport. Applied Thermal Engineering. Retrieved from http://peer.ccsd.cnrs.fr/docs/00/52/89/53/PDF/PEER_stage2_10.1016\%252Fj.appl thermaleng.2008.06.027.pdf

Thomassen, M.A., van Calker, K.J., Smits, M.C.J., Iepema, G.L., \& de Boer, I.J.M. (2008). Life cycle assessment of conventional and organic milk production in the Netherlands. Agricultural Systems, 96, 95-107.

Tilman, D. (1999). Global environmental impacts of agricultural expansion: the need for sustainable and efficient practices. Proc. Natl Acad. Sci. USA, 96. pp. 5995-6000.

Tillman, A-M. (2010). Methodology for life cycle assessment. In: U. Sonesson, J. Berlin \& F. Ziegler (eds.). Environmental Assessment and management in the food industry: Life cycle assessment and related approaches. Woodhead publishing limited, Cambridge, UK.

Tscharntke, T., Clough, Y., Wanger, T. C., Jackson, L., Motzke, I., Perfecto, I., Vandermeer, J., et al. (2012). Global food security, biodiversity conservation and the future of agricultural intensification. Biological Conservation, 151(1), 53-59. doi:10.1016/j.biocon.2012.01.068

T.W.T. (Then We Travel). (2012). Then we travel info: Map of North America. Retreived from http://thenwetravel.info/maps/world-maps/byu-maps/byu-blanknorth-america-outline-map-black-and-white.html

UNEP-SETAC Life Cycle Initiative. (2010). About Us: The Life Cycle Initiative, International Life Cycle Partnership for a sustainable world. Retrieved from $\mathrm{http}: / / \mathrm{www}$. estis.net/sites/lcinit/default.asp?site=lcinit\&page_id=9FDF7FDF261F-4F0E-A8E3-5FF4E16B33C2

USDA. (2012). Fresh Deciduous Fruit (Apples, Grapes, \& Pears): World Markets and Trade. Retrieved from http://usda01.library.cornell.edu/usda/fas/decidwm//2010s/2012/decidwm-12-072012.pdf 
van der Werf, H.M. (1996). Assessing the impact of pesticides on the environment. Agriculture, Ecosystems \& Environment, 60(2), 81-96.

van der Werf, H.M., \& Petit, J. (2002). Evaluation of the environmental impact of agriculture at the farm level: a comparison and analysis of 12 indicator-based methods. Agriculture, Ecosystems \& Environment, 93, 131-45.

Venkat, K. (2012). Comparison of twelve organic and conventional farming systems: A life cycle greenhouse gas emissions perspective. Journal of Sustainable Agriculture, 36(6), 620-649. doi:10.1080/10440046.2012.672378

von Wirén-Lehr, S. (2001). Sustainability in agriculture - an evaluation of principal goal- oriented concepts to close the gap between theory and practice. Agriculture, Ecosystems and Environment 84, 115-129

Wackernagel, M. \& W. Rees. (1995). Our Ecological Footprint: reducing human impact on the earth. Gabriola Island, BC: New Society Publishers.

Wackernagel, M.; Schulz, N. B.; Deumling, A. C.; Linares, A. C.; Jenkins, M.; Kapos, V.; Monfreda, C.; Loh, J.; Myers, N.; Norgaard, R.; \& Randers, J. (2002). Tracking the ecological overshoot of the human economy. PNAS 99, 9266-9271.

Weber, C. \& Matthews, S. (2008). Food-Miles and the Relative Climate Impacts of Food Choices in the United States. Environ. Sci. Technol., 42, 3508-3513.

Weibel, F. (2002). Organic Fruit Production in Europe. The Compact Fruit Tree, 35(3), $77-82$.

Weibel, F., \& Häseli, A. (2003). Organic Apple Production - with Emphasis on European Experiences. In Apples: Botany, Production and Uses. D. C. Ferree \& I. J. Warrignton (Eds.) New York, NY: CABI Pub. 551-583.

Weibel, F. P., Bickel, R., Leuthold, S., \& Alfoldi, T. (2000). Are organically grown apples tastier and healthier? A comparative study using conventional and alternative methods to measure fruit quality. Acta Hort., 517, 417-426.

Weibel, F., Tamm, L., Wyss, E., Daniel, C., Häseli, A., \& Suter, F. (2007). Organic fruit production in Europe: successes in production and marketing in the last decade, perspectives and challenges for the future development. Acta Hort. 737, 163-172.

Willer, H., Lernoud, J., \& Kilcher, L. (Eds.) (2013). The World of Organic Agriculture: Statistics and Emerging Trends. International Federation of Organic Agriculture Movements (IFOAM) Bonn, Germany and Research Institute of Organic Agriculture (FiBL), Frick, Switzerland 
Williams, A.G., Audsley, E., \& Sandars, D.L. (2006) Determining the environmental burdens and resource use in the production of agricultural and horticultural commodities. Main Report. Defra Research Project IS0205. Bedford: Cranfield University

Winter, M. (2003). Embeddedness, the new food economy and defensive localism. Journal of rural studies, 19(1), 23-32.

Wognum, P.M., Bremmers, H., Trienekens, J.H., van der Vorst, J., \& Bloemhof, J. (2011). Systems for sustainability and transparency of food supply chains Current status and challenges. Advanced Engineering Informatics 25, 65-76. doi:10.1016/j.aei.2010.06.001

Wu, T., Wang, Y., Yu, C., Chiarawipa, R., Zhang, X., Han, Z., \& Wu, L. (2012). Carbon Sequestration by Fruit Trees - Chinese Apple Orchards as an Example. PLoS ONE, 7(6), 1-13. doi:10.1371/journal.pone.0038883 